\title{
NUEVOS LAPAROCERUS SCHOENHERR, 1834 DE LA PALMA, ISLAS CANARIAS (COLEOPTERA, CURCULIONIDAE, ENTIMINAE)
}

\author{
A. Machado*
}

\begin{abstract}
RESUMEN
Se describen 16 nuevos taxones del género Laparocerus, todos endémicos de la isla de La Palma: Laparocerus aeneotinctus n. sp., L. acyphus n. sp., L. femoralis n. sp., $L$. arrochai $\mathbf{n}$. sp., L. cristatus $\mathbf{n}$. sp., L. tanausu n. sp., L. elongatus n. sp., L. mucronatus n. sp., L. feloi $\mathbf{n} . \mathbf{s p}$., L. tarsalis n. sp., L. astralis n. sp., L. supranubius n. sp., L. orone aridane n. ssp., L. amicorum n. sp., L. decipiens $\mathbf{n}$. sp. y L. morrisi n. sp. Se aporta una clave en español e inglés para la determinación de los representantes del género en dicha isla. Además, Laparocerus laevis politus Roudier, 1957 es sinonimizado con L. laevis Roudier, 1957.

Palabras clave: Taxonomía, nuevos taxones, islas Canarias, Macaronesia, Sinonimias, Laparocerus, Curculionidae, Entiminae.
\end{abstract}

\section{ABSTRACT \\ New Laparocerus Schoenherr, 1834 from La Palma, Canary Islands (Coleoptera, Curculionidae, Entiminae)}

Sixteen new endemic taxa of the genus Laparocerus from the island of La Palma are described: Laparocerus aeneotinctus n. sp., L. acyphus n. sp., L. femoralis n. sp., $L$. arrochai $\mathbf{n}$. sp., L. cristatus $\mathbf{n}$. sp., L. tanausu n. sp., L. elongatus n. sp., L. mucronatus n. sp., L. feloi $\mathbf{n} . \mathbf{s p}$., L. tarsalis n. sp., L. astralis n. sp., L. supranubius n. sp., L. orone aridane $\mathbf{n}$. ssp., L. amicorum $\mathbf{n}$. sp., L. decipiens $\mathbf{n}$. sp. and L. morrisi $\mathbf{n}$. sp. A key for all Laparocerus from La Palma is provided in Spanish and English. Furthermore, Laparocerus laevis politus Roudier, 1957 is synonymized with L. laevis Roudier, 1957. Key words: Taxonomy, new taxa, synonyms, Canary Islands, Macaronesia, Laparocerus, Curculionidae, Entiminae.

* c/ Chopin 1, 38208 La Laguna, Tenerife, Islas Canarias. Email. antonio.machado@telefonica.net 


\section{Introducción}

Los curculiónidos entiminos del género Laparocerus Schoenherr, 1834 se distribuyen en la Macaronesia además de en Marruecos occidental, de donde se conoce una única especie. La prospección sistemática de los archipiélagos de Madeira y Canarias en busca de Laparocerus iniciada en 1999, ha deparado numerosos taxones nuevos, varios de los cuales se han descrito en trabajos previos (Machado 2005, 2007a, 2007b, 2008a, 2008b). La presente contribución tiene por único objeto describir nuevas especies y subespecies, en este caso, procedentes de la isla de La Palma. Salvo Laparocerus arrochai n. sp., L. tanausu n. sp. y L. cristatus n. sp. que pertenecen al subgénero Amyntas Wollaston, 1865, y $L$. astralis, que es un Guanchotrox Alonso Zarazaga \& Lyal 1999, las demás especies se dejan sin atribución subgenérica ya que la sistemática supraespecífica del género Laparocerus será modificada en breve, pues requiere una revisión en profundidad según se deduce de los datos moleculares obtenidos y aún no publicados (ver resultados parciales sobre el clado madeirense en Machado et al., 2008).

Para facilitar el reconocimiento de los nuevos taxones, se aporta una clave que abarca todas las especies y subespecies de Laparocerus conocidas de la isla, aunque algunas siguen siendo objeto de estudio mas detallado (marcadas como " $c f$ ", por confirmar). Al tratar las especies en la clave, se anotan solo lo subgéneros confirmados.

Llama la atención la treintena de especies encontradas en esta isla, que es de las más jóvenes de Canarias (1,7 ma., Anguita et al., 2002). Quizás sea este factor de juventud geológica y la intensa dinámica volcánica habida en su mitad meridional, lo que explique la variación morfológica que se observa entre poblaciones de un mismo grupo en diferentes sectores de la isla, como si los procesos de especiación estuvieran aún en plena ebullición.

\section{Material y métodos}

El material objeto de estudio proviene de colecciones privadas y de varias instituciones europeas, así como del recolectado por el autor durante varias campañas de prospección a lo largo de la presente década. El total de ejemplares estudiados asciende a 2.386 Para las series típicas, y como regla general, se ha escogido una sola localidad o localidades muy próximas, a fin de minimizar la variación genética. Los holotipos se han depositado en el Museo de Ciencias Naturales de Santa Cruz de
Tenerife. Las siglas empleadas para referir a las diferentes colecciones son las siguientes:

AAC Agustín Aguiar Clavijo, colección privada. La Laguna, España

AL Andrea Liberto, colección privada Roma, Italia.

AMC Antonio Machado Carrillo, colección privada. La Laguna, España.

DEI Deutsches Entomologisches Institut. Müncheberg, Alemania.

EC Enzo Colonnelli, colección privada, Roma, Italia.

HW Herbert Winkelmann, colección privada, Berlín, Alemania.

JB Jo Brunner, colección privada, Würzburg, Alemania.

JM Jochen Messutat, colección privada, Preussisch Oldendorf, Alemania

MNCN Museo Nacional de Ciecnias Naturales. Madrid. España.

MM Michael Morris, colección privada, Dorchester, Reino Unido.

NHM The Natural History Museum. Londres, Reino Unido.

NMW Naturhistorisches Museum Wien. Viena, Austria.

PS Peter Stüben, colección privada, Mönchengladbach, Alemania

PSH Peter Sprick, colección privada, Hannover, Alemania.

RGB Rafael García Becerra, colección privada. S/C de La Palma, España.

TFMC Museo de Ciencias Naturales. Santa Cruz de Tenerife, España.

ZMUL Zoological Museum, University of Lund, Suecia.

ULL Departamento de Zoología, Universidad de La Laguna

Las disecciones fueron realizadas siguiendo los procedimientos entomológicos al uso. Las fotografías se tomaron con una cámara digital Nikon D70, con objetivo AF Micro Nikon $60 \mathrm{~mm} \mathrm{1:28} \mathrm{D} \mathrm{y} \mathrm{ani-}$ llo de extensión, usando luego el software CombineZM (Aland Hadley, 2007) para la fusión de tomas secuenciales. Los dibujos se realizaron con ayuda de una cámara clara montada sobre microscopio o lupa binocular, y para las mediciones se utilizó la lupa equipada con un micrómetro en el ocular. Las tallas se refieren a la longitud del insecto, descontado el rostro. La convexidad de los ojos se indica dividiendo su altura (sobre el perfil de la cápsula cefálica) por el eje mayor, obteniéndose un porcentaje que viene a representar la porción emergente de un teórico elipsoide o globo completo. Un $50 \%$, por ejemplo, equivaldría a un ojo sobresaliente y hemisférico; un $15 \%$, a un casquete muy reducido u ojo casi plano, etcétera. El término de prorrostro (Damoiseau, 1967) se emplea aquí para referir a la parte anterior y dorsal del rostro delimitada por la línea donde usualmente se inicia el declive apical (justo detrás del nivel de inserción de las antenas); el metarrostro es la porción posterior, hasta su base. La terminología de la espermateca corresponde a Thompson (1989). 
La relación de las figuras en el encabezado de las especies sigue el orden siguiente: imagen del holotipo, edeago, urosternito VIII $\$$ y espermateca. Las letras L y A en la expresión de las ratio significan longitud y ancho, respectivamente.

\section{Descripciones}

\section{Laparocerus aeneotinctus $\mathbf{n}$. sp.}

(Figs. 1, 2A, 5A, 6C y 20A)

Material examinado. La Palma. Holotipo $1 \sigma^{\pi}$, Breña Alta: Pared Vieja, 1350 m 27-1-2001 leg. A. Machado (TFMC n 15934).- Paratipos: misma localidad y fecha, 16 exx leg. A. Machado (AMC), 5 exx leg. R. García (RGB). Breña Alta: Cumbre Nueva 3 exx 27-1-2001 leg. R. García (RGB); idem. 1 ex no 1159 leg. H. Franz (NMW). Fuente del Guaidín 1400 m 2 exx 27-1-2001 leg A. Machado (AMC).

No paratipos: Refugio del Pilar, pista Hilera, 2 exx 23-122008 leg. T. Forcke (AMC); Mazo: Montaña Vinijobre, 1000 m, 10 exx 8-12-2005 leg R. García (RGB), 4 exx ídem. leg. A. Aguiar (AAC).
Localidad TíPICA. Pared Vieja, municipio de Breña Alta, La Palma, islas Canarias. UTM 28R 022403316909.

Medidas DEL holotiPo ( $\left.\sigma^{\pi}\right)$. Longitud: total ( $\sin$ rostro) $8,00 \mathrm{~mm}$, rostro $0,90 \mathrm{~mm}$, escapo $3.20 \mathrm{~mm}$, funículo 2,28 (desmómeros I-IV respectivamente $0,58 / 0,58 / 0,38 / 0,34 \mathrm{~mm})$, maza $0,70 \mathrm{~mm}$, pronoto $1,75 \mathrm{~mm}$, élitros $5,60 \mathrm{~mm}$, tibias (pro- /meso/meta-) 2,60/2,35/2,80 mm. Anchura: cabeza (a nivel de los ojos) $1,40 \mathrm{~mm}$ (interocular) $0,80 \mathrm{~mm}$, rostro (a nivel de los pterigios) 0,93 $\mathrm{mm}$, (mínimo ventral) $0,77 \mathrm{~mm}$ (mínimo dorsal) $0,62 \mathrm{~mm}$, (base) $0,90 \mathrm{~mm}$; escapo $0,16 \mathrm{~mm}$, maza $0,18 \mathrm{~mm}$, pronoto (anterior /máxima /posterior) 1,45/2,30/2,15 mm y élitros (máxima) $3,80 \mathrm{~mm}$. Altura: abdomen $3,00 \mathrm{~mm}$.

DESCRIPCIÓn. Machos: Talla: 6,0-7,5 mm. Cuerpo robusto y grande; tegumento alutáceo de coloración pardo-pícea con ligero viso broncíneo, provisto de escamitas flavo-oliváceas lanceoladas, pequeñas, bastante adpresas y muy abundantes, formando
Fig. 1.- Holotipo $\sigma^{7}$ y paratipo 우 de Laparocerus aeneotinctus $\mathbf{n}$. sp.

Fig. 1.- Holotype $\sigma^{x}$ and paratype 우 of Laparocerus aeneotinctus n. sp.

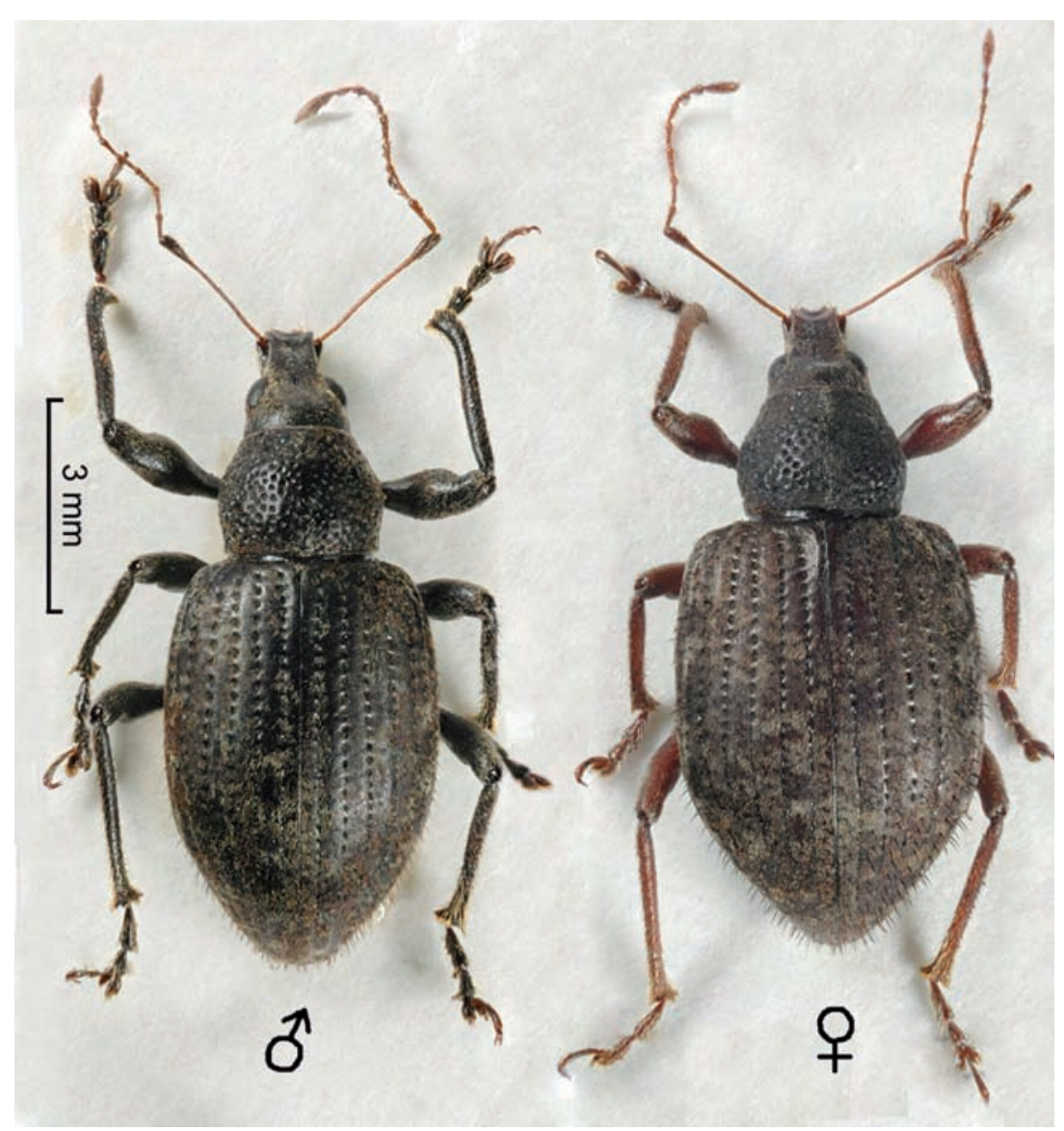



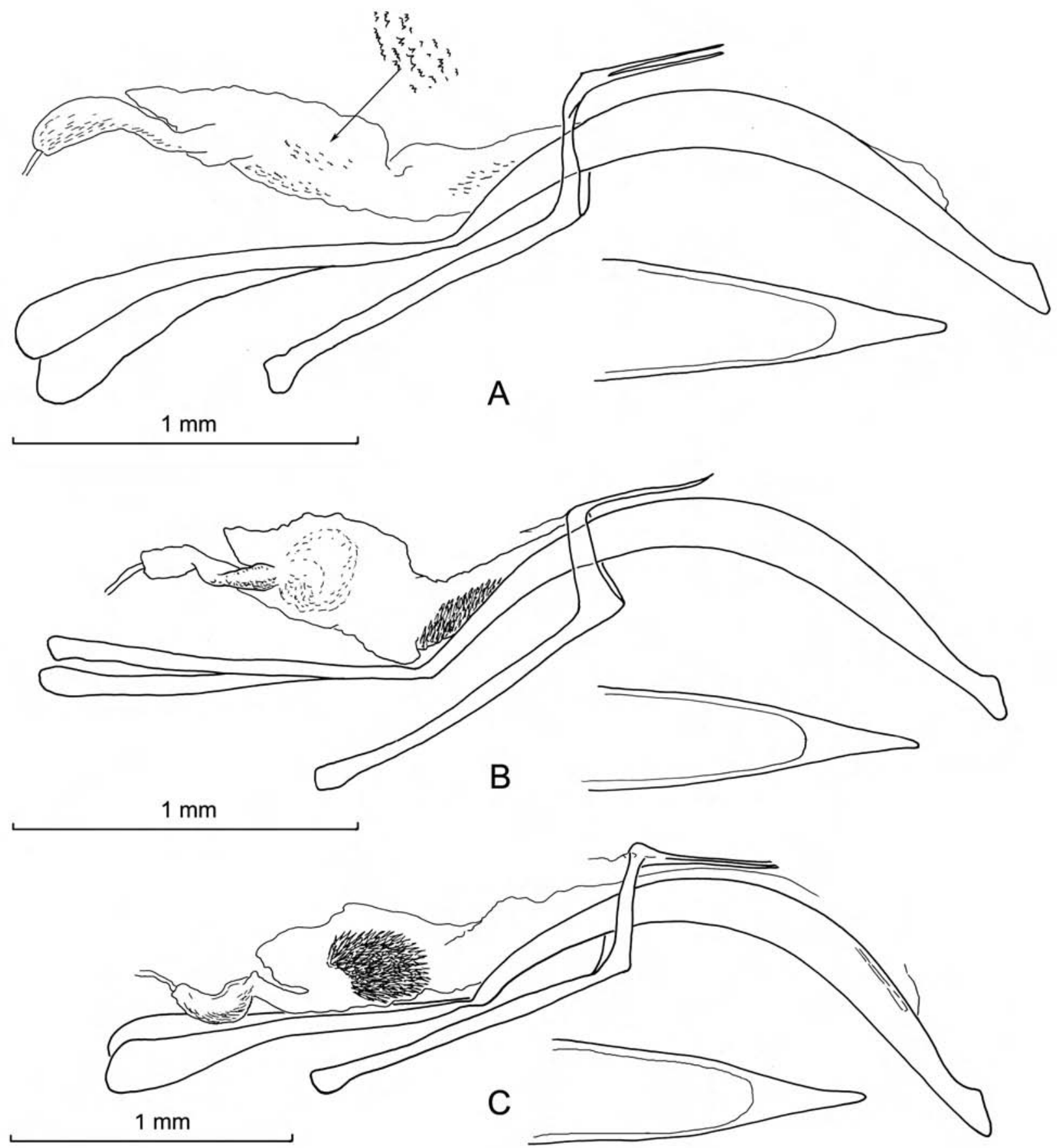

Fig. 2.- Edeago y detalle del ápice del lóbulo medio: Laparocerus aeneotinctus n. sp. (A), Laparocerus femoralis n. sp. (B) y Laparocerus acyphus n. sp. (C).

Fig. 2.- Aedeagi and detail of median lobe apex: Laparocerus aeneotinctus $\mathbf{n}$. sp. (A), Laparocerus femoralis $\mathbf{n} . \mathbf{s p .}$ (B), and Laparocerus acyphus n. sp. (C). 
dibujo en teselas sobre los élitros, éstos con pequeñas sedas negras sobresalientes. Antenas rojizas excepto maza del escapo; ocasionalmente, también las tibias.

Antenas largas, muy delgadas; escapo rectilíneo, $1,2 \mathrm{x}$ la longitud del pronoto, brevemente capitado apicalmente; funículo ligeramente más largo que el escapo, desmómeros 1-2 largos, subiguales; maza fusiforme, delgada, más larga que los tres desmómeros precedentes reunidos.

Cabeza robusta; rostro estrecho, moderadamente alargado, de sección cuadrangular; pterigios largos, poco salientes; prorrostro sin puntos, metarrostro punteado, ligeramente deprimido (no acanalado); frente deprimida, con fóvea breve, profunda, ojival; tegumento punteado. Ojos grandes, oval-alargados $(\mathrm{L} / \mathrm{A}=1,5)$, poco prominentes (convexidad $18-20 \%$ ).

Pronoto transversal $(\mathrm{L} / \mathrm{A}=0,76)$, algo más estrecho por delante que por detrás, sin reborde anterior ni posterior; lados uniformemente curvados en su tramo medio; tegumento alutáceo con doble punteado: puntos muy gruesos y profundos separados un diámetro o más entre sí, puntos menores en las interestrías sobre microrreticulación isodiamétrica incisa muy marcada. Escamitas no más largas que el diámetro de un punto grueso, bastante dehiscentes.

Escudete triangular, amplio, tapizado de escamitas.

Élitros ovalado-acuminados, 1,65x el ancho del pronoto, poco convexos en el disco; lados curvados, máxima anchura a la mitad; hombros marcados, ángulo humeral obtuso, romo, y carena humeral más o menos resaltada; declive apical poco abrupto. Estrías marcadas en el tercio basal por puntos grandes y profundos (iguales a los del pronoto), decrecientes y alargados hacia el ápice. Interestrías subplanas, amplias, algo más convexas hacia los flancos, portando a lo ancho 10-12 escamitas lanceoladas adpresas y a lo largo 1-2 hileras de cerdas negras suberectas, algo arqueadas, más largas y robustas en el tercio apical (no mayores que las uñas); interestría sutural con ligera tumefacción postescutelar.

Cara ventral con pubescencia de escamitas piliformes, menos recostadas que en el dorso; saliente intermesocoxal muy estrecho y aquillado; esternitos abdominales con microrreticulación transversal, salvo $3^{\circ}-5^{\circ}$ más lisos y brillantes, con pubescencia más larga. Quinto esternito apicalmente en arco amplio, más largo que los dos anteriores reunidos.

Patas largas; fémures de grosor normal y constricción preapical en declive suave; tibias delgadas (salvo ápice, engrosado), sinuosas, con pubescen- cia más larga y rala en el tercio apical (no forma cepillo), todas con mucrón triangular muy desarrollado y aparente, protibias incurvadas en el quinto apical, a modo de gancho. Tarsos robustos y alargados, artejo basal 1,8x la longitud del segundo; oniquio sobresale más de la mitad; uñas cortas.

Edeago muy estilizado, poco arqueado; temones algo menores que el lóbulo medio; punta en vista dorsal estrecha y afilada, de perfil con talón dorsal característico (Fig. 2A). Saco interno corto, hacia atrás sin rebasar los temones, su divertículo ciego muy reducido, más corto que el gonoporal, ambos sin dientes o espinas, solo con campos de escámulas.

Hembras. Talla 7,0-9,0 mm. Más robustas y rechonchas que los machos. Élitros más anchos $(\mathrm{L} / \mathrm{A}=1,4$ en vez de 1,5$)$, base más cuadrangular, ángulo humeral menos obtuso, callo humeral más desarrollado; lados subrectos y tercio apical más acuminado (subriangular); tumefacción postescutelar más pronunciada y llamativa; interestrías con sedas más desarrolladas y notorias. Protibias más rectilíneas y poco curvadas en el ápice; mucrón en todas las tibias, pero menos desarrollado. Quinto esternito abdominal ligeramente aquillado al centro, termina en arco más ojival. Urosternito VIII robusto, corto, de punta sagitada estrecha, con cerdas cortas (Fig. 5A). Espermateca, figura 20A.

ETIMOlogía. El epíteto latino aeneotinctus (teñido de bronce) es un adjetivo que hace referencia a la coloración del insecto que presenta un ligero viso broncíneo.

OBSERVACIONES. Laparocerus aeneotinctus pertenece al grupo de L. occidentalis Wollaston, 1864, que cuenta con varias especies en la isla de Tenerife (v. Machado, 2007a), una en el Hierro y otra en Gran Canaria (aún no descrita). De L. occidentalis se distingue por la mayor diferencia existente entre los machos oblongos y las hembras anchas, los élitros más deprimidos dorsalmente y más acuminados, además de presentar tumefacción postescutelar; los puntos elitrales mucho más gruesos y las sedas suberectas doble de largas; también los ojos son más alargados y menos convexos. Respecto de L. crassus Roudier, 1957 se distingue por ser menos robustos, el pronoto menos transversal y ancho en la base, los élitros bastante menos cuadrangulares en la base y el callo humeral no tan marcado en ambos sexos. De $L$. aguiari Machado 2007 se separa fácilmente por tener éste último los puntos de las estrías elitrales la mitad de grandes que los del pronoto y los ojos más cortos y prominentes, además de ser bastante más alargado su cuerpo. L. rugosicollis tiene los ojos 


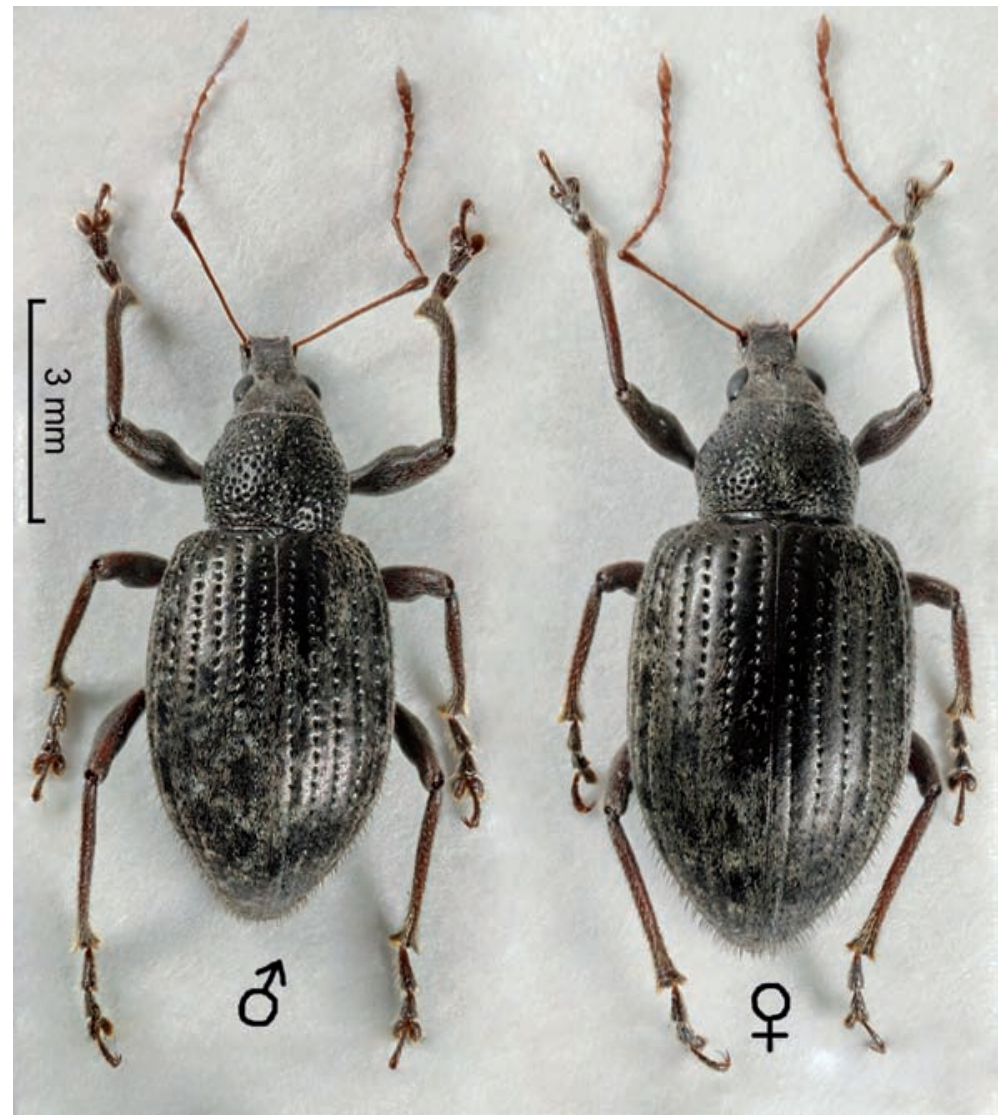

Fig. 3.- Holotipo $\sigma^{\pi}$ y paratipo $\odot$ de Laparocerus acyphus $\mathbf{n}$. sp.

Fig. 3.- Holotype $\sigma^{x}$ and paratype $\bigcirc$ of Laparocerus acyphus $\mathbf{n}$. sp. muy prominentes y los élitros oval-alargados e igualmente convexos en ambos sexos, además de que las sedas son de igual tamaño a todo lo largo de los élitros (se reducen hacia delante en aeneotinctus).

En la isla de La Palma existen otras dos especies (alopátricas) de este grupo que se distinguen bien por el llamativo grosor de los fémures, en el caso de L. femoralis $\mathrm{n}$. sp., o por la ausencia de gibosidad postescutelar, en L. acyphus n. sp. A parte de estos dos parientes próximos, las únicas especies con las que puede confundirse de visu $L$. aeneotinctus son L. elongatus n. sp. y L. mucronatus n. sp. pero ambas son de talla algo menor, tegumento más brillante, frente plana, escapo antenal algo sinuoso, protibias rectilíneas con mucrón mucho menos desarrollado, la base de los élitros $ᄋ$ 우 es recta (hombros incluso algo avanzados) y las sedas emergentes son mucho mayores y están más separadas, mientras que en $L$. aeneotinctus el ángulo humeral siempre es obtuso y los hombros romos. Cualquier duda puede disiparse inspeccionando el edeago, cuya punta es característica y completamente diferente (Fig. 2A).
DISTRIBUCIÓN Y ECOLOGÍA. Laparocerus aeneotinctus es una especie endémica de la isla de La Palma. Se distribuye por la ladera oriental de la parte más joven de la isla, donde habita en zonas boscosas de laurisilva o fayal-brezal, eventualmente mezclado con pinos canarios. Ha sido colectada de noche sobre Rhamnus glandulosa (Rhamnaceae) y Cedronella canariensis (Lamiaceae).

\section{Laparocerus femoralis $\mathrm{n} . \mathrm{sp}$.}

(Figs. 4B, 3B, 5C, 6B y 20B)

Material examinado. La Palma. Holotipo $10^{7}$, Roque Faro, 1080 m 7-12-2004 leg A. Machado (TFMC n ${ }^{\circ}$ 15936).Paratipos: Mismo lugar y fecha 13 exx leg. A. Machado (AMC), 8 exx leg. R. García (RGB), 14 exx leg. A. Aguiar (AAC); Cueva de la Zarza (Garafía), 1 ex 3-2-1975, 17 exx 301-2001 leg. A. Machado (AMC), 2 exx 6-12-2004 leg. A. Aguiar (AAC).

No paratipos: Entrada Marcos y Corderos (Casa del Canal) 6 exx 3-10-2009, Marcos y Corderos 2 exx 15-11-1982, 10 exx 3-10-2009 leg. A. Machado (AMC); 23 exx 3-10-2009 leg. R. García (RGB). Bco Ladera de Tagoja 1050 m 1 ex 19-6-1999, Monte de Barlovento 950-1100 m 8 exx 29-1-2001 leg. A. 
Fig. 4.- Holotipos $\sigma^{7} \sigma^{\top}$ : Laparocerus arrochai n. sp. (A) y Laparocerus femoralis n. sp. (B).

Fig. 4.- Holotypes $\sigma^{7} \sigma^{7}$ : Laparocerus arrochai n. sp. (A), and Laparocerus femoralis n. sp. (B).

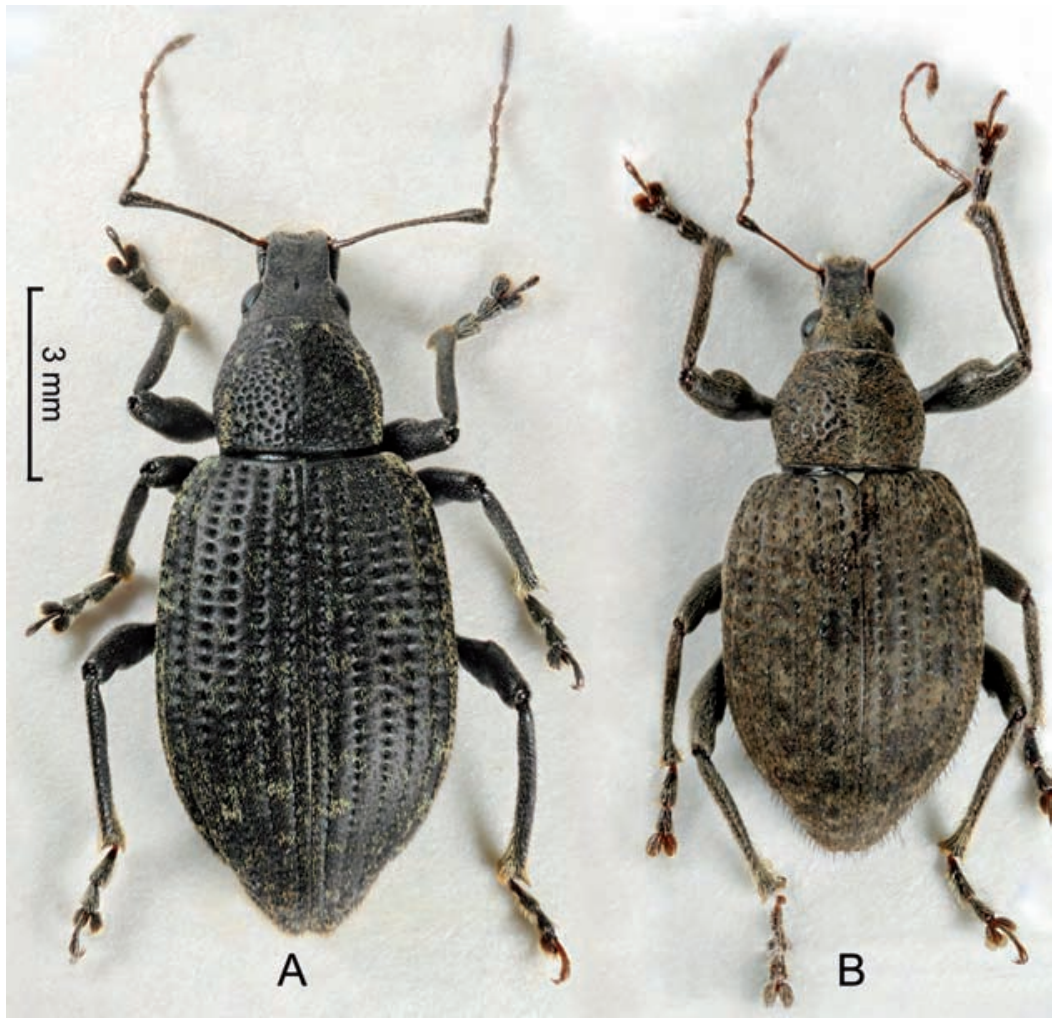

Machado (AMC); Carretera a Juan Adalid 600 m 5-12-2004 3 exx leg. R. García (RGB); ídem. 1 ex leg. A. Aguiar (AAC).

LOCALIDAD TíPICA. Roque Faro, 1080 m, municipio de Garafía, La Palma, islas Canarias. UTM 28R 02185183189098.

DiAgnosis. Talla $0^{7} \sigma^{7} 6,8-8,5 \mathrm{~mm}$, 우 우 7,4-8,7 $\mathrm{mm}$. Igual que la especie anterior, L. aeneotinctus $\mathrm{n}$. $\mathrm{sp}$., pero los fémures mucho más robustos y gruesos, produciéndose el estrangulamiento preapical de forma brusca (relación entre grosor máximo y el del quinto apical igual a 1,7x en vez de 1,45x (Figs. 6BC). Los machos son más anchos y, por tanto, más parecidos a las hembras, incluida la tumefacción postescutelar, que está más desarrollada que en los machos de L. aeneotinctus. Las protibias no son tan sinuosas. El edeago tiene la misma forma, pero el saco interno es algo más corto y presenta un campo basal de dientes muy desarrollado (Fig. 2B). Las sedas apicales del urosternito VIII (Fig. 5C), son largas en vez de minúsculas, y el abultamiento junto al lóbulo del ducto espermático de la espermateca está muchísimo más desarrollado (Fig. 20B).

ETIMOLOGía. El epíteto específico es un adjetivo latino y hace referencia a los fémures muy robustos que caracterizan a este taxón.
DISTRIBUCIÓN Y ECOLOGÍA. Laparocerus femoralis n. sp. es endémico de La Palma y, de las tres especies del grupo, es la más ampliamente distribuida, abarcando las medianías (600-1200 m) de la fachada norte y oriental de la isla, hasta la Cumbre Vieja. Vive en dominio de monteverde y bosque mixto laurisilva-pinar, donde se alimenta de plantas del sotobosque o arbustivas: Cedronella canariensis (Lamiaceae), Viburnum rigidum (Adoxaceae), Gonospermum canariense (Asteraceae), etc.

Laparocerus acyphus $\mathbf{n} . \mathbf{s p}$. (Figs. 2C, 3, 5B y 20C)

Material examinado. La Palma. Holotipo $10^{7}$ El Paso: Montaña de Don Mendo, 1075 m 23-1-2009 leg. A. Machado (TFMC n ${ }^{\circ}$ 15935).- Paratipos, misma localidad y fecha, 7 exx leg. A. Machado (AMC), 17 exx leg. R. García (RGB), 2 exx leg. M. A. Alonso-Zarazaga (MNHN).

LOCALIDAD TíPICA. Montaña de Don Mendo, municipio de El Paso, La Palma, islas Canarias. UTM 28R 0220321624.

DiAgnosis. Talla $0^{7} \sigma^{7}$ 6,8-7,6 mm, 우 우 7,5-8,5 $\mathrm{mm}$. Laparocerus muy próximo a $L$. aeneotinctus n. sp. y L. femoralis n. sp. de los que se distingue 


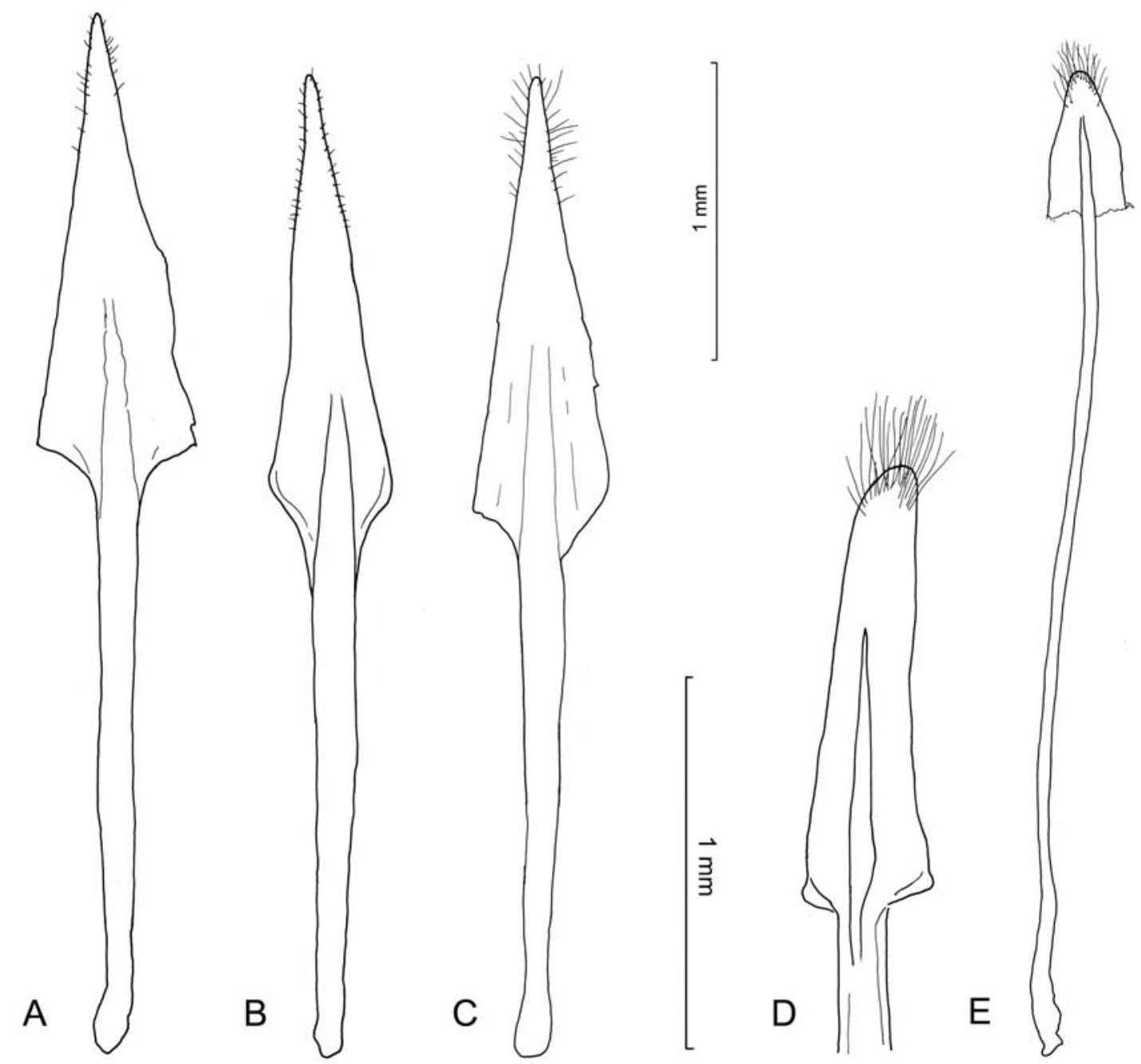

Fig. 5.- Urosternito VIII femenino: Laparocerus aeneotinctus n. sp. (A), Laparocerus acyphus n. sp. (B), Laparocerus femoralis n. sp. (C), Laparocerus arrochai n. sp. (D) y Laparocerus amicorum n. sp. (E).

Fig. 5.- Female urosternite VIII: Laparocerus aeneotinctus n. sp. (A), Laparocerus acyphus n. sp. (B), Laparocerus femoralis n. sp. (C), Laparocerus arrochai $\mathbf{n} . \mathbf{s p}$. (D) and Laparocerus amicorum n. sp. (E).

por ser más convexo (disco elitral no deprimido), de aspecto más delicado; las hembras menos ensanchadas y por tanto más parecidas a los machos (élitros de lados curvados); punteado del pronoto algo más apretado; élitros en ambos sexos sin tumefacción postescutelar; hombros en los $O^{x} O^{x}$ brevemente angulosos; patas con fémures de grosor normal y más estilizados; protibias $\sigma^{7} \sigma^{7}$ sinuosas y algo más curvadas en el ápice. El edeago tiene la misma forma que en las otras dos especies, pero es el campo medio de saco interno el desarrollado con dentículos apretados, y no el basal (Fig. 2C). La espermateca presenta solo una incipiente joroba junto al lóbulo del ducto espermático (Fig. 20C). Urosternito VIII figura 5B.

Etimología. El epíteto específico es un sustantivo griego en aposición (invariable) que significa "sin joroba" en referencia a la ausencia de tumefacción en la base de las interestrías suturales de los élitros, carácter que la distingue de sus parientes.

DistriBUCIÓN Y ECOLOGÍA. L. acyphus n. sp. es endémico de La Palma y hasta ahora se ha localizado solo en el extremo meridional de la isla, en la 
Fig. 6.- Detalle de la metatibia $\sigma^{7}$ de Laparocerus mucronatus n. sp. (A). Fémur y protibia $\sigma^{\pi}$ de Laparocerus femoralis $\mathbf{n}$. sp. (B) y de Laparocerus aeneotinctus n. sp. (C).

Fig. 6.-Apex of metatibia $\sigma^{2}$ of Laparocerus mucronatus n. sp. (A). Femora and protibiae $\sigma^{\prime \prime}$ of Laparocerus femoralis n. sp. (B) and Laparocerus aeneotinctus n. sp. (C).

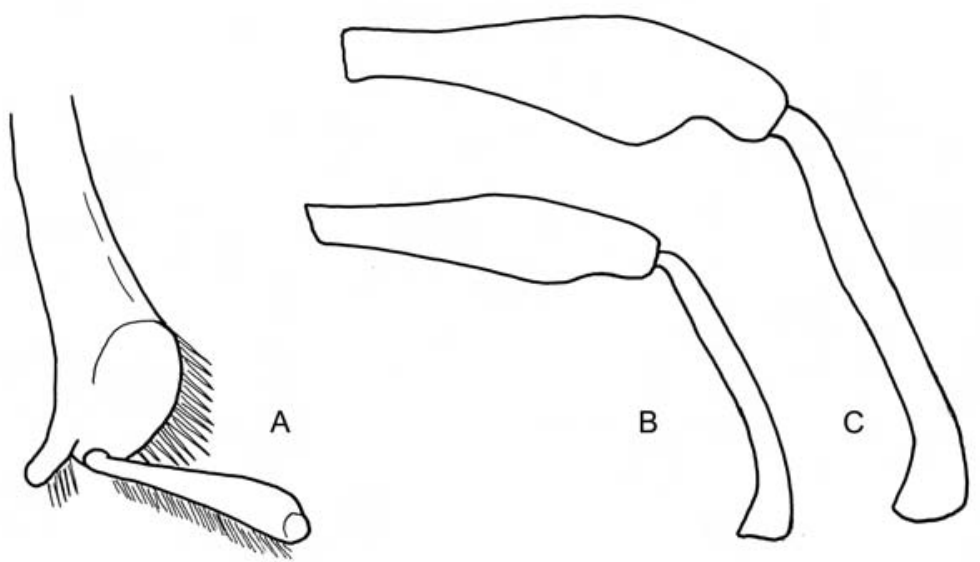

parte geológica más reciente y activa volcánicamente. Se ha colectado de noche alimentándose sobre Aeonium spathulatum (Crassulaceae) en el sotobosque de un pinar canario, a mediana altitud $(1000 \mathrm{~m})$.

\section{Laparocerus arrochai $\mathrm{n} . \mathbf{s p}$.}

(Figs. 4A, 9A, 5D y 20D)

Material examinado. La Palma. Holotipo: $10^{\pi}$ Bco. de los Hombres, $100 \mathrm{~m}, 1-5-2005 \mathrm{leg}$ A. Machado (TFMC $\mathrm{n}^{\circ}$ 15938).- Paratipos: 9 exx, mismos datos, 1 ex 11-7-2006 leg. A. Machado (AMC); ídem 8 exx leg. R. García (RGB); idem $340 \mathrm{~m} 1$ ex 10-7-2006 leg L. Behne (DEI). Bco. Franceses 440 m, 2 exx 19-6-2004, 3 exx 1-5-2005 leg. A. Machado (AMC), idem 3 exx leg. R. García (RGB). Bco. de Gallegos, $550 \mathrm{~m} 1$ ex 1-5-2005 leg. A. Machado (AMC).

LOCALIDAD TíPICA. Barranco de Los Hombres, municipio de Garafía, La Palma, islas Canarias. UTM 28R 02199873192320.

Medidas del holotipo $\left(\sigma^{7}\right)$. Longitud: total ( $\mathrm{sin}$ rostro) $10,05 \mathrm{~mm}$, rostro $1,25 \mathrm{~mm}$, escapo $2,75 \mathrm{~mm}$, funículo 3,30 (desmómeros I-IV respectivamente 0,64 / 0,78 / 0,44/ 0,38 mm), maza $0,90 \mathrm{~mm}$, pronoto 2,25 mm, élitros 7,40 mm, tibias (pro-/meso-/meta-) 2,90/2,70/3,15 mm. Anchura: cabeza (a nivel de los ojos) $1,68 \mathrm{~mm}$, (interocular) $1,05 \mathrm{~mm}$; rostro (a nivel de los pterigios) $1,32 \mathrm{~mm}$, (mínimo dorsal) $0,85 \mathrm{~mm}$ (mínimo ventral) $1,15 \mathrm{~mm}$; escapo $0,24 \mathrm{~mm}$, maza $0,90 \mathrm{~mm}$, pronoto (anterior /máxima /posterior) 1,92/2,60/ 2,45 mm y élitros (máxima) 4,70 mm. Altura: abdomen $3,40 \mathrm{~mm}$.

DesCripCión. Machos: Talla: 9,4-11,1 mm. Cuerpo grande, robusto, ancho y moderadamente deprimido; tegumento de color negro mate, con revestimiento ralo de escamitas pequeñas, estrechas y adpresas de color flavo o dorado, con visos glaucos o cobrizos, formando alguna agrupación más destacada (hombros, pronoto, etc.); el punteado muy grueso y llamativo.

Antenas delgadas, gráciles. Escapo 1,2x la longitud del pronoto, rectilíneo (apenas sinuoso en la mitad basal), capitado en su quinto apical; funículo aún más largo $(1,5 \mathrm{x})$, desmómero I > II, el III > IV; maza fusiforme $(\mathrm{L} / \mathrm{A}=4,1)$, algo menor que los tres desmómeros precedentes reunidos.

Cabeza robusta, cónica; rostro cuadrangular; pregenas robustas, rectilíneas, ligeramente convergentes hacia la base; pterigios largos pero nada sobresalientes (base antenal visible desde arriba); quilla epistomal completa, en "v" invertida, muy desarrollada; prorrostro convergente hacia delante, liso, separado del metarrostro por esbozo de carena mediana, igualmente lisa; metarrostro con márgenes engrosados y paralelos; superficie levemente deprimida, surcado por una línea media fina prolongada hasta el vértice; tegumento fina, densa y longitudinalmente estriado (enmascarando la microrreticulación poligonal diminuta), con algunos puntos superficiales y escamitas dispersas. Ojos grandes, ovales $(\mathrm{L} / \mathrm{A}=1,4)$, poco prominentes (convexidad 20\%), y tangentes al canto lateral de la frente; ésta, ligeramente hundida, con foseta estrecha, alargada y profunda.

Pronoto poco convexo, transversal $(\mathrm{L} / \mathrm{A}=0,87)$, algo más estrecho por delante que por detrás, máxima anchura al centro; base ligeramente convexa, sin reborde; línea mediana imprecisa, a veces ligeramente levantada. Tegumento con microrreticulación poligonal pequeña casi granuliforme; grandes puntos foveiformes separados un diámetro entre sí, algo menores y más distantes en el margen anterior y la línea mediana (cada punto con un pelito dirigido hacia atrás); escamitas finas dispersas, las más 
gruesas (doradas o verdosas) agrupadas formando un arco estrecho que parte de los ángulos posteriores y alcanza el margen anterior al centro (discontinuo en este tramo).

Escudete con la parte visible muy breve, algo levantada, tapizada de escamitas; parte oculta en declive casi vertical sobre el borde anterior del élitro.

Élitros de aspecto ancho $(\mathrm{L} / \mathrm{A}=1,6)$, deprimidos, con declive suave, $3,3 \mathrm{x}$ la longitud del pronoto y $1,8 \mathrm{x}$ su anchura; base amplia, cóncava, los hombros algo achaflanados y ligeramente avanzados; el tramo medio con márgenes subrectos y convergentes hacia delante; tercio apical diferenciado y acuminado (inflexión a partir del anastomosamiento de las interestrías 4-7); punta brevemente truncada o, a veces, bífida. Estrías marcadas por amplios puntos foveiformes (pelito interno menor que el diámetro, no emergente), mayores que los del pronoto, poco separados entre sí, decrecientes en el tercio apical hasta quedar en trazo. Interestrías algo más anchas que las estrías, subconvexas en el disco, más convexas hacia los flancos y careniformes en tercio apical; base de la $6^{\circ}$ deprimida en el húmero (incipiente callo humeral), las suturales a veces deprimidas en el tercio basal. Tegumento con microrreticulación granuliforme enmascarada por un microestriado transversal; escamitas adpresas, pequeñas, finas (menos aparentes) y más anchas, dispersas, las más anchas formando algunos parches densos (contiguas y sobrepuestas), sobre todo en flancos y tapizando los hombros (prolongación del dibujo del pronoto); hileras de pequeñas sedas parduscas curvadas e inclinadas hacia atrás, 1,5x tan largas como las escamitas, pero poco aparentes (mirar de perfil).

Patas robustas, simples; fémures con banda ventral de escamitas claras en tercio apical; tibias rectilíneas, algo arqueadas dorso-lateralmente, engrosadas en el ápice hacia dentro, protibia con el ángulo apical externo achaflanado, mucrón triangular-alargado, apenas sobresaliente de la almohadilla terminal ventral (algo extendida sobre el flanco), mesomucrón igual, metamucrón menor, casi granular.

Cara ventral: Gránulo inter-procoxal posterior poco o nada desarrollado; carínula intermesocoxal, ancha, roma, elevada a $1 / 2$ altura de la coxa; reborde postcoxal profundamente foveolado; fóvea metasternal muy amplia y profunda, proceso anterior del urosternito I con rugosidad muy abrupta a todo lo ancho; tegumento más brillante, con pilosidad fina abierta y escamitas flavas adpresas más abundantes hacia los flancos. Sutura entre urosternito I y II, brevemente deprimida a ambos del tramo medio; urosternito $\mathrm{V}$ con algunos puntos superficiales, margen posterior truncado, recto.

Edeago: Lóbulo medio moderadamente arqueado, punta en vista dorsal digitiforme, vista de perfil rectilínea, roma, con breve gancho superior (visto de perfil); saco interno muy largo, con extenso campo de espinas en el tramo medio del divertículo ciego, que es estrecho (Fig. 9A).

Hembras. Tallas 9,8-11,8 mm. Difíciles de distinguir del macho; élitros ligeramente más convexos; tibias inermes, y margen posterior del urosternito $\mathrm{V}$ algo más estrecho y curvado. Placa del urosternito VIII angosta, con sedas terminales largas (Fig. 5C). Espermateca con lóbulo glandular acodado (Fig. 20D).

Etimología. La especie está dedicada a don Alberto Arrocha Lorenzo, taxidermista que trabajó para el Gabinete de Ciencias Naturales de la Sociedad La Cosmológica de La Palma, quien capturó el primer ejemplar conocido y del que pudimos ver una fotografía.

OBSERVACIONES. Laparocerus arrochai n. sp. pertenece al subgénero Amyntas, por la estructura de su rostro, antenas, tibias, tegumento y escudete. Se parece en todo a su vicariante de la isla de Tenerife, L. bellus Roudier 1957, salvo por ser algo más convexo, presentar el metarrostro paralelo (prorrostro y metarrostro con lados alineados y convergentes hacia delante en bellus); los élitros no son paralelos en su tramo medio sino convergentes hacia la base (y no más alargados en los machos que en las hembras), el callo humeral y la depresión posthumeral están mucho menos desarrollados, el ángulo apical externo de las protibias está más achaflanado, no existe un gránulo posterior interprocoxal grande y desarrollado, el mesocoxal es menos robusto y elevado (alcanza la altura de la mesocoxa en L. bellus), y la rugosidad del proceso anterior del primer urosternito es mucho más exagerada. Por su gran talla, élitros deprimidos groseramente punteados y distribución pulverulenta y en parches de las escamitas (p.ej. hombros tapizados) sobre tegumento mate, no cabe confundir esta nueva especie con ningún otro Laparocerus de los presentes en la isla de La Palma.

DistribuCión Y ECOLOGÍA. Endemismo de la isla de La Palma localizado hasta el momento sólo en la fachada norte en dominio del bosque termófilo (100-500 m de altitud), alimentándose exclusivamente de Jasminum odoratissimum (Oleaceae), circunstancia que se repite en su vicariante L. bellus, en la isla de Tenerife. 
Fig. 7.- Holotipos $\sigma^{x} \sigma^{x}$ : Laparocerus cristatus n. sp. (A) y Laparocerus tanausu n. sp. (B).

Fig. 7.- Holotypes $\sigma^{7} \sigma^{x}$ : Laparocerus cristatus n. sp. (A) and Laparocerus tanausu n. sp. (B).

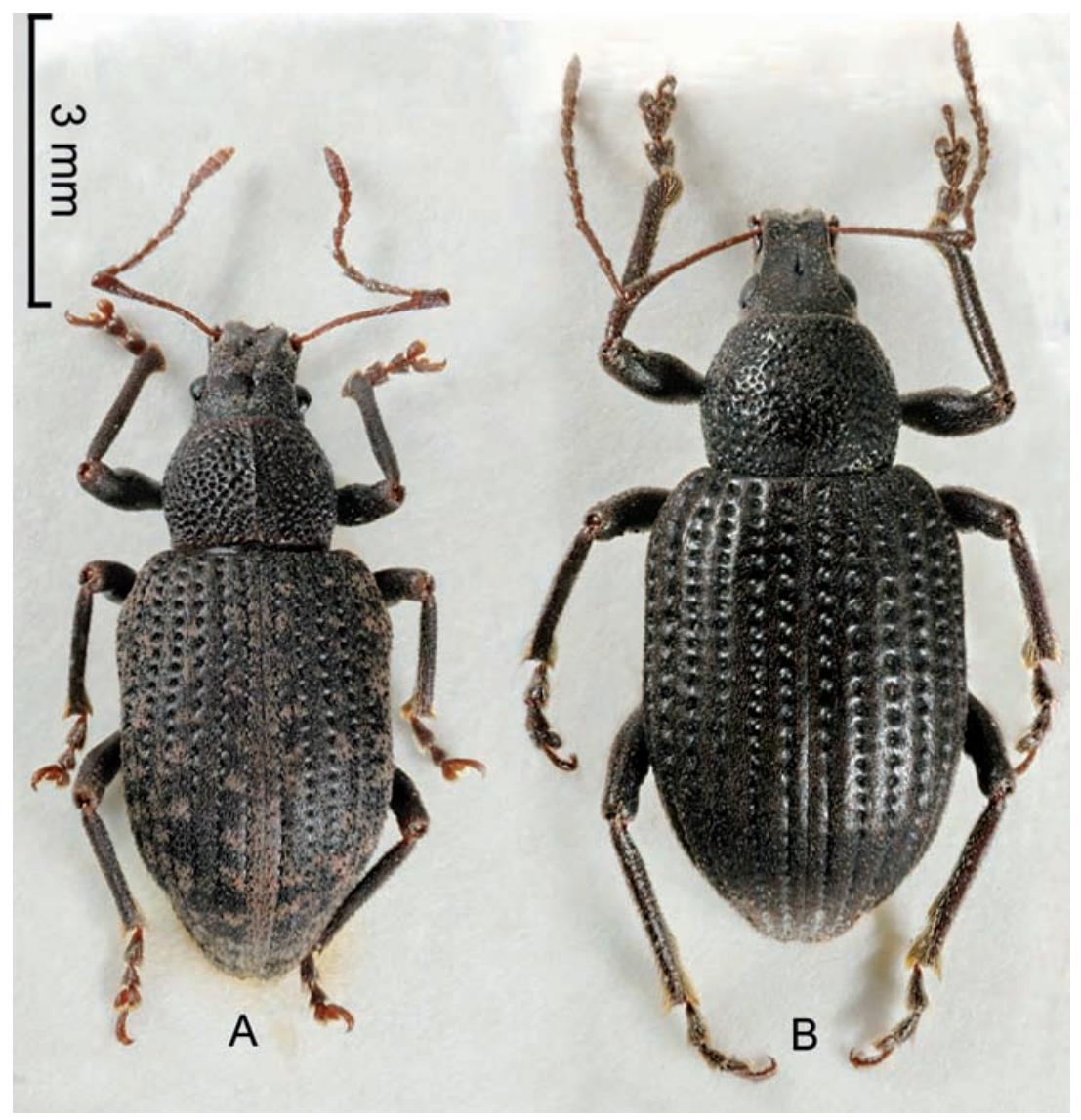

Laparocerus cristatus n. sp.

(Figs. 7A, 8, 9B, 12A y 20E)

Material examinado. La Palma. Holotipo $10^{\pi}$ infra Jedey, $540 \mathrm{~m} \mathrm{1-2-2001}$ leg. A. Machado (TFMC no 15940).Paratipos, misma localidad 12 exx 1-2-2001, 3 exx 23-12009 leg A. Machado (AMC); ídem 6 exx leg. R. García (RGB), idem 3 exx leg. M.A. ALonso-Zarazaga (MNCN). Las Manchas, 490 m, 5 exx 1-2-2001 leg A. Machado (AMC). Carretera a Puerto Naos, 250 m 3 exx 1-2-2001, 11 exx 12-10-2001 leg. A Machado (AMC). Los Llanos: Las Norias 375 m 11-6-2009 leg Jo Brunner (JB). Hoyo de Las Norias 250 m 10 exx 12-10-2001, 15 exx 17-12-2005; El Remo 3 exx 22-2-1991, 3 exx 12-1-1992 leg R. García (RGB); idem. 2 exx, 1-2002; Tamanca 473 m, 6 exx 15-82003 leg. H. López (ULL).

No paratipos: Fuencaliente: La Caldereta 250 m 11 exx 712-2005 leg R.García (RGB, Ladera de Herrera 400 m 2 exx 712-2005; Cresta del Gallo 40 m 1 ex 7-12-2005 leg A. Aguiar (AAC). Cumbre Nueva $1050 \mathrm{~m}$ [localidad muy dudosa] 4 exx 18-3-1990 leg W. Schawaller (DEI).

LOCALIDAD TíPICA. Por debajo del caserío de Jedey, municipio de Los Llanos de Aridane, La Palma, islas Canarias. UTM 28R 02177983165333.
MEDIDAS DEL HOLOTIPO $\left(0^{\pi}\right)$. Longitud: total ( $\mathrm{sin}$ rostro) $7,20 \mathrm{~mm}$, rostro $0,85 \mathrm{~mm}$, escapo $1,88 \mathrm{~mm}$, funículo 2,21 (desmómeros I-IV respectivamente 0,44 / 0,52 / 0,33/ 0,24 mm), maza 0,58 mm, pronoto $1,60 \mathrm{~mm}$, élitros $5,25 \mathrm{~mm}$, tibias (pro- /meso/meta-) 2,04/1,88/2,20 mm. Anchura: cabeza (a nivel de los ojos) $1,44 \mathrm{~mm}$, (interocular) $1,00 \mathrm{~mm}$; rostro (a nivel de los pterigios) 1,12 mm, (mínimo dorsal) $0,98 \mathrm{~mm}$ (mínimo ventral) $1,00 \mathrm{~mm}$; escapo $0,22 \mathrm{~mm}$, maza $0,16 \mathrm{~mm}$, pronoto (anterior /máxima /posterior) $1,45 / 2,10 / 1,93 \mathrm{~mm}$ y élitros (máxima) 3,27 mm. Altura: abdomen 2,60 mm.

DesCRIPCIÓn. Machos: Talla: 6,4-7,2 mm. Cuerpo grande, de aspecto ancho, moderadamente convexo y groseramente punteado. Tegumento alutáceo de color pardo o pardo-negruzco (antenas y tarsos algo más claros); revestimiento de escamitas lanceoladas pequeñas, adpresas, hialinas, o más anchas y doradas con visos cobrizos o glaucos (formando dibujo en los élitros), y cerdas negras cortas, recurvadas apenas sobresalientes (extremidades y escapo incluidos). 


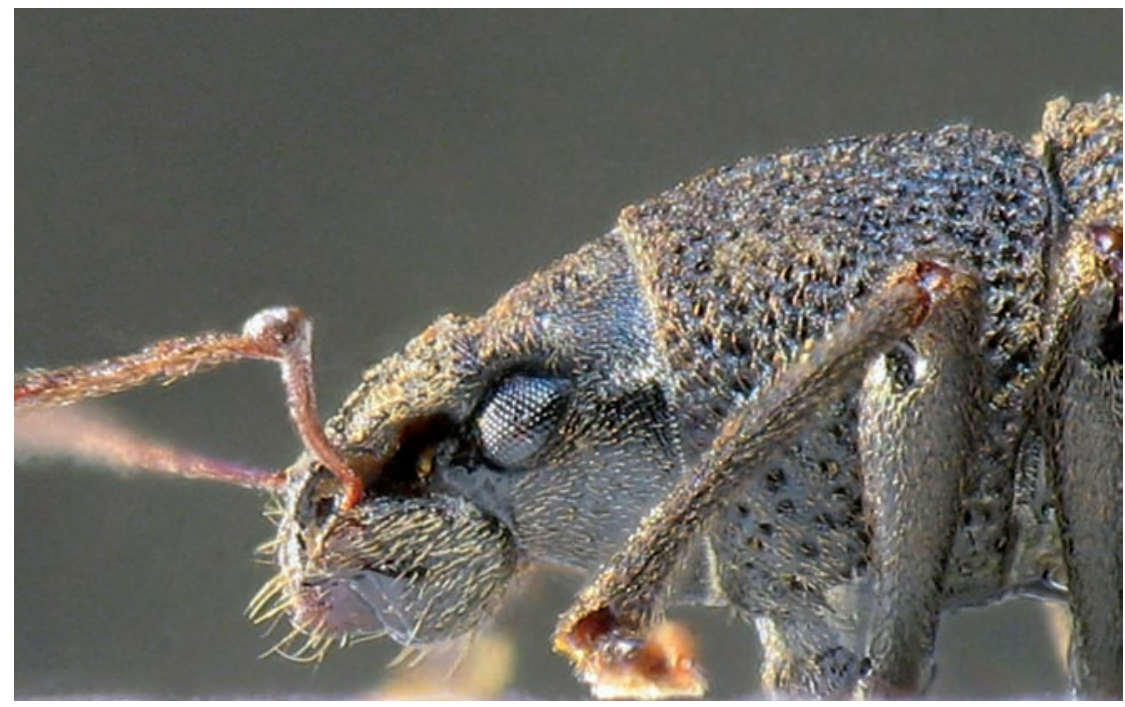

Fig. 8.- Detalle de la cabeza y escroba de Laparocerus cristatus $\mathbf{n}$. sp.

Fig. 8.- Detail of head and scroba of Laparocerus cristatus $\mathbf{n} . \mathbf{s p}$.
Antenas. Escapo sinuoso en la base y ápice, 1,2x la longitud del pronoto, robustamente capitado en su tercio apical; funículo 1,2x la longitud del escapo, desmómero II más largo que el I, y el III más largo que el IV; maza estrecha, filiforme, más corta que los tres desmómeros precedentes reunidos y apenas más ancha que cualquiera de ellos.

Cabeza muy robusta, de aspecto deforme y tegumento ruguloso; vértice poco convexo, foseta frontal amplia y profunda, prolongada hacia atrás, situada al medio de un surco transversal que separa abruptamente el prorrostro tumefacto de márgenes elevados en forma de U o V abierta hacia delante, dejando un canal profundo (usualmente surcado por una fina línea), que desemboca en una depresión lisa prorrostral; quilla epistomal en $\mathrm{V}$, bien desarrollada. Rostro, en su conjunto, de sección cuadrangular, algo más ancho que largo; dorso de lados subparalelos o convexos hasta el nivel de las antenas (formando un alero sobresaliente), luego sensiblemente convergentes hacia delante (base antenal visible desde arriba); pregenas robustas, muy infladas y delimitadas por el amplio canal escrobal que alcanza el borde inferior del epicráneo, pterigios sin solución de continuidad, poco sobresalientes. Escrobas enormes, caverniformes, internándose profundamente en el rostro, con una pequeña almohadilla de sedas en el "suelo" interior (Fig. 8). Ojos ovales $(\mathrm{L} / \mathrm{A}=1,3)$, algo asimétricos, prominentes (convexidad $40 \%$ ), emplazados a la mitad de la gena, por debajo del voladizo del margen lateral del prorrostro que enmarca la cavidad escrobífera.

Pronoto transversal $(\mathrm{L} / \mathrm{A}=0,76)$, máxima anchura al medio, algo más estrecho por delante que por detrás (sin rebordes), base ligeramente cóncava; línea media elevada, en forma de quilla estrecha, muy llamativa (disminuida en el tercio anterior). Tegumento con microrreticulación isodiamétrica marcada, abundantes puntos gruesos foveiformes, separados menos de un diámetro entre sí; escamitas doradas limitadas a pequeños parches sueltos que orlan el disco.

Escudete estrecho, emplazado en posición dorso-ventral, sobresaliendo como un gránulo sobre el perfil del élitro.

Élitros moderadamente deprimidos, en forma de trapecio alargado $(\mathrm{L} / \mathrm{A}=1,6), 3,3 \mathrm{x}$ la longitud del pronoto y 1,6x su anchura; base ligeramente cóncava; hombros marcados; declive apical poco pronunciado. Estrías marcadas por puntos foveiformes tan gruesos como los del pronoto, separados un diámetro entre sí; interestrías más anchas que las estrías, más convexos hacia los márgenes, la $7^{\mathrm{a}}$ formando carena humeral, la $8^{\mathrm{a}}$ inflada y sobresaliente en el tercio anterior (máxima anchura) y visible desde arriba; las suturales planas en el tramo apical; 3 hileras de sedas negras recurvadas a lo largo de las interestrías, 10-12 escamitas adpresas a lo ancho (alternan teselas claras y oscuras en las interestrías pares). Microrreticulación del tegumento marcada, reconocible.

Epipleuras prácticamente lampiñas; esternitos con fina pilosidad levantada y escamitas flavas adpresas en los flancos; gránulo inter-procoxal posterior desarrollado, saliente meso-coxal estrecho, poco prominente; $5^{\circ}$ esternito truncado apicalmente.

Patas normales, fémures poco engrosados; tibias rectilíneas, protibia brevemente torcida en el ápice (ángulo externo obtuso, el interno agudo), con mucrón pequeño; meso- y metatibias inermes. 
Edeago de perfil muy estrecho, poco arqueado, con temones muy largos; punta en vista dorsal roma, simple; saco interno con un largo campo mediano de dentículos y otro terminal en el divertículo ciego; el gonoporal tan largo como éste (Fig. 9B).

Hembras. Talla 7,0-7,5 mm. Muy parecidas al macho, pero con élitros más anchos (L/A elitral $=$ 1,4), máxima anchura pasada la mitad; punteado más grueso y estrías tan anchas como las interestrías, la $9^{\text {a }}$ tumefacta en el tercio apical. Protibias inermes, gránulo pro-coxal ausente, $5^{\circ}$ esternito no truncado en el ápice. Urosternito VIII, figura 12A; espermateca, figura $20 \mathrm{E}$.

Etimología. El nombre de cristatus es un adjetivo latino que hace referencia a la fina quilla que, a modo de cresta, recorre el pronoto longitudinalmente y es característica destacada de esta especie.

OBSERVACIONES. Laparocerus cristatus n. sp. pertenece al subgénero Amyntas Wollaston, 1865 y su adelfotaxon es Laparocerus tanausu n. sp. (datos moleculares inéditos). Se la distingue fácilmente de cualquier otro Laparocerus por la estrecha quilla que recorre longitudinalmente el pronoto, por el prorrostro tumefacto profundamente acanalado, así como por la escroba enorme que se interna a modo de caverna en el interior del rostro (Fig. 8). Esta estructura es semejante a la que presenta Biphyllus lunatus (Fabricius, 1792), que es micófago, aunque aún no se ha comprobado que se trate de un micangio para almacenar y transportar esporas y conidios de hongos (Crowson, 1983). Por lo pronto, L. cristatus se alimenta de hojas de plantas, mientras que escrobas cavernosas similares, aunque no tan desarrolladas, las presenta también Laparocerus tesserula Wollaston, 1864, que habita en el suelo y se encuadra en el subgénero Fernandezius Roudier, 1957. La funcionalidad de estas estructuras que, obviamente, han evolucionado por separado, queda pendiente de estudio.

DisTRIBUCIÓN Y ECOLOGÍA. Laparocerus cristatus n. sp. es endémico de La Palma, habiéndose localizado en hábitat de matorral abierto, en la ladera occidental de la parte geológicamente más nueva de la isla, a altitudes intermedias. Se ha colectado de noche alimentándose sobre Rumex lunaria (Polygonaceae), en otoño e invierno.

\section{Laparocerus tanausu n. sp.}

(Figs. 7B, 9C, 12F y 20F)

Material examinado. La Palma. Holotipo $10^{7}$ Las Caletas (Fuencaliente) 240 m 26 exx 27-6-1999 leg A. Machado
(TFMC n ${ }^{\circ}$ 15948).- Paratipos: 26 exx mismos datos (AMC), 4 exx 28-1-2001 leg. R. García (RGB).

No paratipos: Supra Santa Cruz, 2 exx leg. Wollaston ex litt. (MNH). Barranco de Las Nieves, $300 \mathrm{~m} 80$ exx (muchos inmaturos) 4-2-2001 leg A. Machado (AMC), 1 ex 3-5-1973 leg A. Evers (DEI). Montaña Loreal NE 210 m 20 exx 28-12001, Bco Herradura (Barlovento) 300 m 7 exx 1-5-2005, s. Salemera 135 m 2 exx 5-4-2008 leg. A. Machado (AMC). Hoyo Mazo 2 exx 14-4-1962 leg T. Palm (ZMUL). Mazo: Altos del Porís $300 \mathrm{~m} 1$ ex 8-12-2005 leg. A. Aguiar (AAC). Mazo 1 ex 17-12-1986; Bco. Herradura 3 exx 1-5-2005; Santa Cruz, La Grama 4 exx 20-3-1999, Playa de Nogales 4 exx 224-1991, 2 exx 9-3-1991, Bco. Las Nieves 4 exx 4-2-2001, Jedey 2 exx 3-2-2001, 3 exx 23-1-2009, Bco. La Madera 8 exx 4-2-2001, El Remo 4 exx 3-2-2001, Fajana Franceses 2 exx 107-2007, Mirca 1 ex 25-3-1990 leg. R. García (RGB).

LOCALIDAD TíPICA. Las Caletas, municipio de Fuencaliente, La Palma, islas Canarias. UTM 28R0 22396315536.

MedidAs DEL HOLOTIPO $\left(\sigma^{\pi}\right)$. Longitud: total ( $\mathrm{sin}$ rostro) $9,55 \mathrm{~mm}$, rostro $1,15 \mathrm{~mm}$, ojo $0,54 \mathrm{~mm}$, escapo 2,60 mm, funículo $3,20 \mathrm{~mm}$ (desmómeros IIV respectivamente $0,66 / 0,64 / 0,44 / 0,44 \mathrm{~mm}$ ), maza $0,78 \mathrm{~mm}$, pronoto $2,03 \mathrm{~mm}$, élitros $6,05 \mathrm{~mm}$, tibias (pro- /meso- /meta-) 2,75/2,50/2,95 mm. Anchura: cabeza (a nivel de los ojos) 1,50 mm, (interocular) 1,00 $\mathrm{mm}$; rostro (a nivel de los pterigios) $1,14 \mathrm{~mm}$, (mínimo dorsal) 0,84 mm (mínimo ventral) $1,02 \mathrm{~mm}$; ojo $0,40 \mathrm{~mm}$; escapo $0,22 \mathrm{~mm}$; maza $0,20 \mathrm{~mm}$; pronoto (anterior /máxima /posterior) $1,65 / 2,52 / 2,30 \mathrm{~mm}$ y élitros (máxima) 4,05 $\mathrm{mm}$. Altura: abdomen 3,10 mm.

DesCRIPCIÓn. Machos: Talla: 8,2-9,0 $\mathrm{mm}$. Amyntas de talla grande, robusto, de color negro subnítido (pronoto brillante), antenas pardas (salvo maza); tegumento con revestimiento de escamitas minúsculas hialinas (nunca blancas o glaucas) y cerdas recurvadas pequeñas tumbadas poco notorias (visibles con aumento).

Antenas gráciles y largas; escapo rectilíneo, $1,3 \mathrm{x}$ la longitud del pronoto, capitado en el quinto apical; funículo más largo que el escapo, desmómero I y II iguales, III mayor que el IV; maza muy delgada $(L / A=3,9)$, menos gruesa que la maza del escapo, usualmente menos larga que los tres desmómeros precedentes reunidos.

Cabeza robusta, de aspecto cónico; rostro tan largo como ancho, de lados subparalelos; poco estrechado dorsalmente; pterigios largos, moderadamente prominentes; prorrostro diferenciado, punteado, epistoma con microescultura granular, carena epistomal completa, poco levantada; metarrostro acanalado (a menudo con microrrugosidad longitudinal); frente no deprimida, fóvea romboidal 


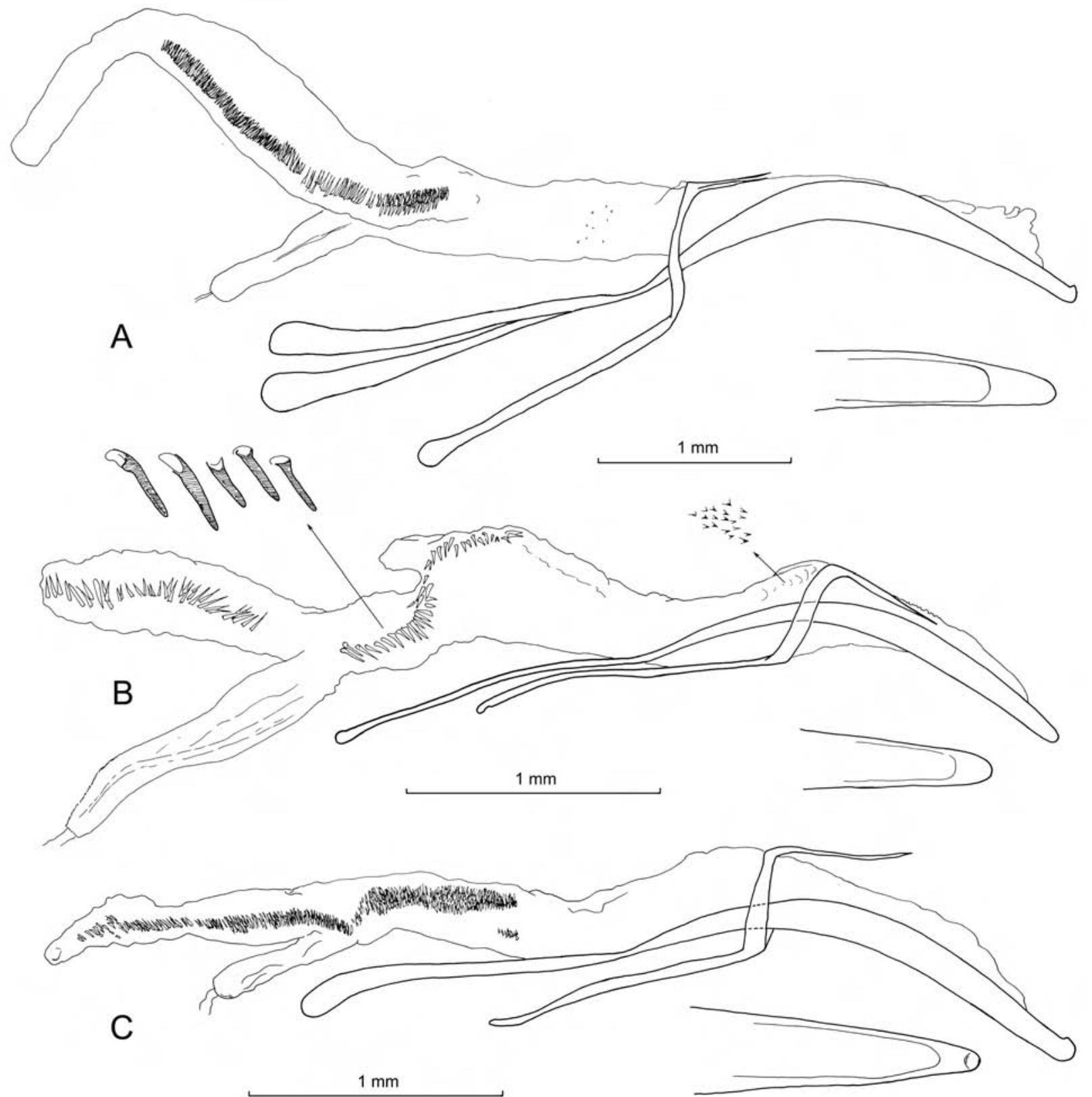

Fig. 9.- Edeago y detalle del ápice del lóbulo medio: Laparocerus arrochai n. sp. (A), Laparocerus cristatus n. sp. (B) y Laparocerus tanausu $\mathbf{n}$. sp. (C).

Fig. 9.- Aedeagi and detail of median lobe apex: Laparocerus arrochai n. sp. (A), Laparocerus cristatus n. sp. (B), and Laparocerus tanausu $\mathbf{n}$. sp. (C). 
profunda, amplia, frecuentemente prolongada como línea en el metarrostro (no hacia el vértice). Escroba profunda, dirigida oblicuamente hacia abajo. Ojos grandes, ovales $(\mathrm{L} / \mathrm{A}=1,3)$, aplastados (convexidad $<18-24 \%$ ), el cenit algo desplazado hacia atrás, separados del canto lateral de la frente por un surco periocular profundo.

Pronoto transversal $(\mathrm{L} / \mathrm{A}=0,8)$, convexo, $\sin$ reborde, lados curvados, máxima anchura al medio, borde anterior ligeramente convexo al medio. Punteado doble, puntos gruesos más o menos profundos, separados 1-2 diámetros, los finos muy patentes sobre fondo liso. Línea media a veces desarrollada (varios ejemplares con irregularidades en el disco (abultamientos o depresiones). Revestimiento inconspicuo.

Escudete minúsculo, en posición sagital, nada o poco sobresaliente.

Élitros amplios $(\mathrm{L} / \mathrm{A}=1,5)$, poco convexos, 3,0x la longitud del pronoto y $1,6 \mathrm{x}$ su anchura; base ligeramente bicóncava (levantada respecto al pronoto), hombros muy marcados, generalmente achaflanados; lados bastante paralelos (ligero ensanchamiento posthumeral), máxima anchura al medio. Estrías con enormes puntos foveiformes (doble que los del pronoto) decrecientes hacia el ápice, tan anchas como las interestrías; éstas más convexas hacia los flancos y ápice, a lo ancho con 9-10 escamitas inconspicuas bien separadas y 3-4 sedas recurvadas negras, tumbadas (menores que una uña, 2x el largo de una escamita). $8^{\mathrm{a}}$ interestría oculta por el reborde elitral (no visible desde arriba). Unión de la $3^{\mathrm{a}}$ y $9^{\mathrm{a}}$ estría tumefacta, calliforme, quebrando el perfil del declive apical. Tegumento con retículo abierto impreciso, subnítido.

Patas robustas; tibias con sedas flavas densas en tercio apical; protibias apicalmente quebradas (en chaflán) hacia adentro, con mucrón triangular; mesotibias con talón inflado y mucrón en quilla interna; metatibias con incipiente alerón laminar en el canto interno a 1/3 del ápice; sin mucrón. Tarsos robustos.

Cara ventral con pubescencia rubia abierta, más concentrada en franja media esternal; saliente intermesocoxal muy grueso e inflado, normalmente sin rebasar las coxas hacia delante (cae a plomo). Esternitos abdominales $1^{\circ}-2^{\circ}$ con microrrugosidad transversal notoria, en $3^{\circ}-5^{\circ}$ isodiamétrica reconocible, con puntos superficiales. Esternito $5^{\circ}$ truncado apicalmente.

Edeago progresivamente estrechado, punta con breve gancho hacia arriba (visto de perfil); saco interno largo, rebasando bastante los temones; divertículo gonoporal relativamente corto; campo de dentículos denso a todo lo largo (Fig. 9C).
Hembras. Talla 7,8-9,2 mm. Más robustas que los machos; élitros generalmente más amplios, cortos y deprimidos $(\mathrm{L} / \mathrm{A}=1,4)$. Apófisis intermesocoxal más desarrollada, disco menos convexo, estrías más superficialmente puntuadas, interestrías planas. Metatibias sin alerón anteapical. Último esternito abdominal curvado apicalmente. Urosternito VIII (Fig. 12F), espermateca (Fig. 20F).

ETimología. El epíteto especifico es el nombre en aposición del mencey aborigen de la isla de la Palma llamado Tanausú, y permanece por tanto invariable.

OBSERVACIONES. Wollaston (1864 p. 338) describió Laparocerus tibialis sobre ejemplares procedentes de Tenerife (Puerto de la Cruz) y de La Palma (por encima de Santa Cruz). Machado (2006) designó como lectotipo un ejemplar del Puerto de La Cruz, quedando los dos únicos ejemplares de La Palma presentes en la colección Wollaston, como paralectotipos. Sin embargo, los datos moleculares obtenidos (pendientes de publicación) han revelado que, a pesar de que los imagos se ven iguales a primera vista, se trata de dos especies que están muy separadas ente sí (distancia genética $8,9 \%$ ) y que, además, el adelfotaxon de $L$. tanausu n. sp. es L. cristatus n. sp. (distancia genética $3,4 \%$ ), igualmente endémico de la isla de $\mathrm{La}$ Palma y con una morfología muy diferenciada.

Laparocerus tanausu n. sp. L. tibialis y $L$. incomptus (Wollaston, 1865) presentan un característico alerón preapical en el canto interno de las metatibias de los machos y la $8^{a}$ interestría elitral no es visible desde arriba, detalles que les separa de las otras especies negras del subgénero Amyntas Wollaston, 1865: L. tetricus (Boheman, 1834) y L. fernandezi Roudier, 1957).

Las diferencias entre L. tanausu y L. tibialis son poco llamativas y requieren un examen comparativo minucioso, dada la variabilidad de ambas: la especie palmera es por lo común más robusta y de talla mayor (promedio $8,5 \mathrm{~mm}$ frente a 7,5 $\mathrm{mm}$ ), carece de escamitas adpresas blancas o glaucas $(L$. tibialis presenta algunas dispersas en élitros o flancos del pronoto), las antenas son en su conjunto más largas; los ojos son igualmente aplastados pero con la mayor convexidad algo desplazada hacia atrás (no al centro); el punteado del pronoto es algo más grueso y menos denso; los élitros son de lados más paralelos, más anchos y más deprimidos, presentando en ambos sexos un ligero ensanchamiento posthumeral; los puntos de las estrías son más grandes, y éstas son tan anchas como las interestrías (bastante menos en L. tibialis); la tumefacción 
apical de la $3^{\mathrm{a}}$ y $9^{\mathrm{a}}$ interestrías está más desarrollada y forma un escalón en el declive elitral. El edeago es menos estrecho, la punta presenta el ganchito apical generalmente bien desarrollado, y el saco interno es bastante más largo (rebasa mucho los temones), aunque el divertículo gonoporal es, por el contrario, más corto que en L. tibialis.

Laparocerus incomptus se distingue fácil de ambas por su tamaño menor, élitros más estrechos (particularmente en la base) y la escroba más cavernosa.

DISTRIBUCIÓN Y ECOLOGÍA. Laparocerus tanausu n. sp. es endémica de La Palma y vive en la orla semiárida de la isla, por debajo de los $350 \mathrm{~m}$, aunque todavía no se ha localizado en la fachada norte. Se aprecian ligeras diferencias morfológicas según las zonas, cuyo alcance aún no ha sido evaluado. El insecto se alimenta de plantas propias del cardonaltabaibal y bosque termófilo, tales como Aeonium ciliatum (Crassulaceae), Bosea yerbamora (Amaranthaceae), Teucrium heterophylum (Lamiaceae) y Apollonias barbujana (Lauraceae), pero sobre todo de Rumex lunaria (Polygonaceae).

\section{Laparocerus elongatus $\mathbf{n}$. sp.}

(Figs. 10A, 11A, 12H y 20G)

Material examinado. La Palma. Holotipo $10^{7}$, Túnel de la Cumbre, E (Breña Alta) 1000 m, 2-2-2001 leg. A. Machado (TFMC $\mathrm{n}^{\circ}$ 15942).- Paratipos, misma localidad y fecha 15 exx; Pared Vieja (Breña Alta), 1350 m 11 exx 27-1-2001 leg A. Machado (AMC). Ibídem 4 exx 27-1-2001; Cumbre Nueva 3 exx 27-1-2001 leg. R. García (RGB).

No paratipos: Montaña de Venijobre (Mazo) 830 m, 2 exx 5-4-2008 leg A. Machado (AMC), 22 exx 7-12-2005 leg. A. Aguiar (AAC), 8 exx 8-12-2005 leg. R. García (RGB); Llanada de Barlovento 650 m, 15 exx 29-1-2001; Monte del Pueblo (Barlovento) 950-1100 m, 52 exx 29-1-2001, 3 exx 24-7-2009; Pinar de Garafía, 1450 m, 3 exx 30-1-2001; Cueva de la Zarza (Garafía) 980 m, 5 exx 5-12-2004, 14 exx 30-1-2001; Carretera a Juan Adalid 300 m, 3 exx 5-12-2004; Montaña de las Varas 900 m, 3 exx 5-12-2004; Roque Faro1000 m, 4 exx 6-12-2004 leg. A. Machado (AMC). Carretera Juan Adalid 3 exx 5-122004, Roque Faro-Las Goteras $1000 \mathrm{~m} 7$ exx 6-12-2004 leg. A. Aguiar (AAC). Monte del Pueblo 2 exx 24-7-2009; Laguna Barlovento 11 exx 27-3-1999 leg. R. García (RGB); Barlovento 1 ex 19-3-1957 leg J.F. Guerra (TFMC). El Pinar 6 km NE Túnel Cumbre Nueva $630 \mathrm{~m} 2$ exx leg L Behne (DEI).

LOCALIDAD TíPICA. Lomo Los Mestres (junto a entrada del túnel de la cumbre), municipio de Breña Alta, La Palma, islas Canarias. UTM 28R 0224476 3172957.

Medidas DEL holotipo $\left(\sigma^{T}\right)$. Longitud: total ( $\mathrm{sin}$ rostro) $7,40 \mathrm{~mm}$, rostro $0,90 \mathrm{~mm}$, escapo $1,92 \mathrm{~mm}$, funículo 2,30 (desmómeros I-IV respectivamente $0,50 / 0,56 / 0,29 / 0,29 \mathrm{~mm})$, maza $0,68 \mathrm{~mm}$, pronoto $1,63 \mathrm{~mm}$, élitros $5,25 \mathrm{~mm}$, tibias (pro- /meso/meta-) 2,25/1,95/2,40 mm. Anchura: cabeza (a nivel de los ojos) $1,14 \mathrm{~mm}$, (interocular) $0,58 \mathrm{~mm}$; rostro (a nivel de los pterigios) 0,84 mm, (mínimo dorsal) $0,48 \mathrm{~mm}$ (mínimo ventral) $0,70 \mathrm{~mm}$; escapo $0,19 \mathrm{~mm}$, maza $0,19 \mathrm{~mm}$, pronoto (anterior /máxima /posterior) 1,25/1,97/ 1,70 mm y élitros (máxima) 2,95 mm. Altura: abdomen 2,50 mm.

DESCRIPCIÓN. Machos: Talla: 6,1-7,4 mm. Laparocerus de talla mediana, alargado, fusiforme, convexo y patilargo. Tegumento brillante de color negruzco en cabeza y pronoto, pardo negruzco en élitros, extremidades pardas con tarsos generalmente más claros; revestimiento abierta de escamitas adpresas lanceoladas pequeñas, de color testáceo o glauco, con visos cobrizos o verdes, formando dibujo teselado en los élitros (bastante variable); cerdas pequeñas poco conspicuas en el ápice elitral.

Antenas largas, gráciles; escapo 1,2x la longitud del pronoto, ligeramente sinuoso en el tercio basal, capitado en el tercio apical; funículo 1,2x la longitud del escapo, desmómeros I y II subiguales y bastante largos, III y IV iguales; maza elíptica, alargada, tan larga como los tres desmómeros precedentes reunidos.

Cabeza alargada, rostro más largo que ancho, dorsalmente estrechado (aspecto acanutado), de bordes subrectos o algo cóncavos; prorrostro no acanalado, en el mismo plano que la frente (vértice poco convexo); prorrostro bien delimitado (en $\mathrm{V}$ con márgenes levantados), punteado; quilla epistomal completa, poco levantada; pterigios cortos, algo sobresalientes. Fóvea frontal romboide, profunda, rara vez prolongada. Ojos grandes $(\mathrm{L} / \mathrm{A}=1,2)$, poco convexos $(25 \%)$, próximos al canto de la frente. Tegumento con escamitas y microrreticulación isodiamétrica bien marcada, puntos superficiales separados, más densos en el vértice (algo estriado).

Pronoto transversal $(\mathrm{L} / \mathrm{A}=0,8)$ moderadamente convexo, de lados bastante curvados, máxima anchura a la mitad; base finamente rebordeada, más ancha que el borde anterior. Superficie brillante, con puntos gruesos separados, bastante irregulares y más o menos impresos, los pequeños apenas destacados; línea media más o menos amplia en el disco (a veces, también con áreas lisas laterales); escamitas escasas, más concentradas hacia los márgenes.

Escudete amplio, triangular, liso.

Élitros elíptico-alargados, estrechos $(\mathrm{L} / \mathrm{A}=1,8)$, $3,2 \mathrm{x}$ la longitud del pronoto y $1,5 \mathrm{x}$ su anchura; base 


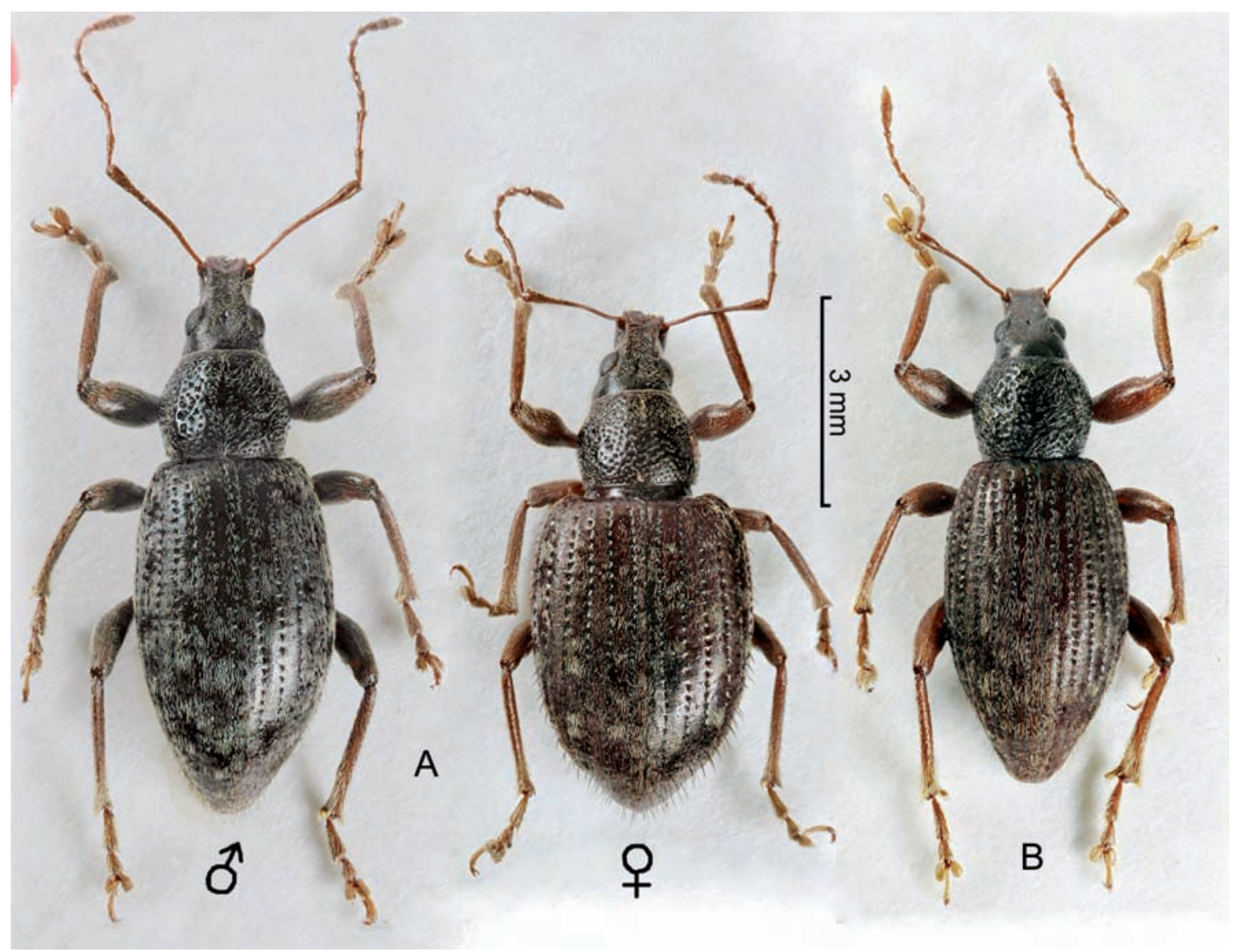

Fig. 10.- Holotipo $\bigcirc^{\nearrow}$ y paratipo $ᄋ$ de Laparocerus elongatus n. sp. (A) y holotipo de Laparocerus mucronatus n. sp. (B).

Fig. 10.- Holotype $\sigma^{\nearrow}$ and paratype $\odot$ of Laparocerus elongatus n. sp. (A), and holotype of Laparocerus mucronatus n. sp. (B).

recta, en declive; lados poco curvados; hombros cortos con breve pero notorio callo humeral. Estrías marcadas por puntos gruesos en la mitad basal, desvanecidos progresivamente hacia el ápice; interestrías apenas convexas, a lo ancho con 10-12 escamitas adpresas, separadas (se solapan a lo largo), dejando áreas libres (muy variable); unas pocas cerdas claras sobresalientes e inclinadas, pequeñas en la base, algo más largas y destacadas en el ápice (no más largas que una uña). Tegumento con microescultura irregular, algo alutácea.

Patas bastante largas; tibias finas, todas con mucrón pequeño, agudo; protibias rectilíneas, brevemente dobladas y expandidas hacia dentro en el ápice (ángulo externo romo). Tarsos grandes, tan anchos como las tibias.

Cara ventral brillante; saliente intermesocoxal careniforme, estrecho, poco elevado; esternitos abdominales finamente bordeados, con pilosidad fina, tumbada, muy abierta, más larga en los márgenes y ápice. Tegumento en esternitos 1-2 con microestrías transversales (casi lampiños), 3-5 con microrreticulación isodiamétrica precisa y punteado superficial; el último convexamente truncado.

Edeago poco arqueado, temones y lóbulo medio de longitud equivalente; punta afilada de planta triangular, sin placa apical diferenciada; saco interno corto, poco más largo hacia atrás que los temones, con dos campos medianos de dentículos y dos distales menos desarrollados en el divertículo ciego (Fig. 11A).

Hembras. Talla 6,1-7,2 mm. Más rechoncha que el macho (Fig. 10A), menos brillante, puntos del pronoto generalmente menores y más densos (microrreticulación más destacada); élitros más 

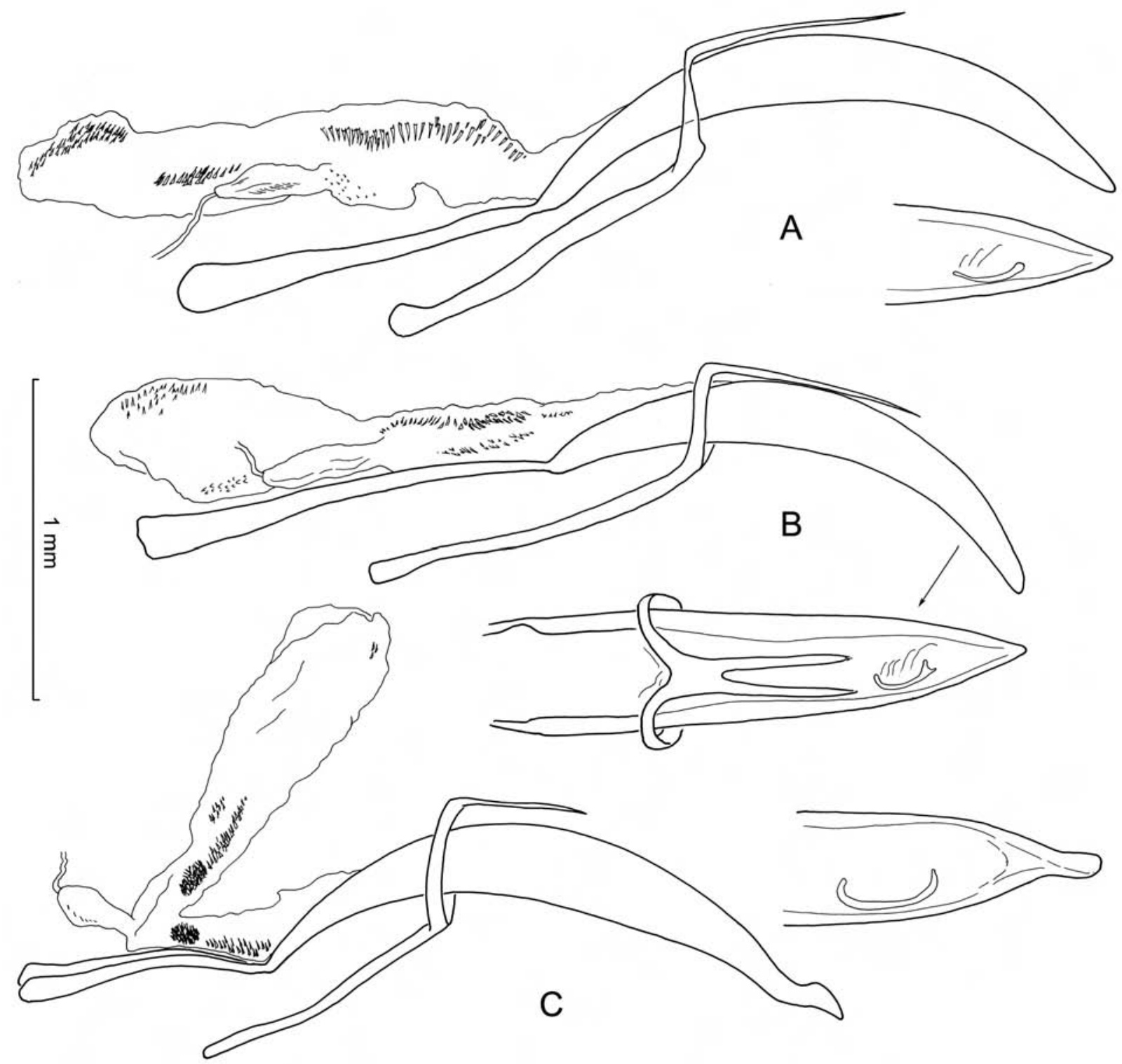

Fig. 11. - Edeago y detalle del ápice del lóbulo medio: Laparocerus elongatus n. sp. (A), Laparocerus mucronatus $\mathbf{n} . \mathbf{s p}$. (B) y Laparocerus feloi $\mathbf{n}$. sp. (C).

Fig. 11.- Aedeagi and detail of median lobe apex: Laparocerus elongatus n. sp. (A), Laparocerus mucronatus n. sp. (B), and Laparocerus feloi $\mathbf{n}$. sp. (C).

inflados, base más ancha, callo humeral más desarrollado (hombros a veces avanzados y la base cóncava); declive apical brusco, a plomo y retraído en el ápice (aspecto navicular); ligera depresión en la región postescutelar; estrías menos marcadas (puntos menores), interestrías planas; sedas negras suberectas, más largas y conspicuas (mayores que una uña) en todo el élitro. Último esternito abdominal no truncado apicalmente. Urosternito VIII figura $12 \mathrm{H}$, espermateca figura $10 \mathrm{G}$.

ETimología. El epíteto latino "elongatus" es un adjetivo que hace referencia a la forma alargada del 
cuerpo en relación con la de sus vicariantes en las otras islas.

OBSERVACIONES. Laparocerus elongatus n. sp. varía bastante de localidad a localidad en lo que concierne al desarrollo de las escamitas y hombros de las hembras (más o menos avanzados). Destacan tres únicos ejemplares obtenidos en la vertiente occidental de la isla (mucho más seca que la nororiental) con el rostro algo más corto, ojos aún menos convexos, pronoto con punteado menor, algo más denso y tegumento fuertemente reticulado (más mate), además de los hombros menos marcados y el aspecto general de los élitros más redondeado. También llama la atención la alta proporción de machos frente a las hembras capturadas en la mitad meridional de la isla, mientras que en mitad septentrional ocurre exactamente al revés.

Laparocerus elongatus $\mathrm{n}$. sp. se distingue de las otras especies del género presentes en La Palma por el cuerpo alargado y brillante de los machos, élitros elípticos y estrechos sin pilosidad destacada y con callo humeral, que, aunque pequeño, es muy característico. De sus parientes más próximos L. obtriangularis Wollaston, 1864 de Tenerife y L. junonius Machado, 2007, de La Gomera, se separa por su forma notoriamente más alargada y tamaño generalmente mayor. En la especie tinerfeña el pronoto es menos transversal y de lados menos curvos, los élitros, más cortos y bruscamente acuminados, con la base más ancha, y el punteado (pronoto y élitros) es menos grueso. La diferencia es más llamativa en las hembras, cuyos élitros de base extremadamente ancha son casi triangulares, acuminados en $2 / 3$ de su longitud (en L. elongatus solo el tercio apical es ojival). Algo parecidas son las hembras de L. junonius, mientras que los machos, de base elitral también más ancha que en la especie palmera, presentan las protibias sin curvatura apical, y las metatibias sin mucrón.

DisTRIBUCIÓN Y ECOLOGÍA. Laparocerus elongatus $\mathrm{n}$. sp. es endémico de La Palma, donde está ampliamente repartido por la fachada norte y oriental de la isla, mientras que en la vertiente occidental solo se ha encontrado en una localidad, y los pocos ejemplares presentan ciertas diferencias morfológicas aún pendientes de estudio. El área de distribución oriental parece interrumpirse al medio en los municipios de Santa Cruz de La Palma y Puntallana, donde habita L. mucronatus n. sp., sin que, de momento, se haya constatado solapamiento.

Es un insecto nocturno que se alimenta de plantas bajas y arbustos, tanto en matorral abierto como en claros o bordes de camino en la laurisilva, siem- pre en condiciones de alta humedad. Parece tratarse de un animal nocturno relativamente polífago, habiéndose colectado sobre Senecio papyraceus y Argyranthemum webbii (Asteraceae), Erica arborea (Ericaceae), Bystropogon canariensis, Sideritis sp. y Cedronella canariensis (Lamiaceae), y Phyllis nobla (Rubiaceae).

\section{Laparocerus mucronatus $\mathbf{n}$. sp.}

(Figs. 10B, 6A, 11A, 12C y 20H)

Material examinado. La Palma. Holotipo $10^{\pi}$ Cubo de La Galga 600 m, 28-1-2001 leg A. Machado (TFMC n 15945).Paratipos, misma localidad 2 exx 18-6-1999, 4 exx 28-1-2001, 2 exx 23-11-2002 leg. A. Machado (AMC) 11 exx 28-1-20001 leg. R. García (RGB). Montaña del Loreal NE 210 m, 1 ex 281-2001.

No paratipos: Barranco de la Madera (Santa Cruz) $700 \mathrm{~m}$, 16 exx 4-2-2001 leg. A. Machado (AMC). Montaña Tagoja 1020 m, 1 ex 4-1-1989, 1 ex 25-3-1990; Las Lomadas (Los Sauces) 6 exx 3-10-2009; Entrada Marcos y Corderos 1300 m, 1 ex 28-10-2000 leg. R. García (RGB); ídem. 1 ex 24-1-2009; Marcos y Corderos 1300 m 13 exx 3-10-2009, leg. A. Machado (AMC), ídem 9 exx; leg R. García (RGB).

Localidad TíPICA. Cubo de la Galga, municipio de Puntallana, La Palma, islas Canarias. UTM 28R 0228731857.

Medidas DEL HOLOTIPO $\left(\sigma^{7}\right)$. Longitud: total ( $\sin$ rostro) $6,72 \mathrm{~mm}$, rostro $0,80 \mathrm{~mm}$, escapo $1,82 \mathrm{~mm}$, funículo $2,24 \mathrm{~mm}$ (desmómeros I-IV respectivamente $0,48 / 0,54 / 0,27 / 0,27 \mathrm{~mm}$ ), maza $0,66 \mathrm{~mm}$, pronoto $1,44 \mathrm{~mm}$, élitros $4,70 \mathrm{~mm}$, tibias (pro- /meso/meta-) 2,05/1,73/2,15 mm. Anchura: cabeza (a nivel de los ojos) $1,06 \mathrm{~mm}$, (interocular) $0,56 \mathrm{~mm}$; rostro (a nivel de los pterigios) $0,74 \mathrm{~mm}$, (mínimo dorsal) $0,44 \mathrm{~mm}$ (mínimo ventral) $0,60 \mathrm{~mm}$; escapo $0,17 \mathrm{~mm}$, maza $0,18 \mathrm{~mm}$, pronoto (anterior /máxima /posterior) 1,14 / 1,76/ 1,55 mm y élitros (máxima) 2,75 mm. Altura: abdomen 2,25 mm.

DESCRIPCIÓN. Talla $0^{7} 0^{\pi}$ 6,8-7,6 mm, ㅇ 7,5$8,5 \mathrm{~mm}$. Igual en aspecto y detalles que Laparocerus elongatus, salvo por las escamitas, en general, algo más largas; élitros $\sigma^{\pi} \sigma^{\top}$ un poco más curvados lateralmente (máxima anchura a veces pasada la mitad); estrías más groseramente punteadas, interestrías más convexas.

Machos con protibias más robustas, ampliamente curvadas en el tercio apical (aspecto falciforme); mesotibias ensanchadas en el ápice, éste truncado oblicuamente (estrecho y romo en L. elongatus) y mucrón grande; metatibias cuneiformes, progresivamente ensanchadas hacia el ápice, éste doble de 

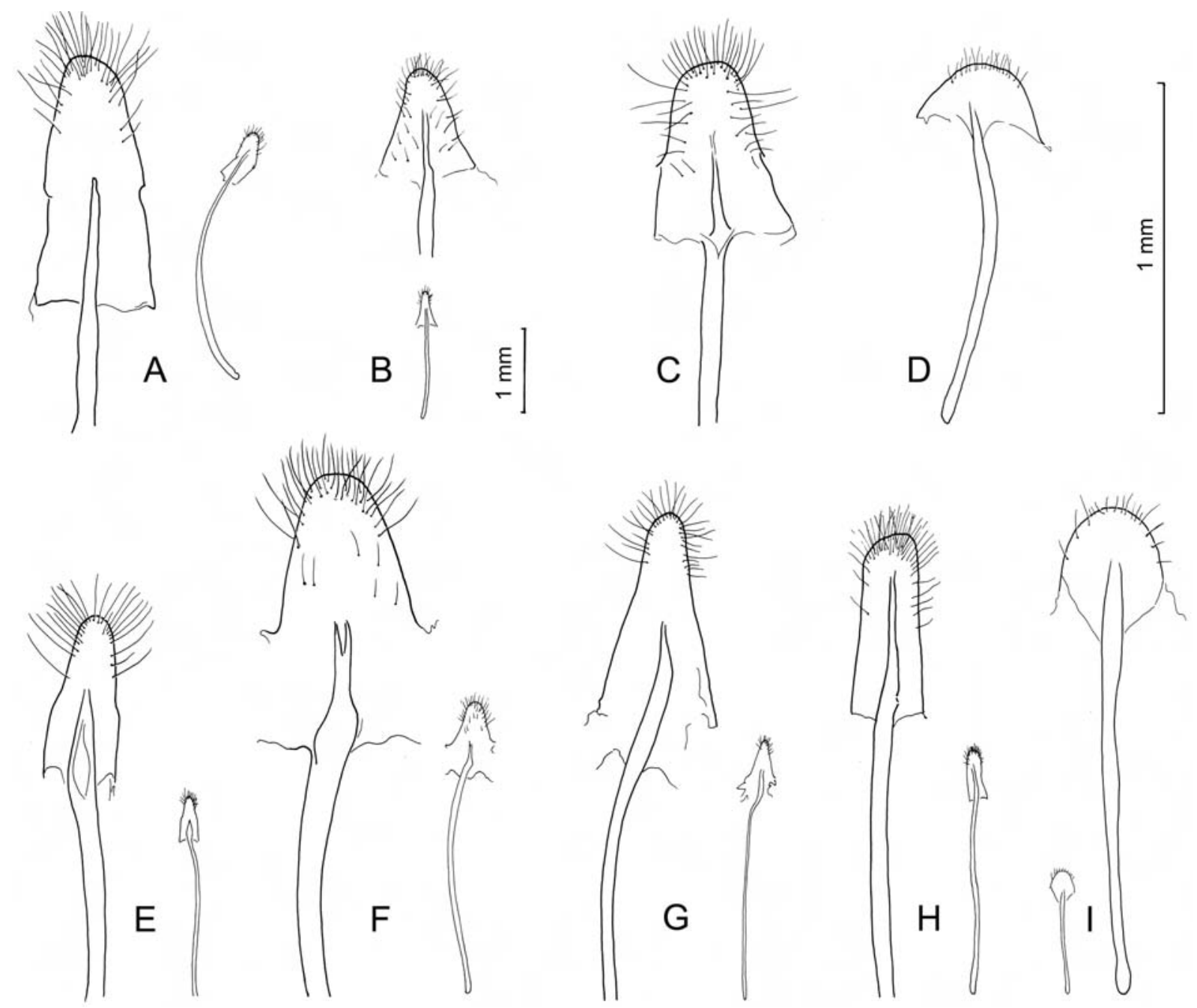

Fig. 12.- Urosternito VIII femenino y detalle de placa apical: Laparocerus cristatus $\mathbf{n} . \mathbf{s p .}$ (A), Laparocerus morrisi n. sp. (B), Laparocerus mucronatus $\mathbf{n}$. sp. (C), Laparocerus supranubius $\mathbf{n} . \mathbf{s p}$. (D), Laparocerus astralis $\mathbf{n}$. sp. (E), Laparocerus tanausu n. sp. (F), Laparocerus feloi $\mathbf{n}$. sp. (G), Laparocerus elongatus n. sp. (H), y Laparocerus decipiens n. sp. (I).

Fig. 12.- Female urosternites VIII and detail of apical plates: Laparocerus cristatus n. sp. (A), Laparocerus morrisi n. sp. (B), Laparocerus mucronatus n. sp. (C), Laparocerus supranubius $\mathbf{n} . \mathbf{s p}$. (D), Laparocerus astralis $\mathbf{n}$. sp. (E), Laparocerus tanausu n. sp. (F), Laparocerus feloi n. sp. (G), Laparocerus elongatus n. sp. (H), and Laparocerus decipiens n. sp. (I).

ancho que la tibia en su base y truncado oblicuamente (superficie articular expuesta en la cara interior), con el ángulo interno y mucrón muy prominentes, a veces desarrollando una prolongación digitiforme (Fig. 6A), recta o curvada hacia dentro; la pilosidad distal (testácea) de las tibias más llamativa.

Hembras con élitros de ángulo humeral más obtuso (callo humeral menos desarrollado); sedas suberectas bastante más pequeñas (mucho menos conspicuas) y bien desarrolladas solo en el tercio apical.

Edeago (Fig. 11A) de igual conformación, pero proporcionalmente algo más corto (longitud edeago/ élitro $=0,50-0,60$, frente a 0,66-0,68 en L. elongatus); temones casi tan largos como el cuerpo medio, y saco interno (en reposo) apenas más largo que éstos (bastante más en L. elongatus).

Urosternito VIII femenino y espermateca, figuras $12 \mathrm{C}$ y $20 \mathrm{H}$, respectivamente. 
ETimología. El epíteto latino "mucronatus" es un adjetivo que hace referencia al llamativo mucrón metatibial que presentan los machos.

OBSERVACIONES. Las hembras de esta especie se separan de las de L. elongatus n. sp. por lo reducidas que son las sedas suberectas elitrales, limitadas además al tercio apical. Los machos son más parecidos entre sí, salvo por las tibias, que son más robustas y están bien armadas en L. mucronatus (de ahí, su nombre): las anteriores son falciformes y las posteriores se ensanchan progresivamente para terminar en un talón expandido y truncado oblicuamente, con el área articular extendida y expuesta en la cara interna. En la serie típica, el mucrón se prolonga digitiforme a modo de un largo espolón arqueado hacia dentro, sin embargo, en los ejemplares procedentes del barranco de La Madera y de Marcos y Corderos dicho apéndice no se ha desarrollado del todo, aunque el talón está igualmente ensanchado y el ángulo interno es agudo.

Las protibias en L. elongatus son siempre delgadas, están brevemente curvadas en el ápice y las mesotibias y metatibias terminan de forma roma (nunca truncadas oblicuamente) y son apenas más anchas en el ápice que en su tramo medio; además, los mucrones son pequeños, y el metatibial es minúsculo, casi granular.

La singular conformación de las metatibias de $L$. mucronatus recuerda un poco a las expansiones laminares metatibiales que presentan varias especies de Laparocerus de la isla de Madeira, pero sin llegar a desarrollarse tanto. No se dispone aún de datos moleculares del nuevo taxón, pero tanto por la morfología externa como por la conformación del edeago resulta obvio que está directamente emparentado con L. elongatus n. sp.

DISTRIBUCIÓN Y ECOLOGÍA. Laparocerus mucronatus n. sp. se conoce solo de un área limitada de la fachada oriental de la isla de La Palma, en zonas húmedas entre los $200 \mathrm{~m}$ y $1300 \mathrm{~m}$ de altitud, en ambiente tanto de matorral como boscoso. Se ha colectado sobre Aichryson sp. (Crassulaceae), Phyllis nobla (Rubiaceae), Gesnouinia arborea (Urticaceae), Rumex madeirensis (Polygonaceae), Teline sp. (Fabaceae), Erica arborea (Ericacea), Gonospermum canariense y Senecio papyraceus (Asteraceae).

\section{Laparocerus feloi $\mathrm{n}$. sp.}

(Figs. 13A, 11C, 12G y 20I)

Material examinado. La Palma. Holotipo $10^{7}$, Bco. de los Herreros (infra Puntagorda) $450 \mathrm{~m}, 20-11-2002$ leg. A.
Machado (TFMC $n^{\circ}$ 15943).- Paratipos, misma localidad, 120 exx; (la mayoría inmaturos) 20-11-2002, 1 ex 12-10-2001 leg A. Machado (AMC), 30 exx 20-11-2002, Cueva La Mamona 1 ex 16-2-2001, Las Tricias 15 exx 20-1-2003, San Mauro 20 exx 20-1-2003 leg. R. García (RGB). Puntagorda, 500 m. 1 ex. 10-2-1994, leg. K.H. Kielhorn. (HW).

LOCALIDAD TÍPICA. Barranco del Herrero, municipio de Punta Gorda, La Palma, islas Canarias. UTM 28R 020803318606.

Medidas DEL hOLOTIPO ( $\left.\sigma^{\pi}\right)$. Longitud: total ( $\mathrm{sin}$ rostro) $6,20 \mathrm{~mm}$, rostro $0,62 \mathrm{~mm}$, escapo $1,62 \mathrm{~mm}$, funículo 2,06 (desmómeros I-IV respectivamente 0,42 / 0,46 / 0,46/ 0,32 mm), maza $0,60 \mathrm{~mm}$, ojo $0,44 \mathrm{~mm}$, pronoto $1,30 \mathrm{~mm}$, élitros $4,50 \mathrm{~mm}$, tibias (pro- /meso- /meta-) 1,80/1,68/1,96 mm. Anchura: cabeza (a nivel de los ojos) $1,10 \mathrm{~mm}$, (interocular) $0,58 \mathrm{~mm}$; rostro (a nivel de los pterigios) $0,66 \mathrm{~mm}$, (mínimo dorsal) 0,44 mm (mínimo ventral) 0,61 $\mathrm{mm}$; escapo $0,15 \mathrm{~mm}$, maza $0,16 \mathrm{~mm}$, ojo $0,32 \mathrm{~mm}$, pronoto (anterior /máxima /posterior) 1,25/ 1,76/ $1,62 \mathrm{~mm}$ y élitros (máxima) $2,83 \mathrm{~mm}$. Altura: abdomen 2,40 $\mathrm{mm}$.

DESCRIPCIÓN. Machos: Talla: 5,4-6,5 mm. Laparocerus de talla mediana, cuerpo oval-alargado, bastante convexo a lo ancho. Tegumento alutáceo de color pardo negruzco en cabeza y pronoto, pardo oscuro en élitros, pardo algo rojizo en extremidades (tarsos generalmente más claros); revestimiento de aspecto pulverulento a base de escamitas lanceoladas recostadas, testáceas, con visos cobrizos, dorados o glaucos, formando dibujo en los élitros; éstos con cerdas poco prominentes en el tercio apical.

Antenas gráciles; escapo fino, 1,25x la longitud del pronoto, apenas sinuoso, capitado en el tercio apical; funículo $1,28 \mathrm{x}$ la longitud del escapo, desmómero II algo más largo que el I, y III que el IV; maza grande, elíptica y ancha (más que la maza del escapo, $\mathrm{L} / \mathrm{A}=3,5)$, igual de larga que los tres desmómeros precedentes reunidos.

Cabeza recia, de cuello ancho; rostro corto de aspecto trapezoidal; metarrostro de lados convergentes hacia delante, no elevados lateralmente, una pequeña naveta anterior; prorrostro bien demarcado, quilla epistomal mal definida; pterigios muy breves, apenas sobresaliente. Frente generalmente deprimida; foseta puntiforme, no prolongada; sienes elevadas dorso-lateralmente. Ojos ovales, no muy grandes $(\mathrm{L} / \mathrm{A}=1,4)$, poco prominentes (convexidad $=25 \%$ ), alcanzando el canto de la frente. Tegumento con microrreticulación bien marcada (salvo occipucio), puntos superficiales separados 
(rostro incluido), escamitas más o menos abundantes (densas orlando el ojo).

Pronoto bastante transversal $(\mathrm{L} / \mathrm{A}=0,75)$, sin reborde, base más ancha que el borde anterior, máxima anchura generalmente por detrás de la mitad, lados constreñidos anteriormente (formando un collarín incipiente) y, más brevemente, en la base. Tegumento con punteado mediocre poco denso (separados 1-1x diámetros entre sí); micropuntos enmascarados por la microrreticulación bien impresa; escamitas abundantes (dejan ver el tegumento). Línea media estrecha y larga.

Escudete amplio, triangular, tapizado de escamas.

Élitros oval-alargados $(\mathrm{L} / \mathrm{A}=1,6)$, con declive apical suave; lados poco curvados, a veces la máxima anchura por detrás de la mitad; 1,6x la anchura del pronoto, base recta, hombros romos, cortos pero marcados (resaltados por la $7^{\mathrm{a}}$ interestría careniforme). Puntos de las estrías mediocres, casi coalescentes. Interestrías apenas o nada convexas, con varias hileras de cerdas negras recias y cortas (menores que una uña), algo arqueadas, reclinadas en la mitad anterior, sobresalientes y más conspicuas en la mitad posterior. Revestimiento de escamitas lanceoladas muy extendida, separadas lateralmente entre si (10-12 a lo ancho del intervalo), interestrías pares con parches oscuros ocupados por escamitas más finas y escasas. Microescultura del tegumento algo alutácea.

Patas robustas, protibia algo torcida en el ápice hacia dentro, armada con mucrón fuerte, ángulo apical externo romo; mesotibias con mucrón pequeño, metatibias inermes, con pilosidad alargada en el tercio distal (incipiente cepillo tibial); canto interno con 5-8 dientes de sierra agudos. Tarsos grandes, tarsómero I alargado, de base ancha; II triangular.

Cara ventral con revestimiento regular de escamitas claras, mezcladas con otras piliformes levantadas; la densidad aumenta hacia los márgenes, en coxas y trocánteres. Saliente intermesocoxal, careniforme, apenas levantado, erizado de escamitas piliformes; lo mismo el gránulo interproxocal. Esternito $\mathrm{V}$ truncado apicalmente, con breve escotadura al medio.

Edeago poco arqueado, punta en forma de pie invertido, placa espatuliforme apical escorada hacia un lado; temones muy cortos, saco interno moderadamente largo, con dos amasijos de dentículos, uno basal y otro mediano, acompañados de campos más laxos de dentículos; divertículo ciego ligeramente bífido, sin campos de dentículos (Fig. 11C).

Hembras. Talla 6,5-7,6 mm. Mayor que el macho, pronoto algo más transversal; élitros muy inflados y ovoides $(\mathrm{L} / \mathrm{A}=1,45)$, de base más cuadrangular, declive apical bastante pronunciado, punta elitral ligeramente reflejada; interestrías siempre planas (la $3^{\mathrm{a}}$ y $9^{\mathrm{a}}$ no tumefactas en el ápice).su microescultura algo más abigarrada, revestimiento de escamitas más regular; tibias rectilíneas, inermes; último esternito abdominal ojival. Urosternito VIII y espermateca, figuras $12 \mathrm{G}$ y $20 \mathrm{I}$, respectivamente.

ETimología. Tengo el placer de nombrar esta especie en homenaje al biólogo palmero y compañero de colectas, Rafael García Becerra, conocido por "Felo" entre sus amigos.

OBSERVACIONES. Laparocerus feloi $\mathrm{n}$. sp. pertenece al grupo de L. mendicus Wollaston, 1864, que cuenta con varias especies repartidas por las Canarias occidentales y centrales. Las diferencias morfológicas entre vicariantes insulares próximas no son muy destacadas, a pesar de que los datos moleculares (sin publicar) sugieren una separación considerable.

De L. mendicus se distingue por el tegumento menos brillante, los ojos más grandes $(0,75 \mathrm{x}$ la distancia interocular, en vez de $0,50 \mathrm{x})$ pero menos prominentes (convexidad 25\% frente a $30 \%$ ), el pronoto más transversal, con los puntos gruesos más pequeños y densos, (los micropuntos se aprecian bien en mendicus); los élitros son de lados más curvados y las sedas negras sobresalientes más cortas; las metatibias están menos o nada arqueadas en el la mitad posterior y los dientecillos de sierra del canto interior están más desarrollados. Laparocerus longiclava Lindberg, 1953 es mayor y más robusto, y se reconoce fácilmente por la forma alargadas y estrecha de la maza $(\mathrm{L} / \mathrm{A}=4,6$ frente a 3,5$)$, además de ser algo más corta que los tres desmómeros funiculares precedentes reunidos. Las hembras de estas dos especies presentan una tumefacción (interestrías $3^{\mathrm{a}}$ y $9^{\mathrm{a}}$ ), preapical en cada élitro, a menudo bastante desarrolladas y llamativas, inexistentes en $L$. feloi.

La nueva especie se distingue fácil de todos los demás Laparocerus de La Palma por la presencia de dientes de sierra en el canto interior de las metatibias masculinas y las cerdas negras de los élitros destacadas solo en el tercio apical.

Distribución Y ECOlOGía. Especie endémica de La Palma. Se ha localizado en las medianías del extremo noroccidental de la isla, sobre Cistus monspeliensis. y es muy probable que se extienda por todos los jarales de esta vertiente. 
Fig. 13.- Holotipos $\sigma^{7} \sigma^{7}$ : Laparocerus. feloi $\mathbf{n}$. sp. (A) y Laparocerus tarsalis $\mathbf{n}$. $\mathbf{s p}$. (B).

Fig. 13.- Holotypes $\sigma^{x} \sigma^{x}$ : Laparocerus. feloi n. sp. (A), and Laparocerus tarsalis $\mathbf{n}$. $\mathbf{s p}$. (B).

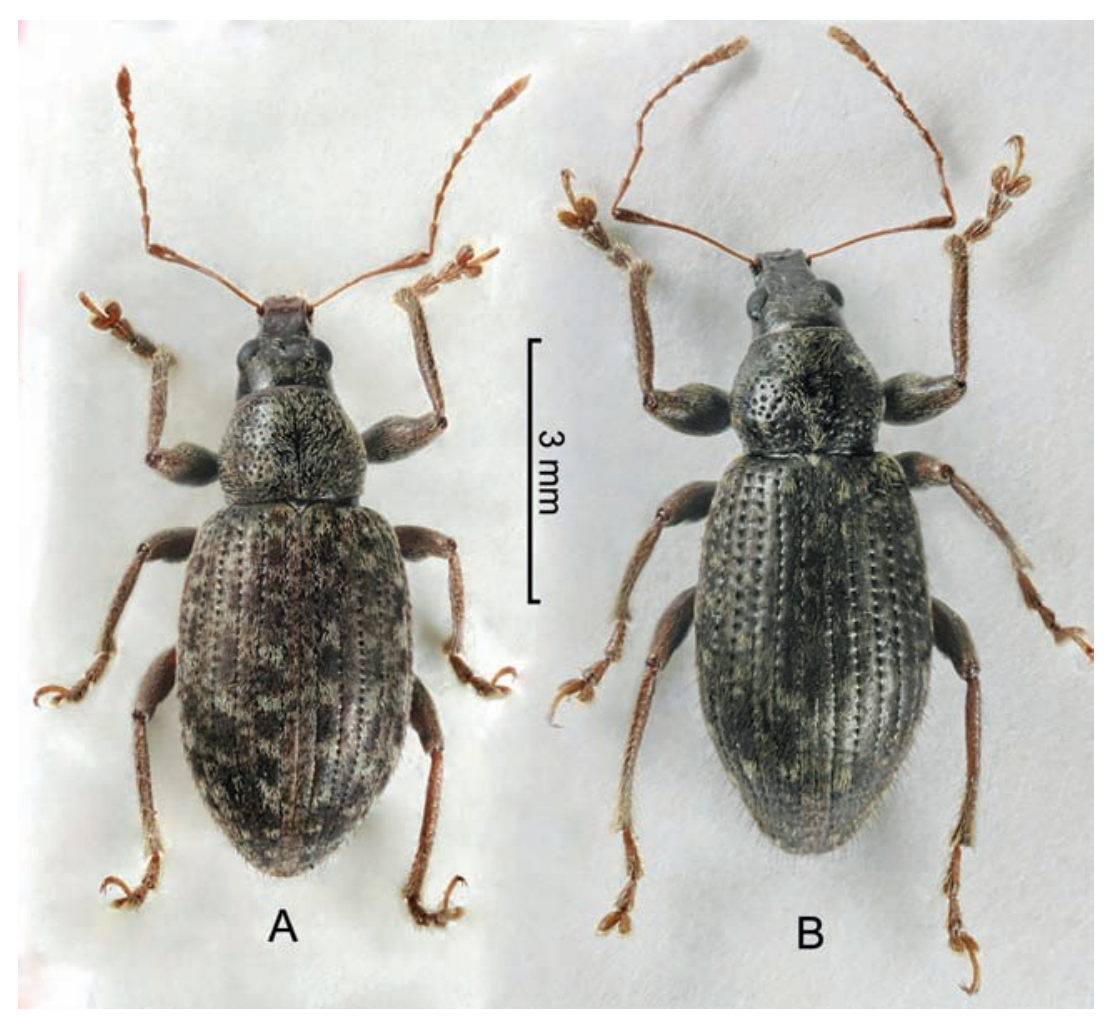

\section{Laparocerus tarsalis n. sp.} (Figs. 13B y 15A)

Material examinado. La Palma. Holotipo 10", Entrada Marcos y Corderos, 1330 m, 24-1-2009 leg. A. Machado (TFMC n ${ }^{\circ}$ 15949).- Paratipos, misma localidad 28 exx 12-122009 leg. A. Machado (AMC), 6 exx leg. R. García (RGB).

LOCALIDAD TÍPICA. Entrada a Marcos y Corderos, municipio de Los Sauces, La Palma, islas Canarias. UTM 28R 02254683186067.

Medidas Del hOlOtiPo $\left(\sigma^{7}\right)$. Longitud: total ( $\sin$ rostro) $6,65 \mathrm{~mm}$, rostro $0,70 \mathrm{~mm}$, escapo $1,70 \mathrm{~mm}$, funículo 2,12 (desmómeros I-IV respectivamente 0,42 / 0,44 / 0,31/ 0,36 mm), maza $0,68 \mathrm{~mm}$, ojo $0,50 \mathrm{~mm}$, pronoto $1,45 \mathrm{~mm}$, élitros $4,85 \mathrm{~mm}$, tibias (pro-/meso- /meta-) 2,02/1,75/2,17 mm. Anchura: cabeza (a nivel de los ojos) 0,93 mm, (interocular) $0,62 \mathrm{~mm}$; rostro (a nivel de los pterigios) $0,74 \mathrm{~mm}$, (mínimo dorsal) $0,50 \mathrm{~mm}$ (mínimo ventral) 0,66 $\mathrm{mm}$; escapo $0,12 \mathrm{~mm}$, maza $0,16 \mathrm{~mm}$, ojo $0,34 \mathrm{~mm}$, pronoto (anterior /máxima /posterior) 1,20/1,85/ $1,60 \mathrm{~mm}$ y élitros (máxima) $2,80 \mathrm{~mm}$. Altura: abdomen 2,40 mm.

Descripción. Macho: Talla: 6,0-7,3 $\mathrm{mm}$. Laparocerus de talla mediana, cuerpo alargado y extremidades largas y delicadas. Tegumento pardo oscuro, subnítido, con ligero viso cobrizo, más claro en tibias y tarsos. Revestimiento poco denso de escamitas lineales largas doradas y opacas, formando dibujo en los élitros, éstos con sedas negras prominentes en toda su superficie.

Antenas gráciles; escapo fino, algo sinuoso, capitado en el tercio apical (3x el grosor en la base); funículo 1,28x la longitud del escapo, desmómeros I y II subiguales, III algo mayor que IV; maza fusiforme $(\mathrm{L} / \mathrm{A}=3,9)$, igual de larga que los tres desmómeros precedentes reunidos.

Cabeza pequeña, rostro poco más largo que ancho; prorrostro bien delimitado, quilla epistomal poco definida, casi obsoleta; metarrostro de lados subparalelos, no levantados (naveta en el tercio anterior), punteado; pterigios pequeños, apenas sobresaliente; frente sin deprimir, foseta corta, puntiforme; vértice con menos puntos, liso. Ojos grandes, tangentes al canto de la frente, poco prominentes $($ convexidad $=25 \%)$, el disco menos convexo. Tegumento con microrreticulación bien marcada (salvo occipucio), puntos superficiales separados; escamitas a menudo levantadas.

Pronoto transversal $(\mathrm{L} / \mathrm{A}=0,78)$, muy poco convexo, lados curvos, máxima anchura pasada la 
mitad, más estrechados por delante que por detrás, en la base brevemente constreñidos (ángulos posteriores rectos). Tegumentos con puntos gruesos variables de tamaño, poco profundos, separados 13 diámetros entre sí, micropuntos reconocibles entre la microrreticulación; ésta bien impresa; escamitas lineares, largas, a menudo semierguidas, las doradas orlando el disco y a lo largo de su franja media. Línea media estrecha y larga.

Escudete amplio, triangular, tapizado de escamas.

Élitros largos, oblongos $(\mathrm{L} / \mathrm{A}=1,73)$ con la máxima anchura hacia el segundo tercio $(1,5 \mathrm{x}$ la anchura del pronoto); lados subparalelos y convergentes hacia delante, suavemente acuminados hacia atrás; base poco más ancha que la del pronoto, hombros cortos, romos, sin callo humeral. Puntos de las estrías tan gruesos como los del pronoto, separados casi un diámetro; interestrías algo convexas, con hilera irregular de sedas oscuras recias y erectas (puntos de inserción destacados), algo arqueadas e inclinadas hacia atrás (algo más largas que las uñas), escamitas largas y finas, las oscuras formando parches sobre las interestrías pares.

Patas largas, profémures robustos, tibias muy delgadas y pilosas; protibias algo torcidas hacia dentro en el cuarto apical, ángulo apical externo romo, el interno expandido, con fuerte mucrón, protarsos grandes, $2^{\circ}$ artejo triangular-ensanchado, $3^{\circ}$ tan ancho como el dorso del rostro; mesotibias con mucrón, metatibias algo arqueadas lateralmente, débilmente aserradas (5-8 dientes espiniformes difíciles de apreciar), pilosidad flageliforme en el tercio distal.

Cara ventral brillante, con pilosidad laxa (escamitas concentradas en metaepisternas). Saliente intermesocoxal, careniforme, apenas levantado, sin escamitas; lo mismo el gránulo inter-proxocal. Esternito V truncado apicalmente, con breve escotadura al medio.

Edeago poco arqueado, punta en forma de pie invertido, la placa apical espatuliforme inclinada a un lado; saco interno algo más largo hacia atrás que los temones, con campos pares de dentículos basal, mediano y distal; el divertículo ciego bífido sobrepasa los temones hacia atrás (Fig. 15A).

Hembras: Talla 6,1-7,8 mm. Bastante más anchas que los machos, élitros de lados más curvados; tibias sin mucrón y protibias apenas incurvadas apicalmente. Novena interestría elitral muy tumefacta apicalmente y sobresaliente hacia atrás, otorgando (en vista dorsal) un aspecto truncado o tricúspide al ápice alitral. Esternito $5^{\circ}$ apicalmente ojival.
ETIMOLOGÍA. El epíteto latino "tarsalis" es un adjetivo que hace referencia a los tarsos grandes y llamativos del insecto.

OBSERVACIONES. Laparocerus tarsalis n. sp. pertenece al grupo de L. mendicus Wollaston, 1864, y se distingue fácilmente de todos ellos por las cerdas negras erguidas y de tamaño uniforme (más largas que las uñas) dispuestas en hileras a lo largo de todo el élitro y no solo sobresalientes en el tercio apical. De $L$. feloi n. sp., especie que también vive en la isla de La Palma, se separa además por la mayor longitud y delgadez de las escamas, punteado del pronoto más grueso y disperso, interestrías elitrales más convexas, la $9^{a}$ llamativamente tumefacta en el ápice, tegumento más brillante, tibias más pilosas, metatibias $\sigma^{x} O^{x}$ más torcidas y los dientes de sierra muy poco desarrollados, difíciles de observar. La maza antenal es más estilizada (L/A $=3,9$ ), pero no tanto como en L. longiclava.

La presencia de cerdas negras erguidas a lo largo de todo el élitro es un carácter que no se repite en ninguna otra especie de la isla, salvo en las hembras de L. elongatus n. sp. cuyos élitros son de base muy ancha, de hombros notablemente desarrollados y carecen de tumefacciones apicales.

DisTRIBUCIÓN Y ECOLOGÍA. Laparocerus tarsalis n. sp. es endémico de la isla de La Palma, habiéndose localizado en la fachada nororiental, mientras que L. feloi $\mathrm{n}$. sp., del mismo grupo, ocupa la fachada noroccidental. Se ha colectado sobre Cistus symphytifolius (Cistaceae) en ámbito boscoso mixto de laurisilva y pinar canario, a $1300 \mathrm{~m}$ de altitud.

\section{Laparocerus astralis n. sp.}

(Figs. 14A, 15B, 12E y 20J)

Material examinado. La Palma. Holotipo $10^{\top}$ Garafía: Roque de los Muchachos 2050-2300 m 19-6-2004 leg. A. Machado (TFMC n ${ }^{\circ}$ 15939). - Paratipos, misma localidad 57 exx 30-1-2001, 10 exx 19-6-2004, 6 exx 4-12-2004 leg A. Machado (AMC); ídem 21-8-2003 8 exx leg. R. García (RGB), 6 exx 5-12-2004 leg. A. Aguiar (AAC), 1 ex 21-3-1995 leg Zerche (EC). 19 exx 17-8-2000, 2 exx 25-8-2000, 4 exx 31-82000, 12 exx 7-9-2000, 1 ex 14-9-2000, 2 exx 21-9-2000, 5 exx 4-10-2000, 1 ex 11-10-2000, 1 ex 6-10-2000, 7 exx 21-32001, 15 exx 28-3-2001, 4 exx 4-4-2001, 6 exx 10-4-2001, 15 exx 18-4-2001, 7 exx 25-4-2001, 7 exx 2-5-2001, 4 exx 9-52001, 12 exx 7-5-2001, 13 exx 23-5-2001, 40 exx 31-5-2001, 12 exx 6-6-2001, 28 exx 4-6-2001, 30 exx 20-6-2001, 56 exx 28-6-2001, 36 exx 4-7-2001, 62 exx 11-7-2001, 23 exx 15-72001 leg. T. Domingo-Quero (MNHN), 16 exx 27-7-2000, 12 exx 27-7-2000, 31 exx 4-8-2000, leg. A. Sánchez Ruiz leg. (MNHN). Pico de la Cruz, 2300, 21 exx 30-1-2001 leg A. 
Fig. 14.- Holotipos $\sigma^{7} \sigma^{7}$ : Laparocerus astralis n. sp. (A) y Laparocerus supranubius n. sp. (B).

Fig. 14. - Holotypes $\sigma^{x} \sigma^{x}$ : Laparocerus astralis n. sp. (A), and Laparocerus supranubius $\mathbf{n}$. $\mathbf{s p}$. (B).

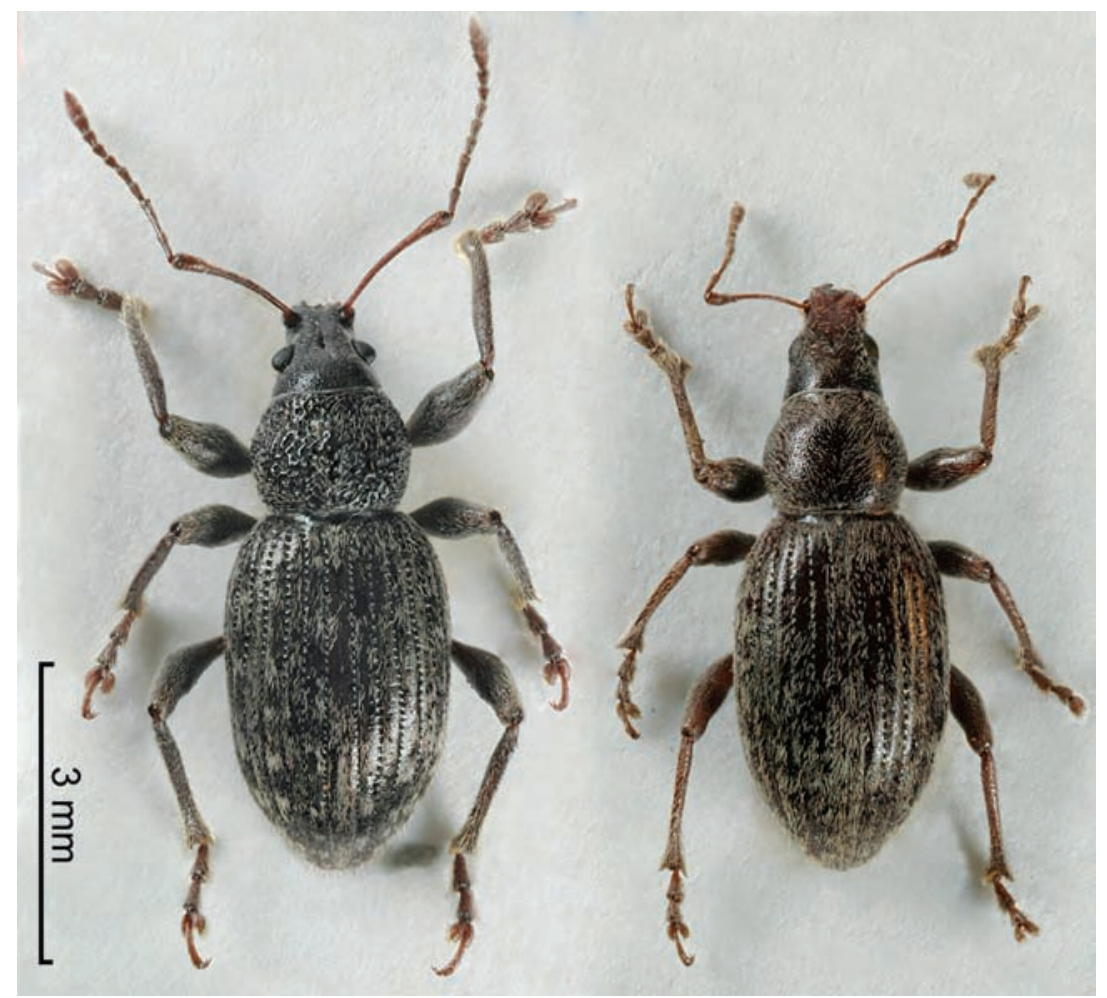

Machado (AMC), 5 exx 10-7-1983, 4 exx 17-1-1986, 3 exx 285-1994 leg R. García (RGB).

No paratipos: Las Moradas 2000 m, 3 exx 21-11-2002 leg. A. Machado (AMC). Roque de los Muchachos 40 exx (nr. 1672) leg H. Franz (NMW). Mirador Andenes, 2200 m 6 exx 21-3-1995 leg. A. Liberto (AL). Mirca $300 \mathrm{~m} 1$ ex (¿transportado?) 25-5-1997, Garafía: Hoya Larga 1900 m 8 exx 25-51997 leg. R. García (RGB).

LOCALIDAD TíPICA. Roque de Los Muchachos, municipio de Garafía, La Palma, islas Canarias. UTM 28R 02183003185300.

MEDIDAS DEL HOLOTIPO ( $\left.\sigma^{\pi}\right)$. Longitud: total ( $\sin$ rostro) $5,60 \mathrm{~mm}$, rostro $0,60 \mathrm{~mm}$, escapo $1,50 \mathrm{~mm}$, funículo 1,84 (desmómeros I-IV respectivamente 0,36 / 0,47 / 0,23/ 0,23 mm), maza $0,56 \mathrm{~mm}$, pronoto $1,25 \mathrm{~mm}$, élitros $3,90 \mathrm{~mm}$, tibias (pro- /meso/meta-) 1,70/1,60/2,01 mm. Anchura: cabeza (a nivel de los ojos) $0,90 \mathrm{~mm}$, (interocular) $0,62 \mathrm{~mm}$; rostro (a nivel de los pterigios) $0,78 \mathrm{~mm}$, (mínimo dorsal) $0,32 \mathrm{~mm}$ (mínimo ventral) $0,63 \mathrm{~mm}$; escapo $0,18 \mathrm{~mm}$, maza $0,19 \mathrm{~mm}$, pronoto (anterior /máxima /posterior) 1,20 / 1,70/1,35 mm y élitros (máxima) 2,40 mm. Altura: abdomen 2,00 mm.

DESCRIPCIÓN. Machos: Talla: 5,2-6,4 mm. Laparocerus mediano, de aspecto oblongo alarga- do. Tegumento brillante de color negruzco, tarsos y antenas a menudo pardo-rojizo; revestimiento poco denso de escamitas flavas lanceoladas, finas y adpresas, poco aparente en el pronoto, formando dibujo poco contrastado en los élitros; éstos con sedas emergentes separadas.

Antenas muy largas; escapo arqueado, 1,2x la longitud del pronoto, anchamente capitado en su cuarto apical; funículo más largo que el escapo, desmómero II 1,3x la longitud del I, y tan largo como el III y IV reunidos; maza fusiforme, tan ancha como la maza del escapo, apenas más larga que los tres desmómeros precedentes reunidos.

Cabeza cónica, robusta; rostro corto (más ancho en la base que largo), muy estrangulado dorsalmente (ancho dorsal mitad que el ventral), flancos y escrobas visibles desde arriba (base antenal completamente expuesta); pterigios auriculares, breves, algo salientes; prorrostro mal delimitado, quilla epistomal apenas marcada; metarrostro de cantos romos, profundamente acanalado (línea media incisa); frente algo deprimida, fóvea frontal profunda, prolongada en surco rostral; tegumento con microrreticulación isodiamétrica patente, con puntos dispersos y algunas escamitas. Ojos en plano inclinado, de aspecto moruloide, ovales ( $\mathrm{L} / \mathrm{A}=$ 


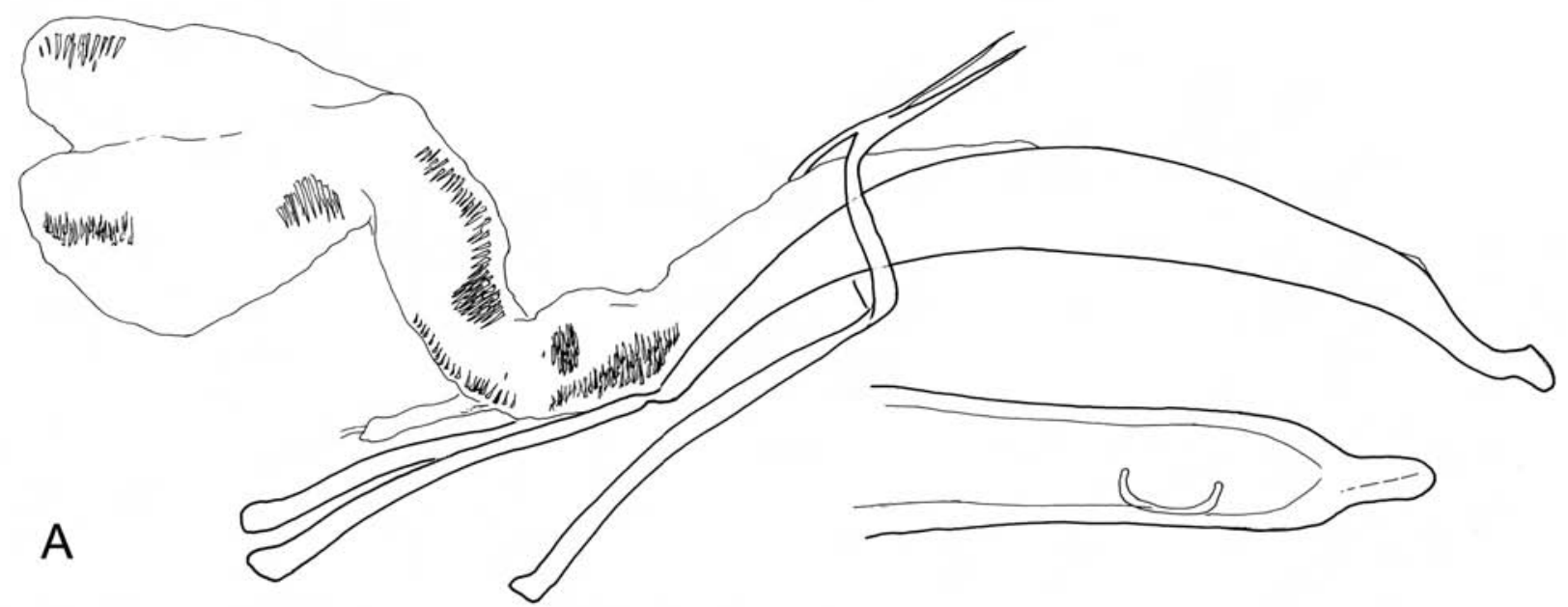

B
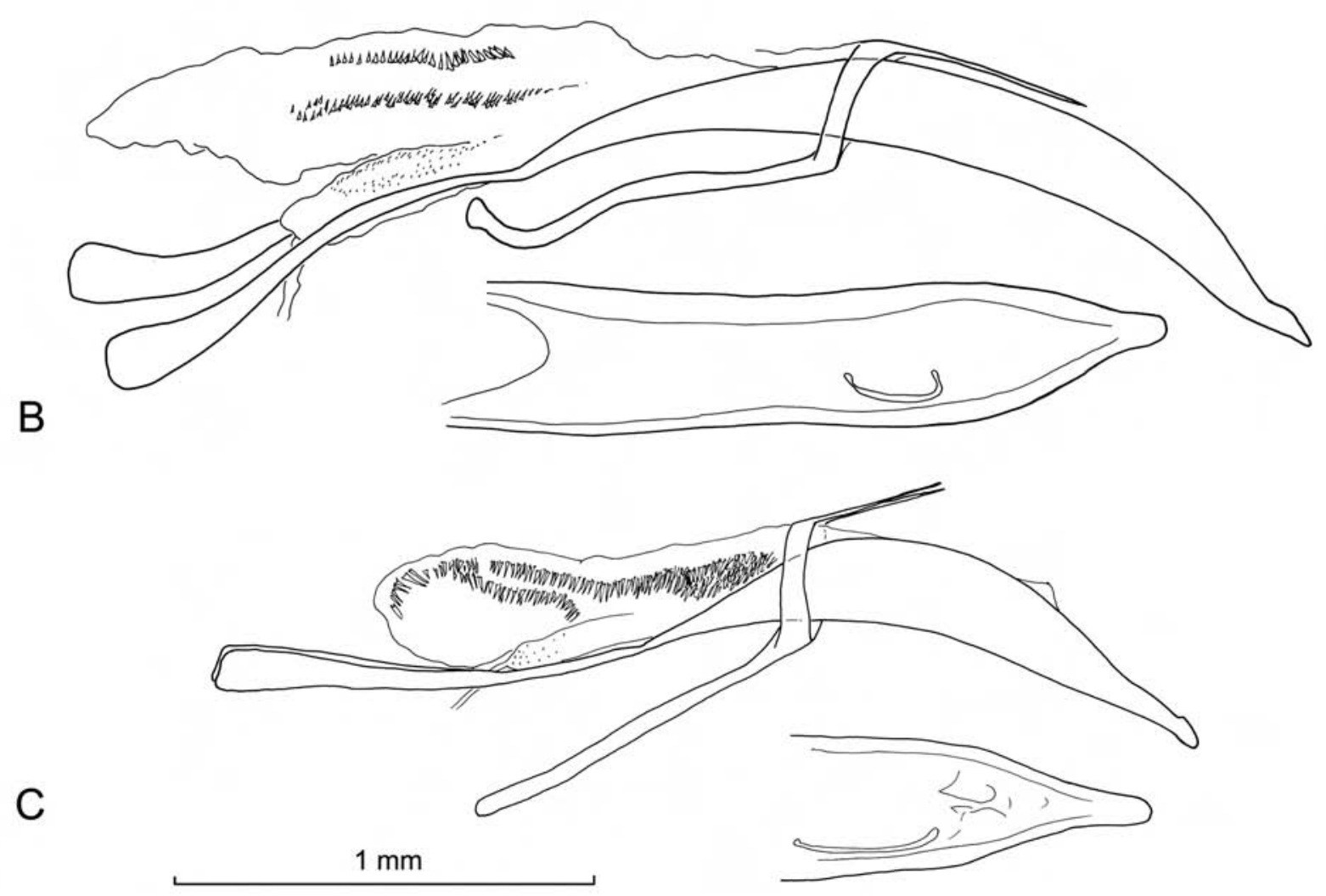

Fig. 15.- Edeago y detalle del ápice del lóbulo medio: Laparocerus tarsalis n. sp. (A), Laparocerus astralis n. sp. (B) y Laparocerus supranubius n. sp. (C).

Fig. 15.- Aedeagi and detail of median lobe apex: Laparocerus tarsalis n. sp. (A), Laparocerus astralis n. sp. (B), and Laparocerus supranubius $\mathbf{n} . \mathbf{s p}$. (C). 
1,30), prominentes (convexidad 40-45\%), subcónicos, con el cenit desplazado hacia atrás, rodeados por un profundo surco periocular (con escamitas).

Pronoto isodiamétrico, convexo, sin rebordes, apenas más estrecho por delante que por detrás; lados uniformemente curvados; dorso con depresión postmarginal anterior moderada; línea media algo levantada (quilla incipiente); tegumento con puntos foveiformes llamativamente grandes, separados menos de un diámetro entre sí, y espacios libres convexos con algunos micropuntos (aspecto general del punteado muy escabroso), escamitas aisladas, escasas, nada aparentes.

Escudete triangular, corto, con escamitas.

Élitros oblongo-alargados (L/A >1,6), 3,1x la longitud del pronoto y $1,4 \mathrm{x}$ su anchura; hombros nada marcados, máxima anchura algo desplazada hacia delante o al medio, lados subparalelos en su tramo medio; disco usualmente deprimido. Estrías con puntos gruesos, menores que los del pronoto, separados $2 / 3$ de su diámetro; interestrías usualmente planas. Tegumento brillante, con microescultura transversal imprecisa; escamitas lanceoladas más o menos densas (7-10 a lo ancho de la interestría), dejando algunos parches libres en las interestrías pares (dibujo teselado poco aparente); sedas recias emergentes de color claro, algo arqueadas, inclinadas hacia atrás, no mayores que una uña, progresivamente más desarrolladas hacia al ápice (más aparentes).

Cara ventral brillante, con pilosidad rubia, fina, abierta e inclinada. Saliente intermesocoxal, estrecho, breve, aquillado. Esternitos abdominales con microestriación transversal, el $5^{\circ}$ truncado apicalmente.

Patas grandes; protibias delgadas, curvadas hacia dentro en el cuarto apical (sinuosidad interior poco marcada), ángulo apical externo ampliamente romo; mucrón pequeño, algo mayor que en meso- y metatibias.

Edeago de perfil poco arqueado; punta brevemente levantada, terminada en forma de bota invertida con escaso talón (Fig. 15B), placa apical en vista dorsal triangular estrechada en el ápice. Saco interno hacia atrás apenas más largo que los temones, dos campos basales de dentículos poco esclerotizados; divertículo ciego poco más largo que el gonoporal.

Hembras. Talla 4,8-6,0 mm. Más cortas y rechonchas que al macho. Pronoto con una fuerte y llamativa joroba mediana longitudinal. Élitros más cortos $(\mathrm{L} / \mathrm{A}<1,5)$ de aspecto cordiforme, inflados en la base (interestría $8^{\circ}$ visible desde arriba, hom- bros curvados); el disco deprimido (interestrías suturales a veces algo hundidas); sedas oscuras, más robustas y desarrolladas en todo el élitro. Mucrón de la pro- y mesotibia minúsculo (difícil de apreciar); ausente en metatibias. Abdomen inflado ventralmente; esternito $5^{\circ}$ no truncado en el ápice. Urosternito VIII y espermateca, figuras $12 \mathrm{~B}$ y $20 \mathrm{~J}$, respectivamente.

ETimología. El epíteto astralis es un adjetivo derivado del latín astrum, astro, en alusión metafórica a que vive junto a los astros, pues el insecto habita en la parte más alta de la isla y contempla el cielo nocturno estrellado al igual que hace el Observatorio de Astrofísica del Roque de Los Muchachos, emplazado en su localidad típica.

OBSERVACIONES. Laparocerus astralis n. sp. pertenece al subgénero Guanchotrox Alonso-Zarazaga \& Lyal, 1999, y es muy parecido al generotipo Laparocerus canariensis (Boheman, 1842), que es su vicariante en la isla de Tenerife, donde vive en igual ambiente de alta montaña. Se diferencia fácilmente de ésta especie por el punteado grosero y abrupto del pronoto; los puntos en $L$. canariensis son también gruesos, pero menores, más abundantes y están separados más de un diámetro entre sí, mientras que en L. astralis son ampliamente foveiformes y la separación es inferior al diámetro (casi contiguos, aspecto varioloso). Además, en L. canariensis el escapo es más fino, la depresión postmarginal del pronoto es más profunda y patente, los élitros son más elípticos (lados curvados) en los machos, mientras que en las hembras, aunque ensanchados, son nada o apenas cordiformes; los puntos de las estrías son casi contiguos (separados $2 / 3$ de diámetro en $L$. astralis); las sedas son menores (un tercio más cortas) y están mucho menos desarrolladas en la mitad basal de los élitros masculinos. Las protibias masculinas están más largamente curvadas y sinuosas en la mitad distal. No se aprecian diferencias relevantes en los edeagos, lo cual suele ocurrir en vicariantes interinsulares de este género.

La nueva especie se distingue rápidamente de los demás Laparocerus de la isla por los ojos de aspecto moruloide y forma cónica, con el cenit desplazado hacia atrás. El rostro, muy estrangulado dorsalmente y con las escrobas visibles desde arriba, es también muy característico.

DISTRIBUCIÓN Y ECOLOGÍA. Laparocerus astralis n. sp. es endémico de la isla de La Palma, donde habita en la comunidad de matorral de alta montaña que se desarrolla por encima de los $2000 \mathrm{~m}$ de altitud. Es un 
insecto nocturno aparentemente activo todo el año, escaso en otoño, pero común en invierno, a pesar del frío y la nieve ocasional. Se alimenta preferentemente de Adenocarpus viscosus spartioides y Spartocytisus supranubius (Faba-ceae), y también se ha vareado en Descurainia gilva (Brassicacea) y Pterocephalus porphyranthus (Dipsacaceae). Vive en iguales condiciones ambientales que su vicariante tinerfeño, L. canariensis.

\section{Laparocerus supranubius $\mathbf{n}$. sp.}

(Figs. 14B, 15C, 12D y 20K)

Material examinado. La Palma. Holotipo $10^{7}$ Pico de la Cruz, 2.345 m, 30-1-2001 leg A. Machado (TFMC n 15947).- Paratipos: 14 exx mismos datos (AMC), 10 exx 171-1986, 2 exx 2-8-1987 leg. R. García (RGB). Las Moradas 2000 m 18 exx 21-11-2002, 15 exx 7-12-2004 leg A. Machado (AMC), 4 exx 4-12-2004 leg. R. García (RGB), 4 exx 4-122004, 7 exx 7-12-2004 leg A. Clavijo (AAC). Roque de los Muchachos 2100 m 8 exx 30-1-2001, leg. A. Machado (AMC), 1 ex 4-12-2004 leg. A. Aguiar (AAC), 1 ex 11-2-1994 leg. K. H. Kielhorn (HW), 5 exx 4-3-1994 leg. P. Sprick (PSH), 14 exx (nr 1491) leg. H. Franz (NMW), 4 exx 17-10-2000, 3 exx 2610-2000, 9 exx 21-3-2001, 9 exx 28-3-2001, 5 exx 4-4-2001, 5 exx 10-4-2001, 12 exx 18-4-2001, 5 exx 25-4-2001, 2 exx 2-52001, 6 exx 9-5-2001, 6 exx 17-5-2001, 2 exx 23-5-2001, 6 exx 31-5-2001, 5 exx 6-6-2001, 4 exx 14-6-2001, 1 ex 28-62001, leg. T. Domingo-Quero (MNHN).

No paratipos. Cumbre de Puntallana 2050 m, 34 exx 14-91987 leg. A. Machado (AMC). Jieque 200 m 15 exx 11-22004; Marcos y Corderos 1 ex 30-12-1982; Bco. del Río 400 m 1 ex 1-4-1983 leg R. García (RGB). Pico de Las Nieves, 4 ex 21-4-1989 leg. J. Messutat (1 DEI, 4 JM). Pinar de Garafía Km 341900 m, 4 exx 30-1-2001, Cueva de La Zarza 980 m, 1 ex 30-1-2001 leg. A Machado (AMC). Mirador de los Andenes 2200 m, 3 exx 21-3-1995 leg. A. Liberto (AL).

LOCALIDAD TíPICA. Pico de La Cruz, municipio de Barlovento, La Palma, islas Canarias. UTM 28R 022137318411.

MedidAS DEL holotipo $\left(0^{\pi}\right)$. Longitud: total (sin rostro) $5,45 \mathrm{~mm}$, rostro $0,56 \mathrm{~mm}$, ojo $0,36 \mathrm{~mm}$, escapo $1,24 \mathrm{~mm}$, funículo $1,22 \mathrm{~mm}$ (desmómeros I-IV respectivamente $0,28 / 0,28 / 0,16 / 0,14 \mathrm{~mm})$, maza 0,55 $\mathrm{mm}$, pronoto $1,23 \mathrm{~mm}$, élitros $3,75 \mathrm{~mm}$, tibias (pro/meso- /meta-) 1,50/1,36/1,52 mm. Anchura: cabeza (a nivel de los ojos) 0,92 mm, (interocular) 0,60 mm; rostro (a nivel de los pterigios) $0,65 \mathrm{~mm}$, (mínimo dorsal) $0,46 \mathrm{~mm}$ (mínimo ventral) $0,60 \mathrm{~mm}$; ojo 0,31 $\mathrm{mm}$; escapo $0,12 \mathrm{~mm}$; maza $0,14 \mathrm{~mm}$; pronoto (anterior /máxima /posterior) $1,06 / 1,48 / 1,26 \mathrm{~mm}$ y élitros (máxima) 2,23 mm. Altura: abdomen 3,00 mm.

DESCRIPCIÓN. Machos: Talla: 5,0-7,3 mm. Laparocerus de talla mediocre, oblongo-alargado; tegumento subnítido, pardo negruzco, con revestimiento más o menos denso de escamitas largas lanceoladas, tumbadas, de color flavo o dorado (bastante dehiscentes), formando (no siempre) dibujo en teselas sobre los élitros; éstos con hileras de sedas finas, blanquecinas, sobresalientes, más o menos desarrolladas.

Antenas cortas; escapo curvado al medio, igual de largo que el pronoto, capitado en el tercio apical; funículo tan largo como el escapo, desmómero I y II iguales, III y IV subiguales; maza elíptica (L/A = 3,2 ), más larga que los tres desmómeros precedentes reunidos.

Cabeza robusta, de cuello abultado; sienes divergentes hacia atrás (tan largas como eje mayor del ojo); rostro corto, de aspecto trapezoidal, pterigios pequeños, nada prominentes; prorrostro lateralmente punteado, al medio con micrroretículo isodiamétrico, carena epistomal completa, poco levantada; metarrostro no acanalado, estrangulado por delante; frente no deprimida, fóvea longitudinal, no prolongada. Ojos pequeños $(\mathrm{L} / \mathrm{A}=1,16)$, aplastados (convexidad 22\%), próximos al canto lateral de la frente. Tegumento punteado, con escamitas lanceoladas y piliformes.

Pronoto dolioliforme $(\mathrm{L} / \mathrm{A}=0,83)$, convexo, con fino reborde basal, lados uniformemente curvos (salvo pequeña constricción anterior), máxima anchura a la mitad; borde anterior ligeramente convexo en el medio. Punteado fino, apretado y bien impreso; tegumento con microrreticulación poligonal generalmente reconocible. Línea media bien desarrollada en el disco. Cobertura de escamas generalmente densa y uniforme (convergen hacia la línea media y base).

Escudete triangular, pequeño, con escamitas.

Élitros estrechos $(\mathrm{L} / \mathrm{A}=1,7)$, moderadamente convexos, sin hombros, $3,1 \mathrm{x}$ la longitud del pronoto y $1,5 \mathrm{x}$ su anchura; lados poco curvados en su tramo medio (aspecto subparalelo), máxima anchura al medio o hacia la base. Estrías con puntos marcados, longitudinales (algo mayores que los del pronoto); interestrías subconvexas, con 8-10 escamitas a lo ancho y una hilera de sedas blanquecinas de desarrollo variable (generalmente más desarrolladas y erectas hacia el ápice). Tegumento con retículo de grandes celdas transversales (a veces impreciso por la rugosidad).

Patas cortas, recias; tibias de longitud poco diferenciada, carenadas externamente; protibias expandidas en el ápice a ambos lados (en "abanico"), con mucrón fuerte; mesotibia progresivamente ensanchada en el tercio apical, mucrón menor; las metatibias igual y mucrón aún menor y preapical. 
Cara ventral con abundante pilosidad en coxas, tramo medio del metasterno y $1^{\text {er }}$ esternito abdominal, los demás con escamitas piliformes tumbadas. Saliente intermesocoxal careniforme, erizado de escamitas. $2^{\circ}$ esternito tan largo como el $3-4^{\circ}$ reunidos o el $5^{\circ}$; este último subtruncado.

Edeago arqueado, suavemente prolongado en temones, de longitud equivalente: punta en vista dorsal triangular estilizada, en perfil levemente inclinada hacia abajo, con pestaña preapical. Saco interno corto recorrido hasta el fondo por campos de dentículos (Fig. 15C).

Hembras. Talla 5,3-6,6 mm. Más anchas y cortas que los machos; pronoto más transversal $(\mathrm{L} / \mathrm{A}=$ $0,77)$; élitros inflados $(\mathrm{L} / \mathrm{A}=1,47)$, disco menos convexo, estrías más superficialmente puntuadas, interestrías planas. Mucrón presente solo en protibias. Pilosidad del metatesterno menos desarrollada; último esternito abdominal curvado apicalmente. Urosternito VIII (Fig. 12D), espermateca (Fig. 20K).

ETIMOLOGía. El epíteto latino "supranubius" es un adjetivo que hace referencia a que la especie vive por encima de las nubes, ya que la altitud a la que se desarrolla su hábitat supera la capa de los alisios, que es donde se generan los característicos mares de nubes en Canarias.

OBSERVACIONES. Los 34 ejemplares procedentes de la Cumbre de Puntallana, presentan todos la pilosidad elitral (setas prominentes) más uniformemente desarrollada, particularmente en las hembras, que son además algo más redondeadas, razón por la que no se han incluido como paratipos a pesar de haberse colectado en el mismo hábitat y en un localidad relativamente próxima a la típica. Igualmente ocurre con ejemplares aislados colectados en Marcos y Corderos y Barranco del Río (Santa Cruz).

Laparocerus supranubius n. sp. es la especie palmera del grupo de L. scapularis Wollaston,1864 y es, a su vez, vicariante ecológico de ésta y de $L$. subparallelus Machado, 2007 que habitan en Tenerife en el mismo tipo de matorral de alta montaña. Las especies de este grupo se parecen mucho entre sí y se diferencian externamente por pequeños detalles y la conformación del cuerpo. Son difíciles de separar si no se cuenta con series para comparar. L. scapularis, L bolivari Uyttenboogaart, 1937, y L. gomerensis Lindberg, 1953, son de tegumentos más lustrosos, tienen el rostro más largo y sienes menos abultadas; la primera de ellas presenta puntos mayores salpicados entre la punteado menudo del pronoto, y en la última, los puntos son mucho más superficiales. L. subparallelus Machado, 2007 es la más parecida a L. supranubius n. sp. por su contorno general y rostro corto trapezoide, aunque la cápsula cefálica es aún más ancha a nivel de occipucio (sobresale lateralmente bastante más que los ojos) y los lados elitrales son más paralelos. La punta del edeago en $L$. gomerensis es afilada y presenta pestaña preapical bien desarrollada, en $L$. scapularis es más ancha, triangular-puntiaguda y carece de pestaña, y en L. subparallelus, el estrechamiento triangular es mucho más corto que el de supranubius $\mathrm{n}$. sp., y la pestaña apenas se insinúa.

DISTRIBUCIÓN Y ECOLOGÍA. Laparocerus supranubius $\mathrm{n}$. sp. es endémico de La Palma y se distribuye por toda la cumbre septentrional de la isla (borde de La Caldera de Taburiente) a altitudes que superan los $2000 \mathrm{~m}$, ambiente donde se desarrolla el característico matorral de leguminosas de alta montaña canaria. No obstante, se han colectado algunos ejemplares a menor altitud $(1000 \mathrm{~m})$ en dominio de pinar o monteverde, e incluso a $400 \mathrm{~m}$ (itransportado con rastrojos?). Existe también un ejemplar inmaturo colectado en el inicio de la cordillera meridional de la isla (Refugio de El Pilar), cuya adscripción a esta especie es dudosa. El insecto es de hábitos nocturnos y se alimenta de Adenocarpus viscosus spartioides y Spartocytisus supranubius (Fabaceae).

\section{Laparocerus orone aridane $\mathbf{n}$. ssp.}

(Figs. 16A, 17A y 20L)

Material examinado. La Palma: Holotipo, Bco. de las Angustias 200 m, $10^{7}$ 31-1-2001 leg. A. Machado (TFMC n ${ }^{\circ}$ 15946).- Paratipos: misma localidad, 47 exx 31-1-2001, 27 exx 3-2-2001, 16 exx 20-11-2002 leg. A. Machado (AMC, MCNTF, MNHN, MNCN, NHM), 6 exx 3-2-2001 leg R. García (RGB). Los Llanos: Montaña de Triana 310 m, 27 exx 29-1-2006 leg. A. Machado (AMC), ídem 14 exx 4-2-2001, 3 exx 29-1-2006 leg R. García (RGB).

LOCALIDAD TÍPICA. Barranco de las Angustias, municipio de Los Llanos de Aridane, La Palma, islas Canarias. UTM 28R 021325317370.

MEDidAs DEL HOLOTIPO $\left(0^{x}\right)$. Longitud: total ( $\mathrm{sin}$ rostro) $4,60 \mathrm{~mm}$, cabeza $0,95 \mathrm{~mm}$, rostro $0,52 \mathrm{~mm}$, escapo $1,10 \mathrm{~mm}$, funículo $1,18 \mathrm{~mm}$ (desmómeros IIV respectivamente $0,24 / 0,30 / 0,15 / 0,16 \mathrm{~mm})$, maza $0,40 \mathrm{~mm}$, ojos $0,28 \mathrm{~mm}$, pronoto $1,16 \mathrm{~mm}$, élitros 3,40 mm, tibias (pro- /meso- /meta-) 1,24 /1,18 /1,26 mm. Anchura: cabeza (a nivel de los ojos) 0,96 mm, (interocular) 0,60 $\mathrm{mm}$, (a nivel de los pterigios) $0,63 \mathrm{~mm}$, (mínimo dorsal) $0,34 \mathrm{~mm}$, 


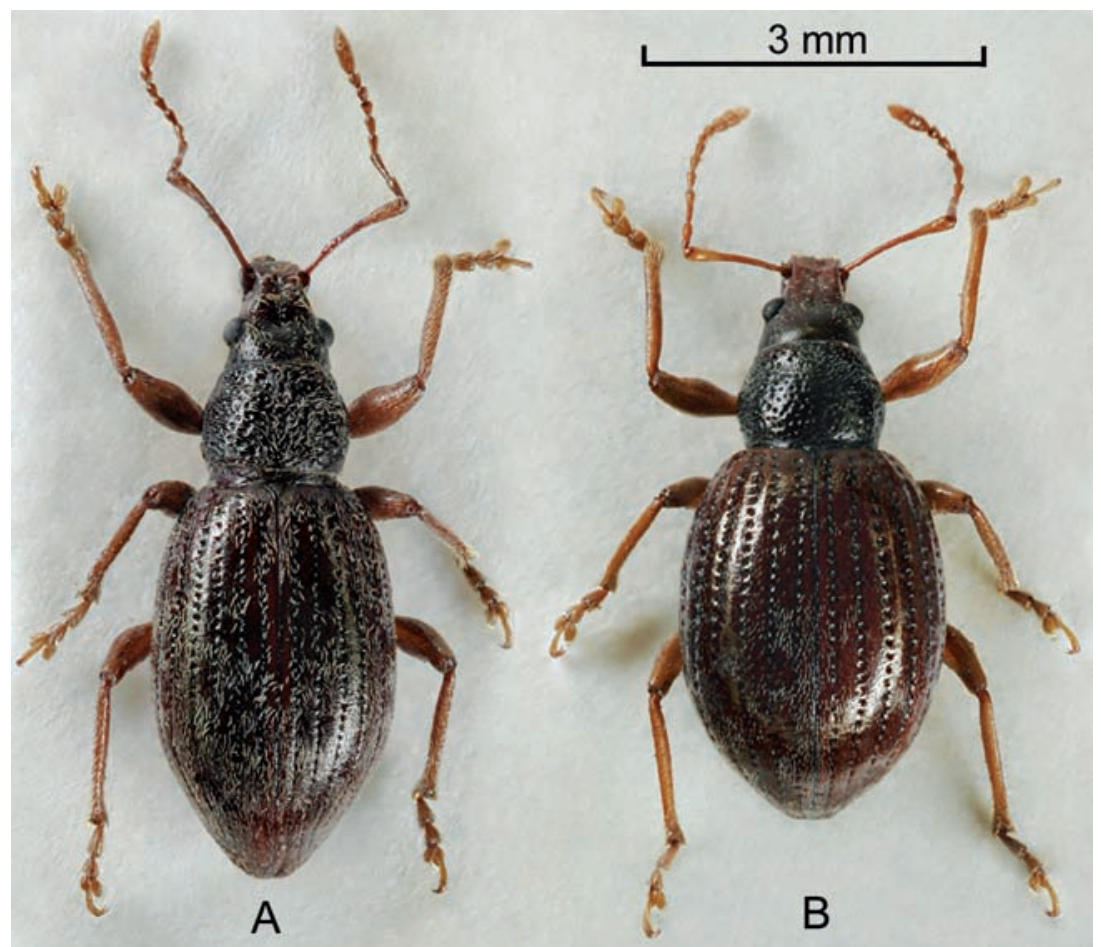

Fig. 16.- Holotipos $\sigma^{7} \sigma^{7}$ : Laparocerus. orone aridane n. ssp. y (A), Laparocerus amicorum n. sp. (B).

Fig. 16. Holotypes $\sigma^{7} \sigma^{x}$ : Laparocerus. orone aridane $\mathbf{n}$. ssp. (A), and Laparocerus amicorum n. sp. (A). (mínimo ventral) $0,56 \mathrm{~mm}$, escapo $0,14 \mathrm{~mm}$, maza $0,12 \mathrm{~mm}$, pronoto (anterior /máxima /posterior) $0,94 / 1,28 / 1,16 \mathrm{~mm}$, y élitros (máxima) $2,20 \mathrm{~mm}$. Altura: abdomen 1,70 mm.

Diagnosis DifERENCIAL. Tallas (s.r.) $\sigma^{\pi} \sigma^{\pi} 3,8-$ 4,7 mm, 우 우 4,0-5,1 mm. Como Laparocerus orone orone Machado 2002, pero más pequeño de tamaño (talla media $\sigma^{7} \sigma^{7} 4,27 \mathrm{~mm}$ en vez de 4,63 $\mathrm{mm}$; 우 $=4,6 \mathrm{~mm}$ en vez de $5,48 \mathrm{~mm}$ ). Antenas ligeramente más cortas (desmómeros V-VII más gruesos). Convexidad ocular 36\%. Élitros femeninos más curvados y menos inflados en la base, los masculinos con los puntos de las estrías menores; interestrías planas. Patas más esbeltas. Edeago igual (Fig. 17A). Espermateca (Fig. 20L).

ETimología. El epíteto subespecífico hace referencia al valle de Aridane, en La Palma, donde se localiza el taxón. Es un nombre en aposición y, por tanto, invariable.

OBSERVACIONES. Laparocerus orone Machado, 2007, descrito de La Gomera, cuenta con poblaciones en El Hierro y en La Palma, cuyas distancias genéticas entre sí (datos moleculares pendientes de publicación) son considerables, aunque la morfología externa presente solo pequeñas diferencias, y en el edeago no se aprecian modificaciones relevantes.
Laparocerus orone aridane n. ssp. se reconoce entre los demás Laparocerus de su talla presentes en La Palma, por la ausencia de cerdas y forma largamente acuminada de los élitros (máxima anchura por detrás de la mitad), pronoto con punteado fuerte y separado sobre fondo brillante, y por la cabeza, de ojos prominentes, con el dorso del rostro fuertemente estrangulado por delante del nivel de inserción de las antenas (aspecto muy trapezoidal), quedando los pterigios muy expuestos. Además, la peculiar forma de la punta del edeago (Fig. 17A) no se repite en ninguna otra especie de la isla.

DisTRIBUCIÓN Y ECOLOGÍA. Laparocerus orone aridane n.ssp. se localiza en la zona baja occidental de la isla de La Palma, sobre vegetación de matorral semiárido, alimentándose al menos de Argyranthemum frutescens (Asteraeae), Lavandula canariensis y Micro-meria herpillomorpha (Labiatae) y, ocasionalmente, de Rumex lunaria (Polygonaceae).

\section{Laparocerus amicorum $\mathbf{n}$. sp.}

(Figs. 16B, 17B, 5E y 20M)

Material examinado. La Palma. Holotipo, $10^{7}$ Barranco de los Hombres 50 m, 7-12-2004 leg. A. Machado (TFMC n ${ }^{\circ}$ 15937). - Paratipos: Misma localidad y fecha, 83 exx leg. A. Machado (AMC), 25 exx leg. A. Aguiar (AAC), 12 exx leg. R. 
García (RGB. Garafía, La Fajana 5 m, 1 ex 6-12-2009 leg. A. Machado (AMC).

No paratipos. Franceses, Las Piedras 440 m 1 ex 1-5-2005 leg. A. Machado (AMC).

LOCALIDAD TípICA. Barranco de los Hombres, 50 m, municipio de Garafia, La Palma, islas Canarias. UTM 28R 02196003192670.

MedidAs DEL hOLOTIPO $\left(\sigma^{x}\right)$. Longitud: total ( $\mathrm{sin}$ rostro) $4,40 \mathrm{~mm}$, rostro $0,56 \mathrm{~mm}$, escapo $1,14 \mathrm{~mm}$, funículo 1,34 (desmómeros I-IV respectivamente 0,26 / 0,36 / 0,16/ 0,16 mm), maza $0,46 \mathrm{~mm}$, pronoto $0,92 \mathrm{~mm}$, élitros $3,15 \mathrm{~mm}$, tibias (pro- /meso/meta-) 1,26/1,10/1,36 mm. Anchura: cabeza (a nivel de los ojos) $0,88 \mathrm{~mm}$, (interocular) $0,52 \mathrm{~mm}$; rostro (a nivel de los pterigios) 0,60 mm, (mínimo dorsal) $0,38 \mathrm{~mm}$ (mínimo ventral) $0,52 \mathrm{~mm}$; escapo $0,12 \mathrm{~mm}$, maza $0,13 \mathrm{~mm}$, pronoto (anterior /máxima /posterior) $0,90 / 1,24 / 1,10 \mathrm{~mm}$ y élitros (máxima) 2,30 mm. Altura: abdomen 1,85 mm.

DesCripción. Machos: Talla: 4,1-5,0 mm. Laparocerus pequeño, de aspecto redondeado, variable. Tegumentos brillantes o algo alutáceos, de color pardo-rojizo, ennegrecidos en pronoto y cabeza (a veces también los élitros), y extremidades más claras; revestimiento laxo de escamitas lineales muy pequeñas, adpresas, glaucas y flavas, formando agrupaciones más o menos delimitadas en los élitros; éstos desprovistos de sedas o cerdas.

Antenas largas; escapo apenas arqueado, 1,3x la longitud del pronoto, largamente capitado apicalmente (1/3); funículo ligeramente más largo que el escapo, desmómero II notablemente más largo que el I, y que el III y IV reunidos; maza fusiforme, delgada, no mucho más gruesa que el escapo, y más larga que los tres desmómeros precedentes reunidos.

Cabeza cónica, robusta; rostro cuadrangular, de sección trapezoidal, bastante estrechado dorsalmente (flancos visibles desde arriba); prorrostro bien delimitado, quilla epistomal completa, poco levantada; metarrostro de cantos poco marcados, convergentes hacia delante; superficie ligeramente hundida (no acanalado); fóvea frontal breve, poco profunda, no prolongada. Ojos brevemente ovales $(\mathrm{L} / \mathrm{A}=1,35)$, algo prominentes (convexidad 35$38 \%$ ), distantes del canto lateral de la frente. Tegumento con microrreticulación isodiamétrica muy visible, con puntos dispersos (más escasos en el vértice) y algunas escamitas.

Pronoto transversal $(\mathrm{L} / \mathrm{A}=0,74)$, algo más estrecho por delante que por detrás, con fino reborde posterior; lados bastante curvados; dorso por lo común con una impresión deprimida postmarginal anterior a cada lado (a veces confluente); puntos grandes separados más de un diámetro entre sí; microrreticulación isodiamétrica muy marcada (tegumento alutáceo), ocasionalmente, algo borrada (tegumento brillante); escamitas aisladas unas de otras.

Escudete triangular, pequeño, lustroso, con un par de escamitas.

Élitros subglobosos, ovales ( $\mathrm{L} / \mathrm{A}=1,37)$, poco o nada acuminados apicalmente, $3,4 \mathrm{x}$ la longitud del pronoto y 1,86x su anchura; hombros apenas marcados, romos. Estrías con puntos gruesos, mayores que los del pronoto; interestrías planas, algo convexas hacia los flancos, las suturales frecuentemente algo hundidas en la base; microrreticulación más o menos impresa (el brillo del tegumento, acorde); escamitas adpresas cortas, sin solaparse (3-5 a lo ancho de la interestría), las glaucas, algo más anchas, formando parches destacados sobre las interestrías impares.

Cara ventral brillante, con pilosidad fina, abierta y tumbada. Saliente intermesocoxal estrecho, breve, aquillado. Esternitos abdominales con estriación transversal, algunos puntos imprecisos en márgenes laterales. Metasternito $1^{\circ}$ y $2^{\circ}$ de igual longitud; el $5^{\text {a }}$ brevemente truncado apicalmente.

Patas normales, poco hirsutas; tibias rectilíneas, armadas con mucrón pequeño; protibias con extremo apical apenas desplazado hacia dentro, el ángulo externo, romo. Tarsos grandes, casi tan anchos como la tibia.

Edeago bastante rectilíneo, ligeramente sinuoso apicalmente; punta en vista dorsal triangular breve, sin prominencias dorsales. Saco interno hacia atrás tan largo como los temones, con campos basal y distal de grandes dentículos bien diferenciados; divertículo ciego mucho más grande y largo que el gonoporal (Fig. 17B).

Hembras. Talla 4,4-5,4 mm. Muy parecidas al macho, con élitros algo más inflados y cortos (lados menos curvados); hombros un poco más marcados; interestrías suturales hundidas y, generalmente, también en el disco (depresión llamativa); escamitas algo más anchas. Mucrón de la protibia minúsculo (difícil de apreciar); ausente en meso y metatibias. $5^{\circ}$ esternito abdominal en arco algo ojival. Urosternito VIII con lámina en forma de lengua, spiculum ventrale muy fino y $5 \mathrm{x}$ tan largo como ésta (Fig. 5E). Espermateca de cuerpo poco voluminoso, lóbulo glandular grande, curvado (Fig. 20M).

ETIMOLOGía. El nombre específico es un genitivo latino que significa "de los amigos", en homenaje a Agustín Aguiar Clavijo, Miguel Ángel Peña 


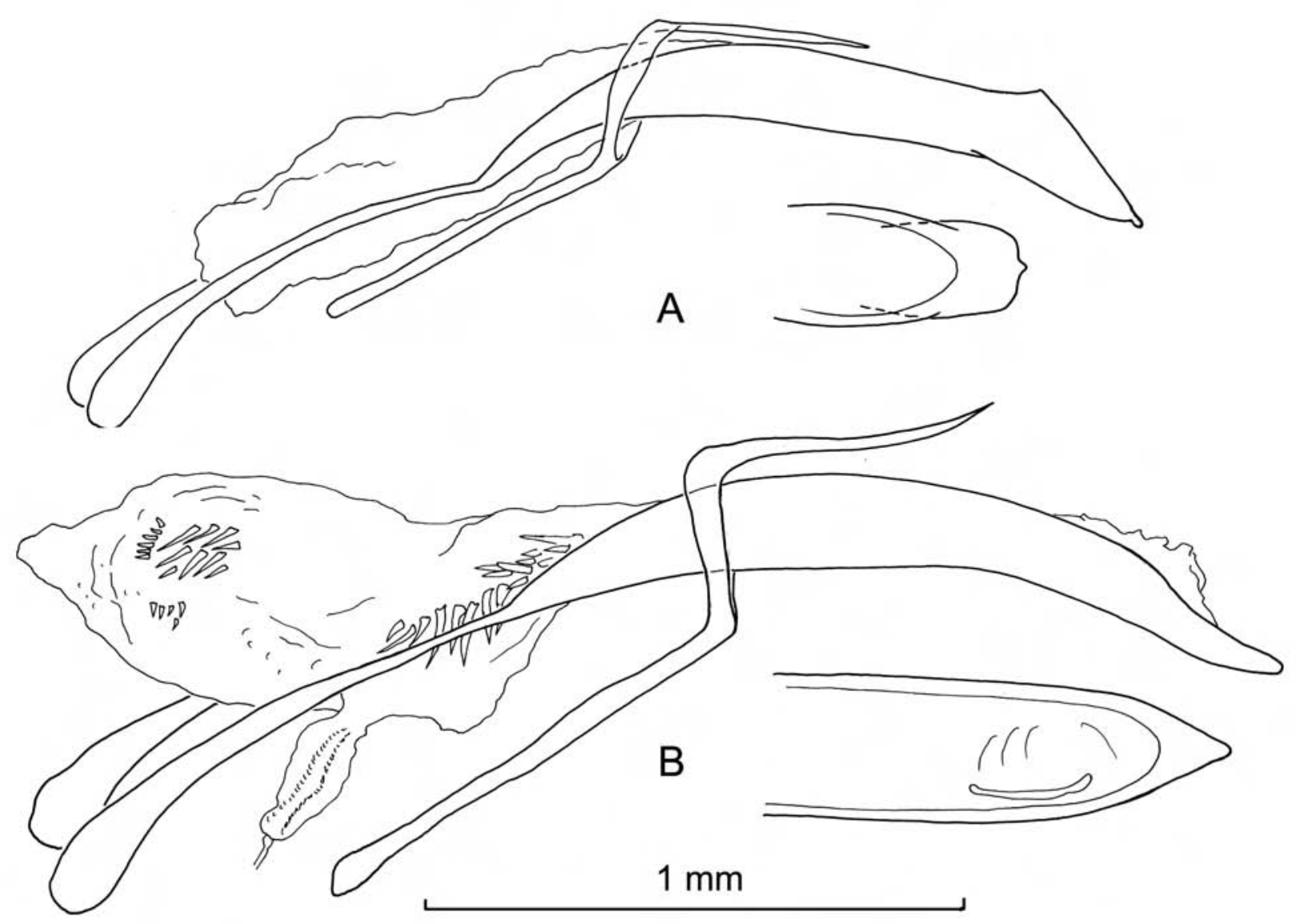

Fig. 17. - Edeago y detalle del ápice del lóbulo medio: Laparocerus orone aridane $\mathbf{n}$. ssp. (A) y Laparocerus amicorum $\mathbf{n} . \mathbf{s p .}$ (B).

Fig. 17.- Aedeagi and detail of median lobe apex: Laparocerus orone aridane $\mathbf{n}$. ssp. (A), and Laparocerus amicorum n. sp. (B).

Estévez y Rafael García Becerra, con quienes he compartido innumerables horas de colecta y en cuya compañía descubrí la especie.

OBSERVACIONES. Laparocerus amicorum n. sp. pertenece al grupo de L. obscurus, presentando un máximo parecido con L. roudieri Machado 2007, que vive en isla de La Gomera en condiciones ambientales similares. Se distingue de esta especie por la coloración menos negruzca y uniforme, las escamitas menos largas y no solapadas, los ojos algo menos sobresalientes, el pronoto más transversal y con solo punteado grueso (puntos menores apenas distinguibles), los élitros más anchos y menos acuminados, los hombros menos marcados, las patas algo más cortas y robustas, y los tarsos más grandes. Es fácil distinguirla de los demás Laparocerus que habitan La Palma por ser la única especie de sus dimensiones y aspecto redondeado que no presenta sedas ni pelos sobresalientes en los élitros.

DistribuCión Y ECOlOGíA. Especie endémica de la isla de La Palma, habiéndose localizado de momento solo en la franja baja de la vertiente norte, desde el nivel del mar hasta los $450 \mathrm{~m}$. Es nocturna y parece tener preferencia por plantas herbáceas como Amaranthus (Amaranthaceae), aunque también se ha encontrado esporádicamente en Echium (Boraginaceae) y Rubia fruticosa (Rubiaceae).

\section{Laparocerus decipiens $\mathbf{n}$. sp.}

(Figs. 18A, 19A, 12I y 20-N)

Material examinado. La Palma. Holotipo $10^{7}$ Las Moradas (Garafía) 2000 m, 21-11-2002 leg. A. Machado (TFMC n 15941). - Paratipos, misma localidad 100 exx 21-11-2002, 74 
Fig. 18. - Holotipos $O^{7} \sigma^{7}$ : Laparocerus decipiens n. sp. (A) y Laparocerus morrisi n. sp. (B).

Fig. 18. - Holotypes $\sigma^{\pi} \sigma^{\pi}$ : Laparocerus decipiens n. sp. (A), and Laparocerus morrisi n. sp. (B).

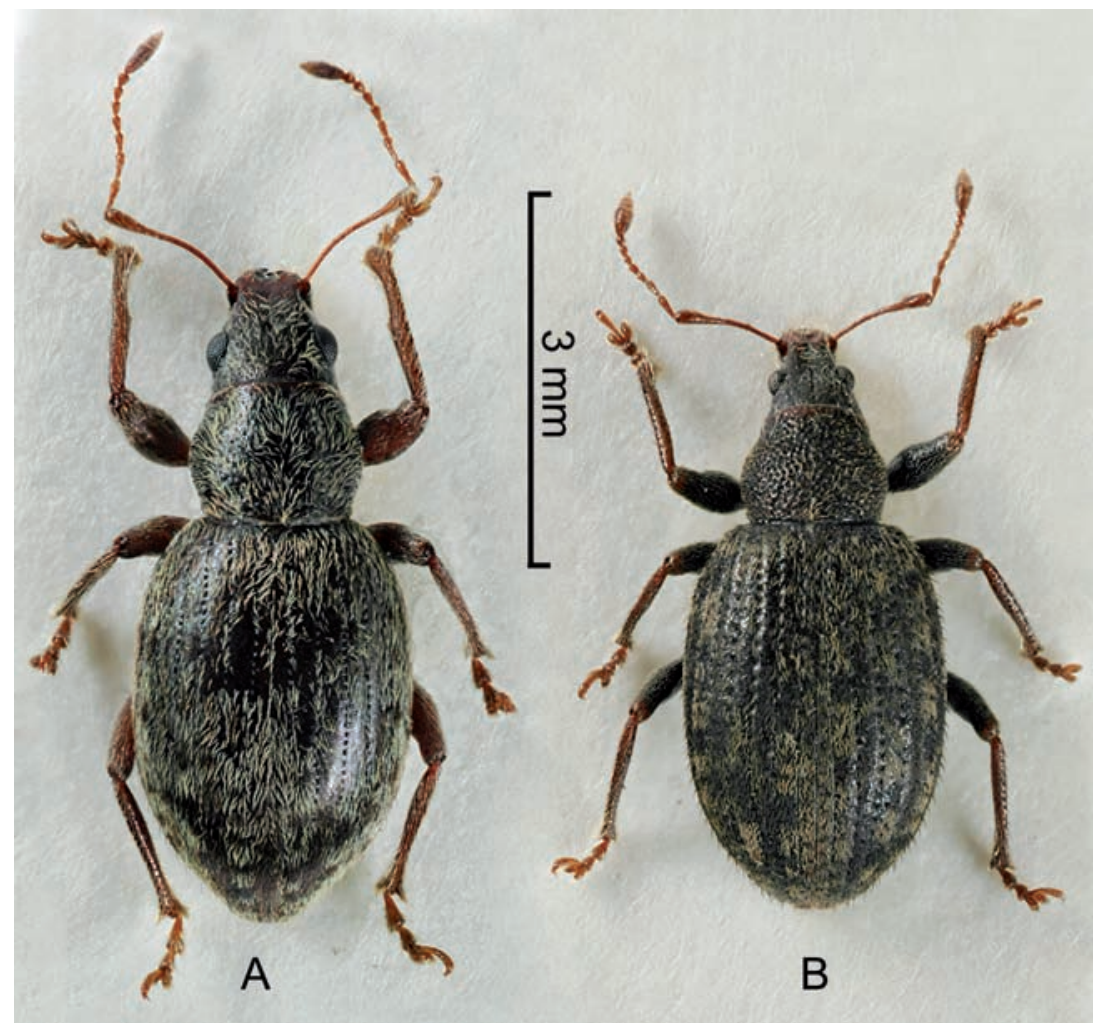

exx 7-12-2004 leg A. Machado (AMC), 23 exx 4-12-2004 leg. A. Aguiar (AAC). Roque de los Muchachos 2100 m, 37 exx. leg. A. Machado (AMC); 2426 m 2 exx 4-3-1994 leg P. Sprick (PS); 6 exx 17-1-1986, 7 exx 7-2-2008 leg R. García (RGB), 5 exx (nr 1768) leg. H. Franz (NMW), 2 exx 4-12-2004 leg. A. Aguiar (AAC), 1 ex 25-4-2001 leg. T. Domingo-Quero (MNHN).

No paratipos: Pinar de Garafía km 34, 1900 m 35 exx leg A. Machado (AMC). Pico de las Nieves 1 ex 21-4-1989 leg J. Messutat (JM). Puntagorda: Jieque 2000 m 20 exx 11-2-2004, Pico de La Cruz 6 exx 17-1-1986, 7-2-2008 leg R. García (RGB). Los Andenes 8 exx 7-2-2008 leg. R. García (RGB). Las Tricias 600 m , 1 ex 3-3-1994, Casas Roque Faro 800 m, 3 exx 3-3-31994 leg. P. Sprick (PS); Las Goteras (Garafía) 1100 m, 6 exx 6-12-2004, Carretera Juan Adalid 600 m, 2 exx 5-122004, Cueva de La Zarza $980 \mathrm{~m} 1$ ex 30-1-2001 leg. A. Machado (AMC).

LOCALIDAD TÍPICA. Las Moradas, municipio de Garafía, La Palma, islas Canarias. UTM 28R 02163903185800 .

MedidAs DEL HOLOTIPO $\left(\sigma^{t}\right)$. Longitud: total ( $\mathrm{sin}$ rostro) $4,62 \mathrm{~mm}$, rostro $0,48 \mathrm{~mm}$, escapo $1,14 \mathrm{~mm}$, funículo 1,20 (desmómeros I-IV respectivamente $0,30 / 0,25 / 0,17 / 0,12 \mathrm{~mm})$, maza $0,44 \mathrm{~mm}$, pronoto $1,08 \mathrm{~mm}$, élitros $3,35 \mathrm{~mm}$, tibias (pro- /meso/meta-) 1,17/1,18/1,22 mm. Anchura: cabeza (a nivel de los ojos) $1,02 \mathrm{~mm}$, (interocular) $0,65 \mathrm{~mm}$; rostro (a nivel de los pterigios) 0,65 $\mathrm{mm}$, (mínimo dorsal) $0,46 \mathrm{~mm}$ (mínimo ventral) $0,67 \mathrm{~mm}$; escapo $0,10 \mathrm{~mm}$, maza $0,13 \mathrm{~mm}$, pronoto (anterior /máxima /posterior) 1,08 / 1,34/ 1,14 mm y élitros (máxima) 2,23 mm. Altura: abdomen 1,54 mm.

DESCRIPCIÓn. Machos: Talla: 3,9-5,5 mm. Laparocerus pequeño de aspecto oblongo-ovalado, convexo. Tegumento subnítido, de color pardo, ennegrecido en cabeza, pronoto y maza, pardo-rojizo en extremidades y margen anterior del pronoto; revestimiento de abundantes escamitas lanceoladas adpresas o muy tumbadas de color flavo/glauco (dominantes) o hialinas, fácilmente desprendibles. Élitros con revestimiento blanquecino uniforme o con algunos parches oscuros (setas hialinas) en las interestrías pares poco destacados; algunas sedas sobresalientes hacia el ápice.

Antenas cortas; escapo sinuoso en el medio, apenas más largo que el pronoto, capitado en su cuarto apical; funículo 1,1x tan largo como el escapo, desmómero II algo más corto que el I (más robusto), y el III más largo que el IV; maza elíptica, grande, más larga que los tres desmómeros precedentes reunidos.

Cabeza relativamente grande, rostro corto (L/A $=0,6)$, dorso marcadamente trapezoide, de lados 

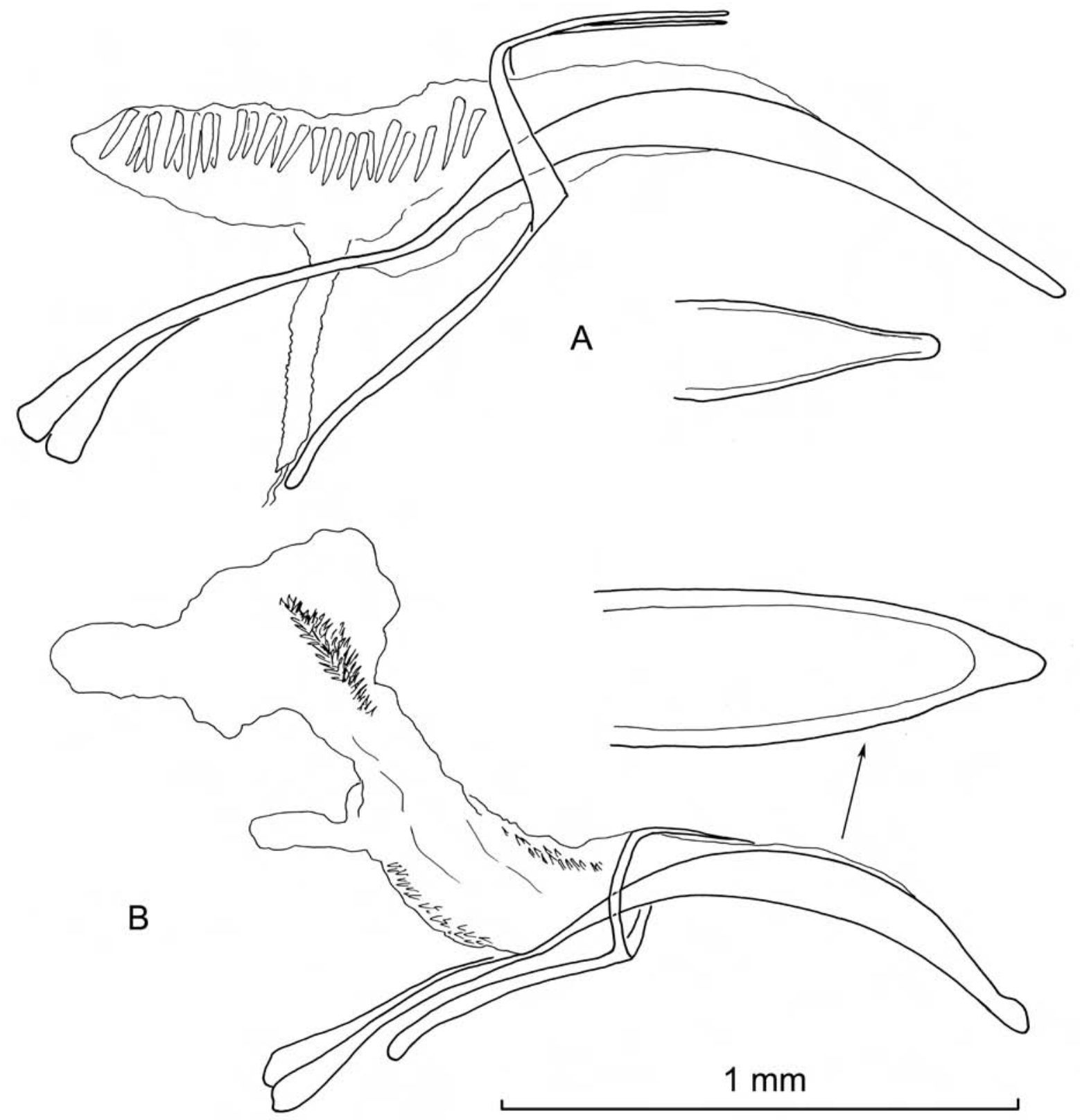

Fig. 19.- Edeago y detalle del ápice del lóbulo medio: Laparocerus decipiens n. sp. (A) y Laparocerus morrisi n. sp. (B).

Fig. 19.- Aedeagi and detail of median lobe apex: Laparocerus decipiens n. sp. (A), and Laparocerus morrisi n. sp. (B).

romos; placa prorrostral poco diferenciada, punteada; quilla epistomal poco definida; pterigios breves, poco salientes; frente apenas o nada deprimida (en el mismo plano que el prorrostro), fóvea frontal romboidal, estrecha, prolongada por el prorrostro como línea fina. Ojos grandes $(\mathrm{L} / \mathrm{A}=1,2)$, modera- damente prominentes (convexidad 30\%), próximos al borde frontal.

Pronoto transversal $(\mathrm{L} / \mathrm{A}=0,8)$, lados bastante curvados, máxima anchura en el medio; base algo convexa en el tramo medio, margen anterior prolongado hacia delante (collarín de color rojizo); sin 


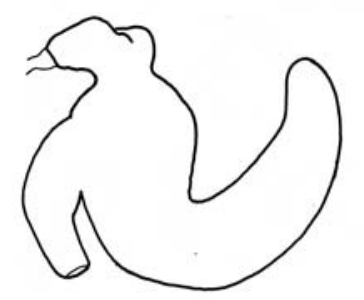

A
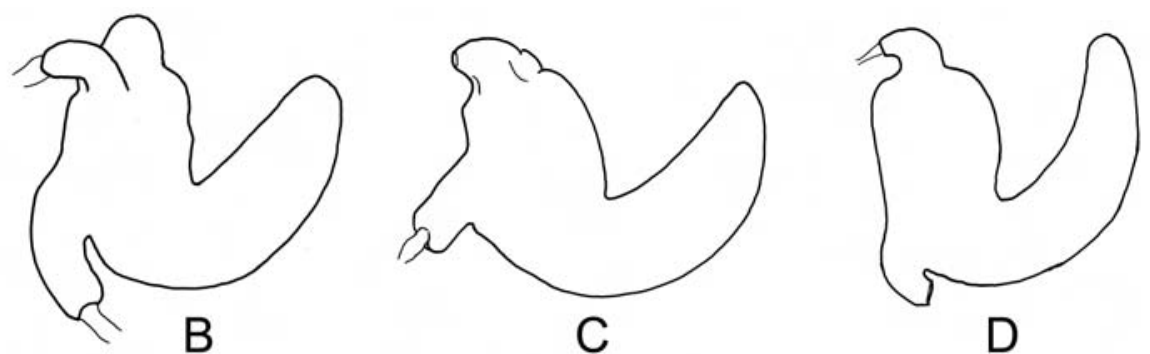

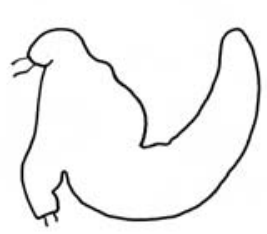

E

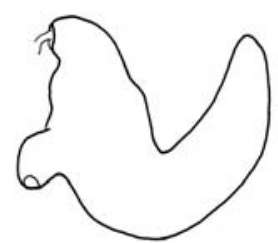

$\mathrm{F}$

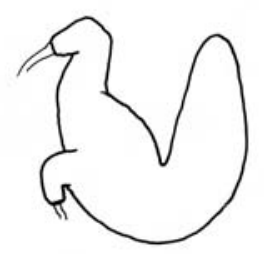

G

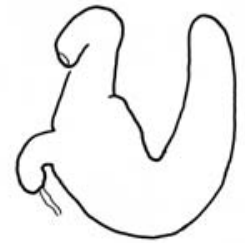

$\mathrm{H}$
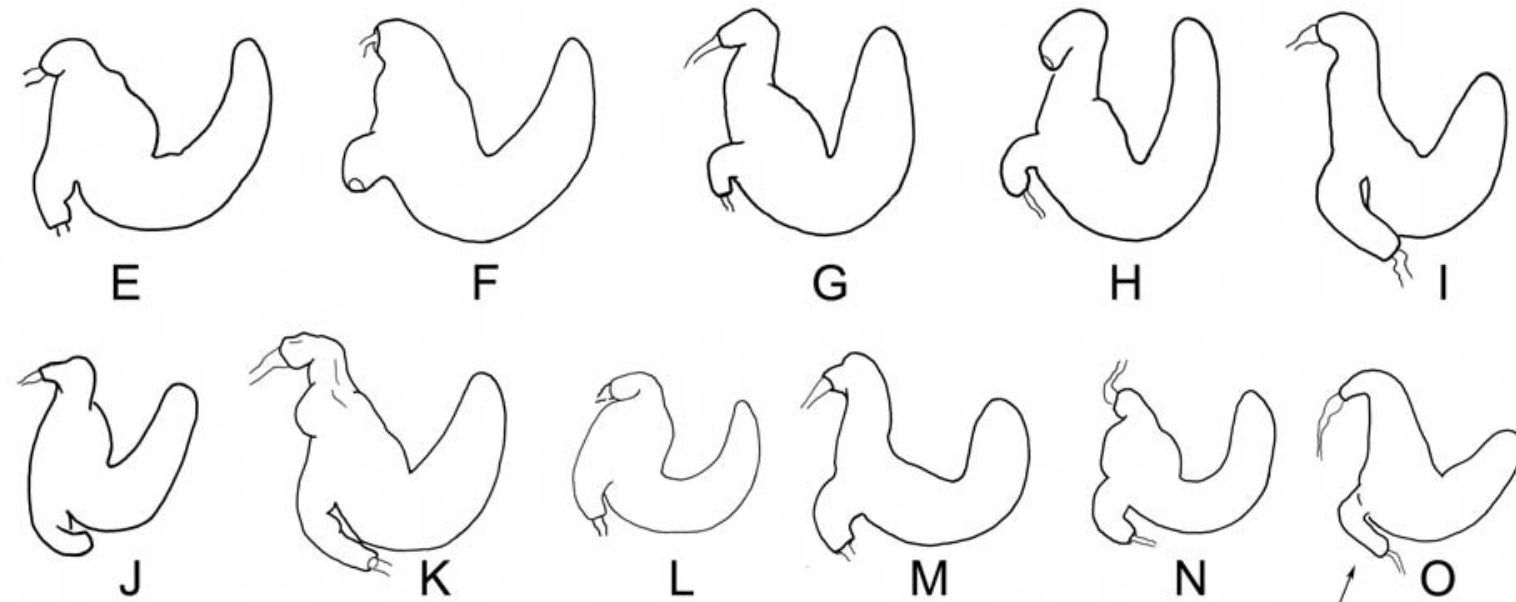

$1 \mathrm{~mm}$
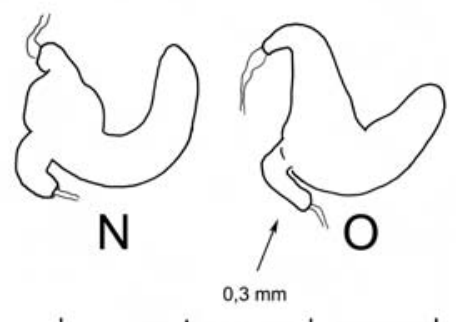

Fig. 20.- Espermateca: Laparocerus aeneotinctus n. sp. (A), Laparocerus femoralis n. sp. (B), Laparocerus acyphus $\mathbf{n} . \mathbf{s p .}$ (C), Laparocerus arrochai $\mathbf{n} . \mathbf{s p}$. (D), Laparocerus cristatus n. sp. (E), Laparocerus tanausu n. sp. (F), Laparocerus elongatus n. sp. (G), Laparocerus mucronatus n. sp. (H), Laparocerus feloi $\mathbf{n} . \mathbf{s p .}$ (I), Laparocerus astralis $\mathbf{n} . \mathbf{s p}$. (J), Laparocerus supranubius $\mathbf{n}$. sp. (K), Laparocerus orone aridane n. ssp. (L), Laparocerus amicorum n. sp. (M), Laparocerus decipiens n. sp. (N), y Laparocerus morrisi n. sp. (O).

Fig. 20.- Spermatheca: Laparocerus aeneotinctus n. sp. (A), Laparocerus femoralis n. sp. (B), Laparocerus acyphus n. sp. (C), Laparocerus arrochai $\mathbf{n}$. sp. (D), Laparocerus cristatus $\mathbf{n}$. sp. (E), Laparocerus tanausu n. sp. (F), Laparocerus elongatus $\mathbf{n} . \mathbf{s p .}$ (G), Laparocerus mucronatus n. sp. (H), Laparocerus feloi $\mathbf{n} . \mathbf{s p .}$ (I), Laparocerus astralis $\mathbf{n} . \mathbf{s p .}$. (J), Laparocerus supranubius $\mathbf{n}$. sp. (K), Laparocerus orone aridane n. ssp. (L), Laparocerus amicorum n. sp. (M), Laparocerus decipiens n. sp. (N), and Laparocerus morrisi n. sp. (O).

línea media. Tegumento con punteado fino, doble y superficial (puntos mayores de diámetro doble que los pequeños).

Escudete triangular, amplio.

Élitros convexos (80\%), oblongo-ovalados (L/A $=1,5)$, algo acuminados en el ápice, sin hombros y lados poco curvados en su tramo medio; $3,1 \mathrm{x}$ la longitud del pronoto y $1,7 \mathrm{x}$ su anchura. Estrías finamente punteadas, interestrías planas, 10-12 escamitas a lo ancho (escamas tan largas como la uña metatarsal); sedas claras y oscuras sobresalientes e inclinadas hacia atrás en el tercio apical, menos desarrolladas hacia la base (flancos).
Cara ventral: esternitos abdominales finamente rebordeados, con abundantes escamitas piliformes; el $5^{\circ}$ truncado apicalmente. Saliente intermesocoxal estrecho, romo y poco levantado.

Patas de complexión normal; tibias casi igual de largas, armadas con mucrón agudo; protibia apicalmente expandida en abanico, bruscamente escotada por dentro en la mitad anterior (escotadura terminando usualmente en un breve dientecillo mediano). Tarsómeros finos y delicados.

Edeago de punta estrecha y afilada, con el ápice romo; apertura ventral a partir de la mitad de lóbulo medio; saco interno en reposo rebasa apenas los temo- 
nes, con dos largas hileras de 14 dientes muy grandes en su mitad distal (divertículo ciego) (Fig. 19A).

Hembras. Talla 4,2-5,3 mm. Igual que el macho pero el punteado del pronoto mejor definido; élitros notoriamente más cortos, anchos y globosos $(\mathrm{L} / \mathrm{A}=$ $1,3)$, de lados poco curvados en su tramo medio, la punta acuminada más aguda y abruptamente diferenciada, a modo de "pico" breve; las sedas sobresalientes más largas (casi el doble que una escamita); mesomucrón reducido y metamucrón ausente. Esternito abdominal $5^{\circ}$ de ápice curvado. Urosternito VIII y espermateca, figuras 12I y 20N, respectivamente.

Etimología. El epíteto latino decipiens es un participio invariable que significa que engaña o defrauda, en alusión al pobre desarrollo que presenta el gránulo basal, el puntuado del pronoto, o la pilosidad elitral que caracterizan a las otras dos especies de su grupo.

OBSERVACIONES. Laparocerus decipiens $\mathrm{n}$. sp. es la especie palmera vicariante de L. puncticollis Wollaston, 1864, de la isla de El Hierro, y de $L$. indutus Wollaston, 1865 (stat. prom.), descrita de La Gomera como subespecie de la anterior, y que merece ser elevada de rango. Las tres especies comparten la característica escotadura en la mitad distal de las protibias masculinas, pero $L$. decipiens se diferencia de las otras dos por ser más ovalada, por tener los tegumentos menos brillantes, el punteado de la cabeza y pronoto fino y mucho menos desarrollado (muy grosero y casi varioloso en $L$ puncticollis), las escamitas son flavas o glaucas (dominan las doradas en las otras dos especies), y las sedas elitrales están mucho menos desarrolladas y casi reducidas al tercio apical, siendo más largas, erectas (3x longitud de escamas) y extendidas por todo el élitro en L. indutus. En L. puncticollis hay algunas cerdas también en el pronoto, y las de los élitros son mucho más abundantes, recias y oscuras (aspecto general bastante hirsuto). La base del pronto femenino carece de la gibosidad típica de $L$. puncticollis o de la corta quilla de L. indutus. Además, los élitros de las hembras son más redondeados, mientras que en las otras especies su aspecto es trapezoide con lados subrectos, ligeramente convergentes hacia el ápice (la máxima anchura se alcanza hacia la base). El saco interno del endofalo porta unos 28 grandes dientes en $L$. decipiens, unos 20 (más pequeños) en L. puncticollis, y de 6 a 9 en L. indutus.

Algunos ejemplares de L. decipiens colectados a altitudes más bajas $(600-1000 \mathrm{~m})$ presentan las interestrías elitrales subconvexas y las sedas se extienden más hacia la base del élitro, siendo igualmente finas, cortas e inclinadas.

En la isla de La Palma, es la única especie de talla pequeña cuyos machos presentan las protibias bruscamente escotadas por dentro.

DistRIBUCIÓN Y ECOLOGÍA. Laparocerus decipiens $\mathrm{n}$. sp. es endémico de la isla de La Palma, siendo particularmente común y abundante en el matorral de alta montaña (1900-2300 m de altitud), donde se alimenta de leguminosas, preferentemente de codesos (Adenocarpus viscosus spartioides), y también de retama (Spartocytisus supranubius). No obstante, su área de distribución se extiende por la mitad occidental de la fachada norte de la isla hasta cotas más bajas $(600 \mathrm{~m})$, colectándose ocasionalmente en ambiente de pinar canario o monteverde. Es un insecto nocturno propio de los meses húmedos (diciembre-abril).

\section{Laparocerus morrisi $\mathrm{n}$. sp.}

(Figs. 18B, 19B y 12B)

Material examinado. La Palma. Holotipo $10^{\pi}$ Las Moradas (Garafía) $2000 \mathrm{~m} \mathrm{21-11-2002} \mathrm{leg.} \mathrm{A.} \mathrm{Machado} \mathrm{(TFMC} \mathrm{n}{ }^{\circ}$ 15944).- Paratipos: Misma localidad, 2 exx 30-11-2000 leg M.G. Morris (MM), 5 exx 21-11-2002, 5 exx 7-12-2004 leg A. Machado (AMC), 3 exx 4-12-2004 leg. R. García (RGB), 7 exx 4-12-2004 leg. A. Aguiar (AAC). Roque de Los Muchachos, $2300 \mathrm{~m} 4$ exx 4-12-2004 leg. A. Machado (AMC), 10 exx leg H. Franz (NMW).

LOCALIDAD TíPICA. Las Moradas, municipio de Garafía, La Palma, islas Canarias. UTM 28R 02163903185800 .

MEDIDAS DEL HOLOTIPO $\left(\mathrm{O}^{\mathrm{T}}\right)$. Longitud: total ( $\mathrm{sin}$ rostro) $4,2 \mathrm{~mm}$, rostro $0,60 \mathrm{~mm}$, escapo $1,22 \mathrm{~mm}$, funículo 0,80 (desmómeros I-IV respectivamente $0,20 / 0,18 / 0,09 / 0,10 \mathrm{~mm}$ ), maza $0,34 \mathrm{~mm}$, ojo $0,22 \mathrm{~mm}$, pronoto $0,97 \mathrm{~mm}$, élitros $3,02 \mathrm{~mm}$, tibias (pro- /meso- /meta-) 1,06/0,98/1,14 mm. Anchura: cabeza (a nivel de los ojos) 0,66 mm, (interocular) $0,39 \mathrm{~mm}$; rostro (a nivel de los pterigios) $0,48 \mathrm{~mm}$, (mínimo dorsal) $0,30 \mathrm{~mm}$ (mínimo ventral) 0,42 $\mathrm{mm}$; escapo $0,10 \mathrm{~mm}$, maza $0,14 \mathrm{~mm}$, ojo $0,19 \mathrm{~mm}$, pronoto (anterior /máxima /posterior) 0,78 / 1,13/ $0,98 \mathrm{~mm}$ y élitros (máxima) 2,07 mm. Altura: abdomen 1,50 mm.

DESCRIPCIÓN. Machos: Talla: 3,8-4,6 mm. Laparocerus de talla reducida, aspecto ovoide-alargado con cabeza pequeña y extremidades cortas; tegumento de color pardo negruzco, parcialmente 
rojizo en tibias y antenas, élitros erizados de cerdas negras cortas arqueadas, con revestimiento poco denso de escamas lanceoladas adpresas doradas e hialinas formando dibujo en teselas.

Antenas cortas; escapo recio doblado al medio fino, $0,90 \mathrm{x}$ la longitud del pronoto, suavemente capitado en el tercio apical; funículo 0,90x la longitud del escapo, desmómero I algo más robusto que el II, el III y IV iguales, cortos, V-VII globulares; maza elíptica, gruesa, muy grande (L/A = 2,43 ), terminada en punta fina, mayor que los cuatro desmómeros precedentes reunidos.

Cabeza muy pequeña, de aspecto cónico; rostro cuadrangular, elongado; pterigios largos, prominentes; prorrostro liso con quilla espistomal completa, poco desarrollada; metarrostro de lados algo convergentes hacia delante, acanalado; frente deprimida de lado a lado, surco medio estrecho prolongado hacia delante y atrás (incluido vértice), fóvea indistinta, Ojos pequeños, moruloides, bastante redondeados $(\mathrm{L} / \mathrm{A}=1,15)$, prominentes $(37-40 \%)$, distantes del canto lateral de la frente. Tegumento punteadoruguloso, con escamitas sueltas.

Pronoto transversal $(\mathrm{L} / \mathrm{A}=0,85)$, poco convexo, sin rebordes, constreñido por delante, lados uniformemente curvos (salvo tramo anterior), máxima anchura a la mitad. Punteado muy grueso, foveiforme, apretado (casi coalescente); tegumento con microrreticulación poligonal y escamitas dispersas.

Escudete pequeño, con escamitas.

Élitros voluminosos (3,1x tan largos y 1,8x tan anchos como el pronoto), ovales ( $\mathrm{L} / \mathrm{A}>1,45)$, disco poco convexo, lados más o menos curvados, máxima anchura en la medio, declive apical y lateral suave $\left(8^{\mathrm{a}}\right.$ interestría visible desde arriba en la mitad anterior); truncados en la base, hombros poco salientes, callo humeral más o menos desarrollado. Estrías con puntos gruesos separados un diámetro; interestrías subconvexas, con 6-7 escamitas a lo ancho (grosor /color varía por tramos) y varias hileras de cerdas negras erectas, arqueadas hacia atrás, tan largas como una uña (dando un aspecto erizado).

Patas cortas, recias; protibia con ángulo apical externo obtuso y romo, el interno agudo, expandido. Mucrón enorme, grande y pequeño en protibia, mesotibia y metatibia, respectivamente, siempre agudo. Artejo tarsal I corto, el II transversal.

Cara ventral con pilosidad fina y rala, escamitas testáceas concentradas en mesoepisternitos y metasterno. Saliente intermesocoxal apenas desarrollado. Esternito $1^{\circ}-2^{\circ}$ con microrreticulación rugosa transversal, $3^{\circ}-4^{\circ}$ poligonal salvo el margen posterior, liso birillante (con fino reborde claro).
Último esternito ampliamente truncado, con leve escotadura al medio.

Edeago poco arqueado, punta en vista dorsal estrecha, triangular, y vista de perfil con cresta leve; saco interno moderadamente largo, con dos campos de dentículos basales y uno mayor en el divertículo ciego (Fig. 19B).

Hembras. Talla 3,7-4,2 $\mathrm{mm}$. Muy parecidas a los machos, generalmente menores, estrangulamiento anterior del pronoto más pronunciado; élitros más cortos y ovoides $(\mathrm{L} / \mathrm{A}<1,45)$, callo humeral más marcado, tibias armadas pero mucrones bastante más pequeños; último esternito abdominal de borde curvado. Urosternito VIII (Fig. 12B), espermateca (Fig. 19B).

Etimología. Laparocerus morrisi n. sp. está dedicada al entomólogo inglés especialista en curculiónidos Mike G. Morris, de Dorchester, cuyos libros sirvieron en su día para introducirme en el conocimiento del grupo, y de quien recibí los primeros ejemplares de esta especie para estudio.

OBSERVACIONES. Laparocerus morrisi n. sp. pertenece al grupo de L. mendicus Wollaston, 1864 (datos moleculares pendientes de publicar) y es el vicariante palmero de L. exiguus Machado, 2007 endémico de La Gomera, con el que comparte el aspecto general, al igual que el mismo modo de vida (ver apartado siguiente). Se diferencia de éste por ser de tamaño generalmente mayor, cuerpo más alargado (sobre todo los $\sigma^{7} \sigma^{7}$ ), el rostro menos trapezoide y más largo, surco frontal desarrollado (fóvea corta en L. exiguus) y, sobre todo, por el punteado del pronoto muchísimo más grande y abigarrado (varioloso). El saco interno del edeago es bastante más largo y los campos de dentículos están mucho más desarrollados.

No cabe confundir L. morrisi n. sp. con ningún otro de los Laparocerus pequeños que viven en La Palma, por su cabeza notablemente reducida y de morro estrecho, ojos moruloides redondeados y prominentes, desmómeros funiculares V-VII globulares, punteado pronotal fortísimo, revestimiento de cerdas pequeñas extendida sobre todo el élitro, y tibias con enormes mucrones y sin escotaduras de ningún tipo.

DisTRIBUCIÓN Y ECOLOGÍA. Laparocerus morrisi n. sp. es un endemismo de las cumbres más altas de la isla de La Palma, habitando en el matorral de alta montaña despejado o en zona de transición, mezclado con pinos canarios (2000 m de altitud). Pertenece al grupo de pequeños Laparocerus (opacos e hirsu- 


\section{CLAVE DE LAS ESPECIES DE LAPAROCERUS DE LA ISLA DE LA PALMA}

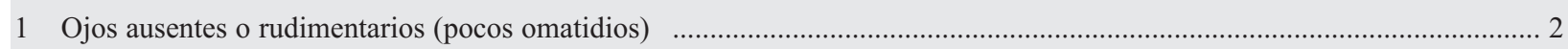

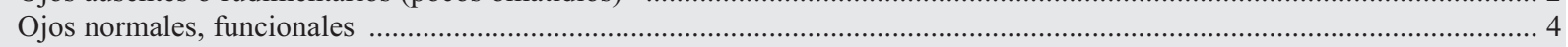

2 Pronoto con punteado menudo disperso sobre tegumento brillante y sin escamas

Laparocerus (Machadotrox) machadoi García, 2006

Pronoto con grandes puntos profundos más o menos coalescentes, con escamitas sobresalientes (bien visibles en los flancos)

3 Élitros con hombros avanzados y margen lateral acanalado ( $7^{\mathrm{a}}$ interestría reflejada en toda su longitud)

Laparocerus (Machadotrox) zarazagai García \& Oromí, 1997

Élitros con hombros romos y margen lateral normal ( $7^{\mathrm{a}}$ interestría normal, subconvexa)

Laparocerus (Machadotrox) dacilae García, 1998

4 Ojos emplazados a la mitad del flanco lateral de la cápsula cefálica, muy alejados del canto lateral de la frente: rostro pro-

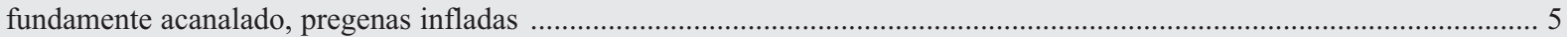

- Ojos emplazados tangentes o próximos al canto lateral de la frente, por encima de la mitad del flanco lateral de la cápsula cefálica; rostro poco o nada acanalado, pregenas normales

5 Pronoto con una carena mediana levantada a todo lo largo. Talla ( $\sin$ rostro) $>6,5 \mathrm{~mm}$

Pronoto sin carena mediana especial. Tallas $<6,5 \mathrm{~mm}$

Laparocerus (Amyntas) cristatus n. sp.

6 Élitros con escamas espatuliformes sobresalientes concentradas sobre grandes tubérculos gibosos. 8 interestría visible desde arriba en la región posthumeral en forma de tubérculo puntiagudo

.Laparocerus (Fernandezius) sculptipennis Wollaston, 1864

Élitros con hileras más o menos regulares de escamas espatuliformes sobresalientes; $8^{\mathrm{a}}$ interestría visible en forma de tumefacción posthumeral alargada

7 Interestrías no carenadas (salvo en el tercio apical) con una hilera regular de escamas sobresalientes; tumefacción visible de la $8^{\mathrm{a}}$ interestría en forma de arco alargado ................... Laparocerus (Fernandezius) tesserula seriesetosus Wollaston, 1854 Interestrías impares carenadas o con tubérculos (particularmente en los flancos), las hileras de sedas más abiertas e irregulares; la tumefacción visible de la $8^{\mathrm{a}}$ interestría en forma de tubérculo binodal

Laparocerus (Fernandezius) subnosodus palmensis Roudier, 1957

8 Élitros en toda su extensión con abundantes pelos finos sedosos y largos, tanto o más largos que el primer metatarsómero .... 9

- Élitros glabros, con cerdas recurvadas, sedas o pelos erguidos más cortos que el primer metatarsómero o restringidos al tercio apical

9 Élitros deprimidos, amplios, acuminados apicalmente, de tegumento alutáceo .... Laparocerus lepidopterus Wollaston, 1864

- Élitros globosos de tegumento brillante o metálico

10 Élitros con interestrías impares lisas; escudete normal, en el mismo plano que el disco elitral

Laparocerus cf. vestitus Wollaston, 1864

Élitros con interestrías impares con abultamientos en su mitad apical; escudete pequeño (visto desde arriba), dispuesto en plano inclinado o vertical sobre el grueso borde basal del élitro ...... Laparocerus inaequalis globulipennis Wollaston, 1864

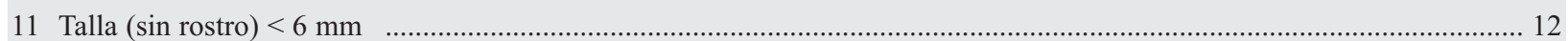

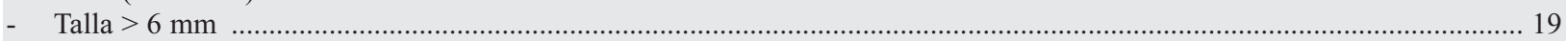

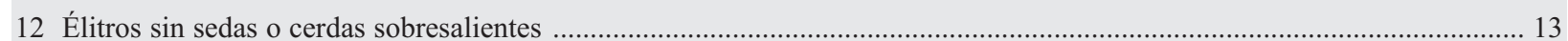

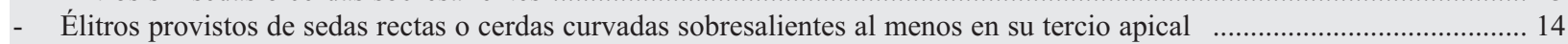

13 Frente lisa; pronoto con puntos superficiales separados sobre fondo alutáceo; élitros ovoides ...... Laparocerus amicorum n. sp.

- Frente fuertemente deprimida de lado a lado; pronoto con punteado grueso varioloso sobre fondo brillante; élitros oblongoacuminados

Laparocerus orone aridane $\mathrm{n}$. ssp.

14 Protibias expandidas en el ápice hacia ambos lados (en "abanico")

Protibias no expandidas apicalmente hacia fuera (ángulo externo romo)

15 Cabeza alargada, más ancha a nivel de cuello que de ojos. Élitros elongados, con hileras de sedas claras erectas bastante separadas. Protibias $\sigma^{7} \sigma^{7}$ sin escotadura

Laparocerus supranubius $\mathrm{n}$. $\mathrm{sp}$.

- Cabeza corta, trapezoidal, más ancha a nivel de ojos que de cuello. Élitros ovoides, con sedas sueltas y más tumbadas, en la mitad apical. Protibias $\sigma^{7} \sigma^{7}$ con fuerte escotadura en su margen interior

Laparocerus decipiens $\mathrm{n}$. $\mathrm{sp}$.

16 Ojos prominentes, subcónicos y asimétricos (cenit desplazado hacia atrás). Pronoto con línea media algo levantada en $\sigma^{7} \sigma^{7}$, fuertemente giboso en 우 우

- Ojos de convexidad normal, simétrica. Pronoto sin gibosidad mediana Laparocerus (Guanchotrox) astralis n. sp.

Pronoto sin gibosidad mediana _......................................................................... 17 
17 Cabeza muy pequeña con rostro estrecho. Élitros erizados de cerdas negras cortas arqueadas hacia atrás y bien visibles. Ángulo externo de la protibia $\sigma^{\top} \sigma^{\top}$ ampliamente curvado .................................................................. Laparocerus morrisi $\mathrm{n}$. $\mathrm{sp}$.

- Cabeza ancha, rostro corto y más o menos trapezoidal; cerdas no sobresalientes o solo en la mitad apical. Protibia $\sigma^{\top} \sigma^{\top}$ apicalmente roma

18 Pronoto con punteado fino, denso. Metarrostro muy estrangulado a nivel de las antenas; pterigios auriculariformes, claramente sobresalientes

Laparocerus palmensis Harald Lindberg, 1953

- Pronoto con punteado grueso, abigarrado. Metarrostro menos estrangulado a nivel de las antenas; pterigios paralelos apenas salientes

Laparocerus $c f$. tessellatus (Brullé, 1839)

19 Escudete minúsculo, granular (visto desde arriba), dispuesto en vertical sobre el grueso borde anterior de los élitros ......... 20

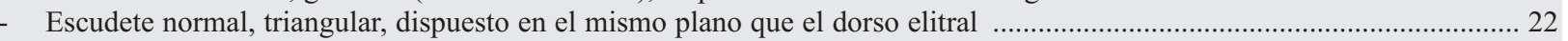

$208^{\mathrm{a}}$ interestría asomando en la región posthumeral y visible desde arriba

-
21
Insecto interestría oculta por el borde del élitro en vista dorsal

Laparocerus (Amyntas) cf. fernandezi Roudier, 1957

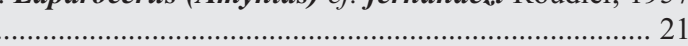

$\sigma^{x}$ con un pequeño alerón ante-apical en su cara interna .............

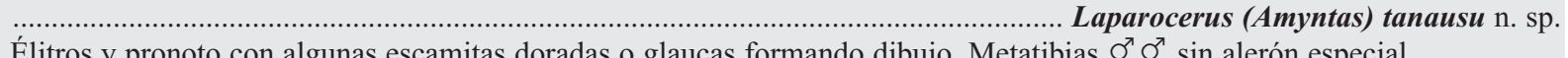
(Amyntas) arrochai $\mathrm{n} . \mathrm{sp}$.

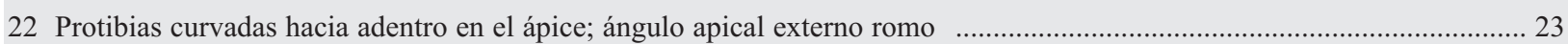

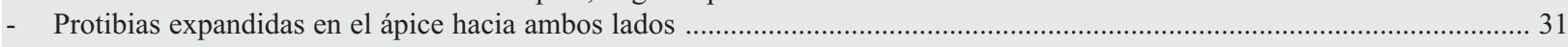

23 Élitros elípticos, muy anchos al medio y fuertemente estrechados en la base, sin hombros, con algunos pelos largos de color claro sobresalientes en el tercio apical ................................................................. Laparocerus ellipticus Wollaston, 1863

Élitros con hombros bien definidos, amplios o cortos, con o sin sedas recias, pero no pelos finos sedosos ....................... 24

24 Élitros a todo lo largo con sedas negras sobresalientes erguidas o algo inclinadas, más largas que una uña (a veces decrecien-

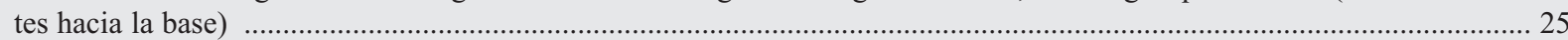

- Élitros con sedas negras más cortas que una uña, tumbadas o limitadas a la mitad o tercio apical ...................................... 26

25 Élitros subtriangulares, de base muy ancha, hombros muy desarrollados y prominentes ...... \& Laparocerus elongatus n. sp. Élitros oblongos, estrechándose hacia la base; los hombros breves, poco llamativos ................... Laparocerus tarsalis n. sp.

26 Pronoto con puntos gruesos profundos y precisos separados un diámetro o menos entre sí, sobre fondo alutáceo densamente micropunteado

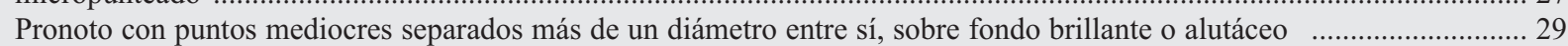

27 Élitros sin tumefacción sutural en la región postescutelar; en las 우 우 de lados curvados, parecidos a los $0^{7} \sigma^{7}$

Laparocerus acyphys $\mathrm{n}$. $\mathrm{sp}$.

Élitros con tumefacción sutural en la región postescutelar (menos desarrollada en $\sigma^{\top} \sigma^{\top}$ que en 우 우); en las hembras con base cuadrangular y lados subparalelos

28 Fémures anteriores muy inflados, con declive preapical brusco (grosor máximo/grosor quinto apical $=1,7$ )

- Fémures anteriores de configuración normal (grosor máximo/grosor quinto apical $=1,45$ )

Laparocerus femoralis n. $\mathrm{sp}$.

29. Metatibia progresivamente engrosada hacia el ápice hasta alcanzar el doble del grosor de su base, truncada oblicuamente ....

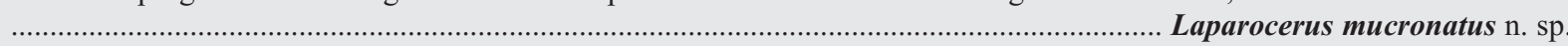

Metatibia normal, poco engrosada hacia el ápice y truncada perpendicularmente

Laparocerus mucronatus n. sp.

30 Élitros oval-alargados, con hombros redondeados. Metatibias ligeramente aserradas en el canto interno distal

Laparocerus feloi $\mathrm{n}$. sp.

Élitros elongado-acuminados, hombros angulosos, con breve callo humeral. Metatibias sin dientecillos preapicales en su canto interno

$\sigma^{7}$ Laparocerus elongatus $\mathrm{n}$. $\mathrm{sp}$.

31 Élitros con hileras de escamas blancas setiformes largas y erguidas (tanto o más largas que una uña). Protibias $\sigma^{7} \sigma^{7}$ no escotadas por dentro ....................................................................... Laparocerus (Machadotrox) combrecitensis Roudier, 1957

- Élitros desprovistos de sedas largas. Protibias $\sigma^{\pi} \sigma^{\pi}$ fuertemente escotadas en más de la mitad de su cara interna 32

32 Pronoto con punteado fino y abigarrado. Élitros con pubescencia rubia de escamitas setiformes retorcidas diminutas ............ Laparocerus (Machadotrox) sculptus (Brullé, 1839) Pronoto con doble punteado abierto de puntos pequeños y mediocres, sobre fondo brillante. Élitros con algunos pelitos microscópicos aislados en la interestrías

Laparocerus (Machadotrox) laevis Roudier, 1957 


\section{KEY TO THE SPECIES OF LAPAROCERUS FROM LA PALMA ISLAND}

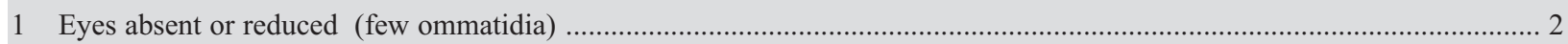

Eyes normal, functional

2 Pronotum with small punctures on shiny integument, without scales ...... Laparocerus (Machadotrox) machadoi García, 2006 Pronotum with large deep punctures more or less coalescent, with protruding scales (visible at best on the sides) .................. 3

3 Elytra with protruding humeri and canaliculate lateral margins ( 7 th interval reflexed in all its length)

Laparocerus (Machadotrox) zarazagai García \& Oromí, 1997

Elytra with gently rounded humeri and lateral margin not canaliculate (7th interval normal, sub-convex)

Laparocerus (Machadotrox) dacilae García, 1998

4 Eyes placed at the middle of the sides of head capsule, distant from lateral border of frons: rostrum deeply canaliculate, pregenae inflated

Eyes placed tangentially or close to the lateral border of frons, above the middle of the lateral side of head capsule; rostrum not or hardly canaliculate, pregenae normal

5 Pronotum with a median keel along its length. Size (without rostrum) $>6.5 \mathrm{~mm}$

Laparocerus (Amyntas) cristatus n. sp.

Pronotum without any special dorsal keel. Size $<6.5 \mathrm{~mm}$

6 Elytra with long protruding spatulate scales concentrated on gibbous tubercles. 8th interval visible from above in the posthumeral region as a single-pointed tubercle

Laparocerus (Fernandezius) sculptipennis Wollaston, 1864 Elytra with more or less regular rows of long spatulate protruding scales; 8th interval visible from above as a posthumeral elongate swelling

7 Intervals not carinate (except on apical third), with a regular row of protruding scales; posthumeral swelling of the 8th interval in the form of a long arc ..................................... Laparocerus (Fernandezius) tesserula seriesetosus Wollaston, 1854 Odd intervals carinate or with tubercles (particularly on the sides), rows of sedae more open and irregular; posthumeral swelling of 8 th interval with the form of a long two-pointed tubercle

Laparocerus (Fernandezius) subnosodus palmensis Roudier, 1957

8 Elytra with abundant long silky hairs all over, as long or longer than the first metatarsal joint

Elytra glabrous, with recumbent sedae, or upstanding sedae or hairs shorter than the first metatarsal joint, or restricted to the apical third

9 Elytra wide, depressed, with acuminate apex and alutaceous integument Elytra globose, with shiny or metallic integument

Laparocerus lepidopterus Wollaston, 1864

10 Odd intervals of elytra flat; scutellum normal, at the same level as the elytral disc

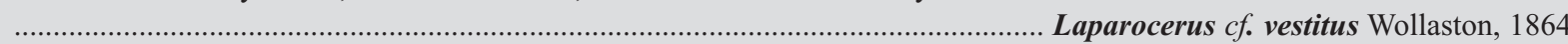
Odd intervals of elytra with swellings on their apical half; scutellum small (seen from above), placed obliquely on the thick anterior border of elytra Laparocerus inaequalis globulipennis Wollaston, 1864

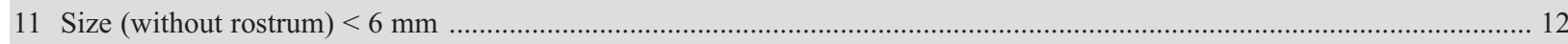

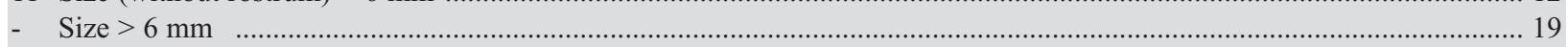

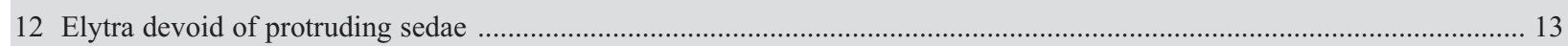

- Elytra with protruding recurved or straight sedae at least on their apical third ........................................................ 14

13 Frons flat; pronotum with superficial separated punctures on alutaceous integument; elytra ovate

Laparocerus amicorum n. sp. Frons deeply depressed from side to side; pronotum coarsely punctured on shiny integument; elytra elongate-acuminate ......

Laparocerus orone aridane $\mathrm{n} . \mathrm{ssp}$.

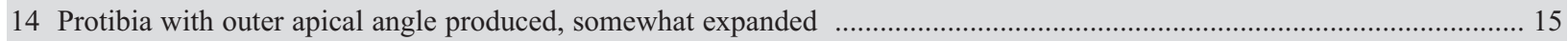

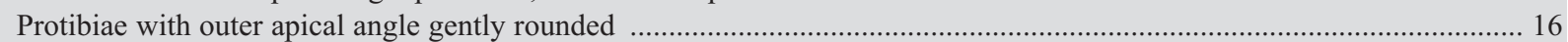

15 Head long, broader at base than at eye level. Elytra elongate, with open rows of whitish protruding sedae. Protibiae $\sigma^{\top} \sigma^{\top}$ normal, not scooped-out

Laparocerus supranubius n. sp. Head short, trapezoid, broader at eye level than at base. Elytra ovate, with sparser and more slanted sedae on their apical half. Protibiae $\sigma^{\pi} O^{7}$ strongly scooped-out at inner margin

Laparocerus decipiens $\mathrm{n}$. $\mathrm{sp}$.

16 Eyes prominent, sub-conical, asymmetrical (apex shifted backwards). Pronotum with median line slightly elevated in $\sigma^{7} \sigma^{7}$, strongly gibbous in 우 우 Laparocerus (Guanchotrox) astralis $\mathrm{n} . \mathrm{sp}$. Eyes normally and symmetrically convex. Pronotum without median gibbosity 
17 Head very small, with narrow rostrum. Elytra beset all over with conspicuous short curved black sedae. Outer angle of protibiae $\sigma^{\top} \sigma^{\pi}$ widely curved Laparocerus morrisi $\mathrm{n}$. sp. Head broad, with short trapezoid rostrum; sedae not clearly protruding or protruding only present in apical half. Apex of protibiae $\sigma^{7} \sigma^{7}$ blunt

18 Pronotum minutely and densely punctured. Metarostrum strongly constricted at the antennal insertion, pterygia curved, clearly protruding

Laparocerus palmensis Harald Lindberg, 1953 Pronotum large and coarsely punctured. Metarostrum less constricted; pterygia almost parallel, hardly protruding

Laparocerus cf. tessellatus (Brullé, 1839)

19 Scutellum minute, granular (seen from above), placed vertically on the thick basal border of the elytra .......................... 20

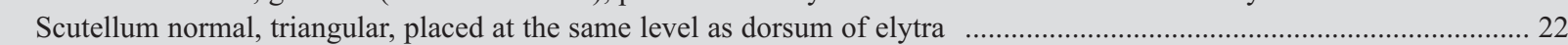

20 8th interval clearly visible from above at posthumeral region ............ Laparocerus (Amyntas) cf. fernandezi Roudier, 1957

- 8 th interval hidden by elytral margin (in dorsal view)

21 Completely black insect, devoid of pattern produced by scales. Metatibiae $\sigma^{\top} \sigma^{\top}$ with a small flattened amplification a little before its inner apex

Laparocerus (Amyntas) tanausu n. sp.

- Elytra and pronotum with some golden or glaucous scales forming a variable pattern. Metatibiae $O^{x} O^{x}$ without inner amplification Laparocerus (Amyntas) arrochai n. sp.

22 Protibiae curved inwards at apex; outer apical angle blunt Protibiae with outer apical angle produced, somewhat expanded

23 Elytra elliptical, broad at middle and strongly constricted at base, devoid of humeri; with some long testaceous hairs at apical third Laparocerus ellipticus Wollaston, 1863

- Elytra with well defined short or broad humeri, devoid of fine hairs, with or without stout sedae ................................... 24

24 Elytra covered all over with somewhat oblique protruding blackish sedae, longer than a claw ...................................... 25

- Elytra with blackish sedae shorter than a claw, pointing backwards or restricted to apical third ......................................... 26

25 Elytra sub-triangular, base very broad, humeri well developed, and prominent Elytra elongate, constricted towards base; humeri short, less noticeable

ㅇ Laparocerus elongatus $\mathrm{n} . \mathrm{sp}$ Laparocerus tarsalis $\mathrm{n}$. $\mathrm{sp}$.

26 Pronotum with large deep and precise punctures separated by one diameter between them, on alutaceous densely micro-punctured integument

- Pronotum with moderate punctures separated by more than one diameter between them, on shiny or alutaceous integument .... 29

27 Elytra without swelling in the post-scutellar region; in $ᄋ$ 우 with curved sides, similar to those of $\sigma^{7} \sigma^{7}$

Laparocerus acyphus n. sp. Elytra with a post-scutellar sutural swelling (less developed in $\sigma^{7} \sigma^{7}$ ); base in $ᄋ$ 우 almost quadrate, with subparallel sides .... 28

28 Fore femora strongly inflated, with sharp pre-apical declivity (maximal width/width of apical fifth $=1.7$ )

Fore femora normally configured (maximal width/width of apical fifth $=1.45$ )

Laparocerus femoralis $\mathrm{n} . \mathrm{sp}$.

29 Metatibiae evidently expanded towards apex (twice as broad at apex than at base), obliquely truncated

Laparocerus aeneotinctus $\mathrm{n}$. $\mathrm{sp}$.

Metatibiae normal, feebly expanded towards apex and perpendicularly truncated

Laparocerus mucronatus $\mathrm{n}$. $\mathrm{sp}$.

30 Elytra of long-ovate shape, humeri gently rounded. Metatibiae slightly serrate at inner apical edge

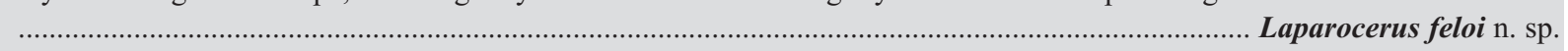

Elytra narrow, of elongate-acuminate shape, with short but angulose humeri. Metatibiae without pre-apical denticles on inner edge

$\sigma^{7}$ Laparocerus elongatus n. sp.

31 Elytra with rows of standing long setae-shaped whitish scales (as long as or longer than a claw). Protibiae $\sigma^{\top} \sigma^{7}$ with inner edge not excised Laparocerus (Machadotrox) combrecitensis Roudier, 1957

- Elytra devoid of long protruding scales or sedae. Protibiae $\sigma^{\top} \sigma^{\top}$ strongly excised more than half of their inner edge ......... 32

32 Pronotum finely and coarsely punctured. Elytra with yellowish pubescence of tiny recumbent linear scales

Laparocerus (Machadotrox) sculptus (Brullé, 1839) Pronotum with open puncturation of small and moderate punctures on shining integument. Elytra with some microscopic hairs isolated on the intervals (difficult to observe)

Laparocerus (Machadotrox) laevis Roudier, 1957 
tos) poco trepadores que se mueven preferentemente en el suelo o a muy escasa altura sobre plantas de poco porte o con ramas a ras de suelo. No es infrecuente obtener ejemplares con tierra adherida al tapiz de cerdas de los élitros (camuflaje). A pesar del frío propio de las cumbres, la especie está activa de noche en el otoño tardío e invierno, aunque se colecta con más facilidad tamizando al pie de sus plantas alimenticias. Entre éstas cuentan Lactuco-sonchus webbii (Asteraceae) y varias leguminosas: Lotus hillebrandi, Adenocarpus viscosus y Chamae-cytisus proliferus (Fabaceae).

\section{Sinonimia}

Roudier (1957) estableció la subespecie Laparocerus laevis politus sobre una única hembra colectada por M. Pécoud, sin indicación de localidad, con la siguiente caracterización: ojos más convexos, élitros casi cilíndricos, estrías más finas e interestrías absolutamente planas, y retículo transversal menos marcado. Salvo por los ojos, he encontrado ejemplares con esta morfología en el Roque de Bejenado, junto a otros normales. Además, y dada la proximidad a la localidad típica todo indica que se trata de una variación común por lo que es preferible suprimir la subespecie politus Roudier 1957 (= laevis Roudier 1957) nov. syn.

\section{AGRADECIMIENTOS}

El autor expresa su agradecimiento a todos los colegas que le permitieron estudiar el material de sus colecciones privadas, así como a los responsables de las colecciones institucionales que facilitaron el acceso a las mismas, entre ellas, al material proveniente del Inventario y Estudio de la Fauna Invertebrada del Parque Nacional de la Caldera de Taburiente (Convenio Parques Nacionales-CSIC). Los Drs Miguel Ángel Alonso Zarazaga y Antonio J. Velázquez de Castro revisaron el manuscrito y el Dr Michael Morris revisó la versión inglesa de las claves.

\section{Referencias}

Anguita, F., Márquez, A., Castiñeiras, P. \& Hernán, F., 2002. Los volcanes de Canarias. Guía geológica e itinerarios. Editorial Rueda, Alcorcón. 222 pp.

Crowson, R. A., 1983. The associations of Coleoptera with Ascomycetes. In: Q. Wheeler \& M. Blackwell (eds.). Fungus-insect relationships. Columbia University Press. New York: 256-280.

DAmoiseau, R., 1967. Monographie des Coléoptères Brentidae du Continent Africain. Annales du Musée royal de l'Afrique Central. Série in 8vo (Sciences Zoologiques), Tervuren, 1: 1-507.

Hadley, A., 2007. CominezZM. http://www.hadlleyweb.pwp.blueyonder.co.uk

MACHADO, A., 2005. Laparocerus bacalladoi, nueva especie de la isla de Tenerife, Canarias (Coleoptera, Curculionidae). Vieraea, 33: 539-543

Machado, A., 2006. The type material of the species of Laparocerus Schönherr, 1834 (Coleoptera, Curculionidae, Entiminae). Journal of Natural History, London, 40(35-37): 2001-2055.

Machado, A., 2007a. New species of Laparocerus Schönherr, 1834 (Coleoptera, Curculionidae) from the island of Tenerife, Canary Islands. Zootaxa, 1457: 35-48.

Machado, A., 2007b. New species of Laparocerus Schönherr, 1834 from La Gomera, Canary Islands (Coleoptera, Curculionidae, Entiminae). Zootaxa, 1643: 1-38.

Machado, A., 2008a. Three new endogean species of Laparocerus Schönherr, 1834 from the Canary Islands (Coleoptera, Curculionidae). Journal of Natural History, 43(17-18): 1277-1288.

Machado, A., 2008b. New taxa of Laparocerus Schönherr, 1832 from Madeira and Porto Santo, with a key to the species of the Madeiran Archipelago (Coleoptera, Curculionidae, Entiminae). Graellsia, 64(2): 307-328.

Machado, A., López, M., Almeida, T. \& Hernández, M., 2008. Mitochondrial DNA phylogenetic analysis of the genus Laparocerus (Coleoptera, Curculionidae, Entiminae). I. The Madeiran clade. Zoologica Scripta, 37: 415-427.

RoudiER, A., 1957. Curculionides nouveaux ou peu connus des îles Canaries (Col.). Annales de la Société Entomologique de France, [1956], 125: 17-55.

ThOMPSON, R. T., 1989. Terminology of the spermatheca - a protest. Curculio, 26(January 15): 3-4.

Wollaston, T. V., 1864. Catalogue of the Coleopterous insects of the Canaries in the collection of the British Museum. Taylor \& Francis. London. $13+648$ pp 